\section{Pacific Northwest}

National Laboratory

Operated by Battelle for the

U.S. Department of Energy

\title{
Technology Gap Analysis for the Detection of Process Signatures Using Less-Than-Remote Methods
}

\author{
J. S. Hartman \\ D. A. Atkinson \\ M. A. Lind \\ A. D. Maughan \\ J. F. Kelly
}

January 2005

Prepared for the U.S. Department of Energy under Contract DE-AC05-76RL01830 


\title{
DISCLAIMER
}

This report was prepared as an account of work sponsored by an agency of the United States Government. Neither the United States Government nor any agency thereof, nor Battelle Memorial Institute, nor any of their employees, makes any warranty, express or implied, or assumes any legal liability or responsibility for the accuracy, completeness, or usefulness of any information, apparatus, product, or process disclosed, or represents that its use would not infringe privately owned rights. Reference herein to any specific commercial product, process, or service by trade name, trademark, manufacturer, or otherwise does not necessarily constitute or imply its endorsement, recommendation, or favoring by the United States Government or any agency thereof, or Battelle Memorial Institute. The views and opinions of authors expressed herein do not necessarily state or reflect those of the United States Government or any agency thereof.

\author{
PACIFIC NORTHWEST NATIONAL LABORATORY \\ operated by \\ BATTELLE \\ for the \\ UNITED STATES DEPARTMENT OF ENERGY \\ under Contract DE-AC05-76RL01830
}

Printed in the United States of America
Available to DOE and DOE contractors from the Office of Scientific and Technical Information,
P.O. Box 62, Oak Ridge, TN 37831-0062;
ph: (865) 576-8401
fax: (865) 576-5728
email: reports@adonis.osti.gov

\begin{abstract}
Available to the public from the National Technical Information Service, U.S. Department of Commerce, 5285 Port Royal Rd., Springfield, VA 22161 ph: (800) 553-6847 fax: (703) 605-6900

email: orders@ntis.fedworld.gov

online ordering: http://www.ntis.gov/ordering.htm
\end{abstract}

$\sqrt{\exists}$ This document was printed on recycled paper. 


\title{
Technology Gap Analysis for the Detection of Process Signatures Using Less-Than-Remote Methods
}

\author{
J. S. Hartman \\ D. A. Atkinson \\ M. A. Lind \\ A. D. Maughan \\ J. F. Kelly
}

January 2005

Prepared for

the U.S. Department of Energy

under Contract DE-AC05-76RL01830

Pacific Northwest National Laboratory

Richland, Washington 99352 



\section{Summary}

Although remote sensing methods offer advantages for monitoring important illicit process activities, remote and stand-off technologies cannot successfully detect all important processes with the sensitivity and certainty that is desired. The main scope of the program is observables, with a primary focus on chemical signatures. A number of key process signatures elude remote or stand-off detection for a variety of reasons (e.g., heavy particulate emissions that do not propagate far enough for detection at stand-off distances, semi-volatile chemicals that do not tend to vaporize and remain in the environment near the source, etc.). Some of these compounds can provide persistent, process-specific information that is not available through remote techniques; however, the associated measurement technologies have their own set of advantages, disadvantages and technical challenges that may need to be overcome before additional signature data can be effectively and reliably exploited.

The main objective of this report is to describe a process to identify high impact technology gaps for important less-than-remote detection applications. The subsequent analysis focuses on the technology development needed to enable exploitation of important process signatures. The evaluation process that was developed involves three interrelated and often conflicting requirements generation activities:

- Identification of target signature chemicals with unique intelligence value and associated attributes as mitigated by environmentally influenced fate and transport effects (i.e., what can you expect to actually find that has intelligence value, where do you need to look for it and what sensitivity and selectivity do you need to see it)

- Identification of end-user deployment scenario possibilities and constraints with a focus on alternative detection requirements, timing issues, logistical consideration, and training requirements for a successful measurement

- Identification of available measurement technology alternatives and associated attributes (available off-the-shelf, in near-term development, likely longer-term development and research-phase possibilities).

Assembling these requirements into attribute versus generic acceptance criteria level tables and then comparing related attributes between tables allows for rapid visualization of technology gaps and gross estimates of the gap size. By simply weighting the attributes and the requirements in various ways, one can also derive the importance of the identified technology gaps. This output can provide the basis for both a near-term technology development roadmap and research focus as well as a decision support tool for selecting the "most likely to succeed" approach.

The evaluation process as presented is generally applicable for the determination of measurement technology gaps for a broad range of applications [e.g., nuclear weapons processes, chemical weapons production, and biological weapons production, as well as classical signature categories (e.g., chemical and radionuclide signatures)]. In this report, the method is applied to the specific case of detecting 
nuclear weapons production processes using semi-volatile chemical signatures. This particular case selection allows the leveraging of significant prior knowledge and experience while still being highly relevant to current detection scenario needs. 


\section{Acknowledgments}

The authors would like to thank a number of people for their insights, critical evaluation, and efforts in the production of this report. First of all, we would like to thank Kathy Probasco and Jerry Birnbaum (through their reports and subsequent discussions) for the insights into the value of the uniqueness/ stability attribute space. This topic is a cornerstone of semi-volatile signature utilization and a main driver for in situ analysis. The authors would also like to thank Rob Clemmer for his critical evaluation of the various concepts and crucial input into making the evaluation methodology more understandable and user friendly. His support in developing the concept into a viable design was invaluable. We would also like to thank Kay Hass for her tireless efforts in formatting the report, which was made difficult by the extensive number of figures. 



\section{Contents}

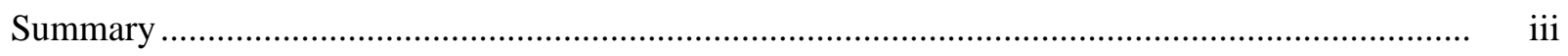

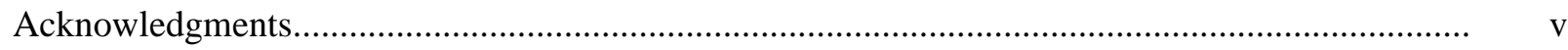

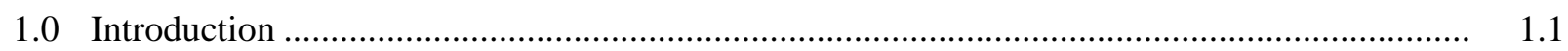

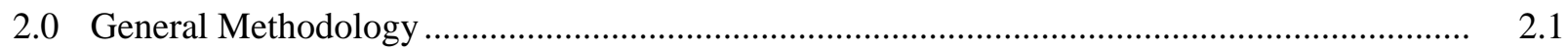

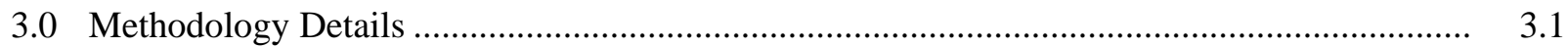

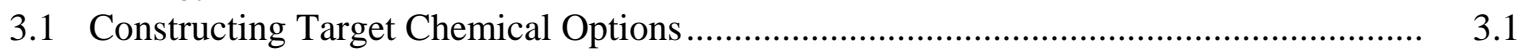

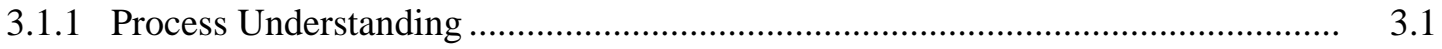

3.1.2 Target Analyte Options ............................................................................. 3.21

3.2 Constructing Deployment Scenario Options .............................................................. 3.21

3.2.1 Deployment Possibilities ........................................................................... 3.21

3.2.2 Identify Deployment Options .................................................................. 3.22

3.2.3 Deployment Attribute Tables .......................................................................... 3.22

3.2.4 Operational Constraints .................................................................................. 3.22

3.2.5 Operational Scenario Filters ....................................................................... 3.22

3.2.6 Deployment Scenario Options....................................................................... 3.23

3.3 Constructing Analysis Methods Options.................................................................. 3.24

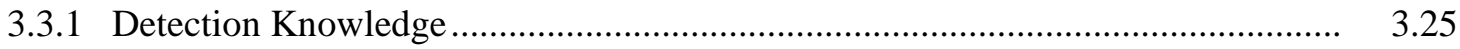

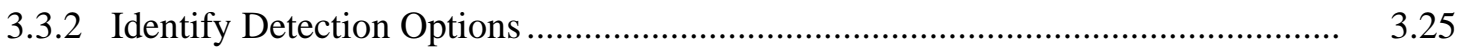

3.3.3 Detector Attribute Tables ....................................................................... 3.25

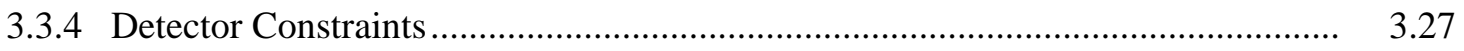

4.0 Technology Selection and Gap Identification Process ................................................... 4.1

4.1 Evaluations for Immediate Applications Using Discrete Criteria (Simple Analysis) ....... 4.1

4.1.1 Technology Evaluation for Immediate Applications ....................................... 4.2

4.1.2 Technology Gap Identification...................................................................... 4.2

4.1.3 Technology Selection for Immediate Applications if No Technologies Meet All Requirement Criteria........................................................................ 4.3

4.2 Technology Evaluations for Future Applications Where Time will Allow

Technology Development and Adaptation................................................................ 4.6

4.2.1 Snapshot of Current Sensor Capabilities ........................................................ 4.7

4.2.2 Graduated Assessment of Sensor Capability Potential ....................................... 4.7

5.0 Application Requirements Assessment by End-Users................................................ 5.1

5.1 Budgeted Point System Method ................................................................................. 5.1

5.1.1 Method 1 - Limited Point Budgeting Approach using Performance

Importance Criteria ............................................................................ 5.4

5.2 Normalized Scoring Using Attribute Rank Ordering .............................................. 5.5 


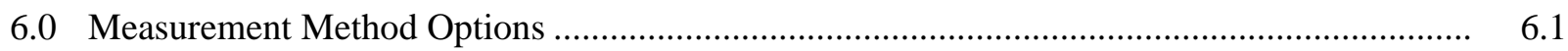

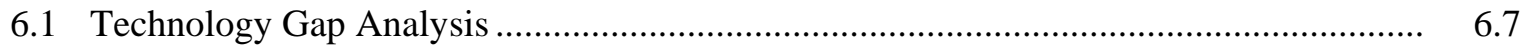

6.1.1 Overlay of Scenario Requirements vs. Measurement Instrumentation vs.

Unique Signature Semi-Volatiles ............................................................. 6.7

6.1.2 Example Gap Determinations ............................................................... 6.8

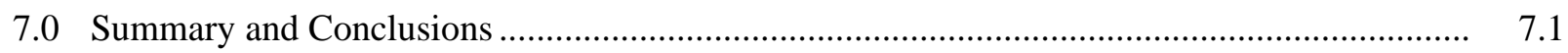

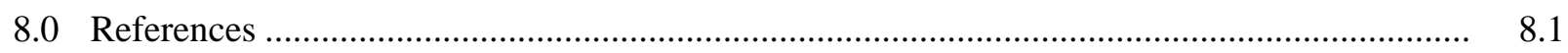

Appendix A - Basis for Selection of Table 3.1 Parameters .................................................. A.1

Appendix B - Basis for Selection of Parameters in Table 3.7 ................................................ B.1

Appendix C - Basis for Selection of Parameters in Table 3.9 ............................................... C.1 


\section{Figures}

1.1 Measurement Method and Deployment Scenario Drive Target Chemical Selection

1.2 Target Chemical and Measurement Method Drive the Deployment Scenario

1.3 Target Chemical and Deployment Scenario Drive the Measurement Method

2.1 General Technology Gap Identification Methodology

2.2 Considerations Feeding the Gap Identification Methodology

2.3 Overall Context of the General Methodology

3.1 Key Chemical Signature Identification Method.

3.2 Parameters Evaluated in the Fugacity Model

3.3 CalTOX Model Compartments

3.4 CalTOX Fugacity Model Compartment and Transport Diagram

3.5 Relative Equilibrium Concentrations of Example Chemicals in Each Compartment for Continuous Emission into a Hot/Wet Environment at a 65-25-10 Ratio.

3.6 Relative Equilibrium Concentrations of Example Chemicals in Each Compartment for Continuous Emission into four Different Climate Regions

3.7 Relative Equilibrium Concentrations of Example Chemicals in Each Compartment for Continuous Emission with Different Release Mechanisms into a Hot/Dry Climate.....

3.8 Relative Equilibrium Concentrations of Example Chemicals in Each Compartment for Continuous Emission with Different Release Mechanisms into a Cool/Wet Climate .........

3.9 Relative Equilibrium Concentrations of Example Chemicals in Each Compartment for a Discontinued Release and Subsequent Time Decay for a Hot/Dry Climate

3.10 Relative Equilibrium Concentrations of Example Chemicals in Each Compartment for a Discontinued Release and Subsequent Time Decay for a Cool/Wet Climate 
3.12 Analysis Method Options Identification Process

4.1 Comparative Examination of Measurement System Performance and Application Requirements Yields Technology Gaps and Measurement System Recommendations

4.2 Derivation of Deployment Scenario vs. Measurement System Performance Criteria Table.....

4.3 Illustration of Technology Gap Magnitude as Illustrated by the Red Arrows.

4.4 Graded Scale Requirements Map

4.5 Combined Scenario Requirements and Measurement System Performance.

4.6 Graded Estimation of Measurement System Performance Gap

4.7 Merging Graduated Information on Scenario Requirements and Measurement System Performance to Qualify Technology Gaps

5.1 Concept of Normalized Scoring Using Attribute Rank Ordering...

6.1 Example of a Receiver Operator Characteristic Curve 


\section{Tables}

3.1 Chemical Attributes vs. Evaluation Criteria ............................................................. 3.3

3.2 Stability vs. Uniqueness of Semi-Volatile Chemical Classes for Nuclear Processes ............... 3.5

3.3 Stability vs. Uniqueness of Volatile Chemical Classes for Nuclear Processes ...................... 3.5

3.4 Selected Properties of Example Compounds from CalTOX Database................................. 3.10

3.5 Environmental and Location Effects Modeled .............................................................. 3.12

3.6 Chemical Release Conditions Modeled .................................................................. 3.14

3.7 Deployment Scenario Attributes vs. Evaluation Criteria................................................ 3.23

3.8 Operational Scenario Mask Developed from Table 3.7 ................................................. 3.24

3.9 Measurement System Attributes vs. Evaluation Criteria.................................................. 3.26

3.10 Simplified Measurement System Evaluation Derived from Table 3.9 with Added Mask Information............................................................................................. 3.27

5.1 Attribute/Performance Table Scoring Methods ........................................................... 5.3

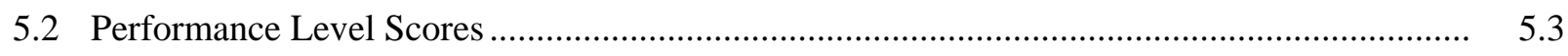

5.3 Scoring Using the Performance Importance Criteria................................................. 5.4

6.1 Example Methodologies and Attribute Applicability for Example Scenario ........................ 6.3 



\subsection{Introduction}

Although remote sensing methods offer significant advantages for monitoring important illicit process activities (e.g., production processes associated with WMD, drug processing, etc.) and they minimize risk to personnel, remote and stand-off methods cannot successfully detect all important processes with the sensitivity and certainty that is desired. This fact has lead to the re-evaluation of complementary process signatures that could improve our ability to detect and quantify important process activities of interest.

A number of process signatures are available that are not amenable to remote or stand-off detection for a variety of reasons (e.g., heavy particulate emissions that do not propagate far enough for detection at stand-off distances, semi-volatile chemicals that do not tend to vaporize and that often remain in the environment near the source, etc.). Effective detection of these potentially exploitable process signatures requires a different suite of sample collection, detection and measurement technologies. The measurement technologies for these less-than-remote measurements may present different and significant technical challenges that must be overcome before these additional signatures can be effectively and reliably exploited.

The objective of this activity under the PNNL In Situ Program is to identify high impact technology gaps for important less-than-remote detection applications in order to allow focused technology development needed to enable exploitation of important process signatures. A systematic method for identifying key technology gaps has been developed and will be described in this report. During the development of this gap analysis methodology, it was recognized that a properly designed evaluation methodology for gap identification could subsequently be extended to develop a tool for objectively evaluating various technologies against specific applications requirements. While this extended tool would be valuable to the community, its full development is beyond the current scope of this project. However, the measurement technology evaluation methodology has been structured so it can meet the immediate need for gap identification, and also serve as the basis for extension to other method/application evaluation tools if subsequently desired.

The methodology discussed is generally applicable for the determination of measurement technology gaps for a broad range of specific applications (e.g., nuclear weapons process, chemical weapons production, etc.) and signature categories (e.g., chemical and radionuclide signatures, etc.). The method has been tested for the specific case of detecting nuclear weapons production processes using semivolatile chemical signatures as a demonstration of the technique. This particular case selection allows the leveraging of significant prior knowledge and experience while still being highly relevant to current detection scenario needs.

The selection of a measurement system is generally driven by three main considerations:

- information about the signature that must be measured (target chemical),

- practical constraints for the measurement apparatus (deployment scenario), and

- sensor systems that might meet the requirement (measurement method). 
For challenging applications, the selection of a final measurement system often requires compromises between these considerations as a "perfect" solution may not be available. In these cases, the compromises that are required, within constraints of the existing technology options, often indicate the technology gaps that prevent the deployment of a measurement system that would more fully meet the application needs. These technology gaps are the targets of this analysis methodology.

Experience indicates that these three drivers can play different roles in various situations. The differences in the technology maturity, measurement method, and deployment scenario details dictate the overall approach in developing solutions. These differing situations are detailed in the figures below, where the top two entries on the triangle are the most mature and developed aspects and lead to development or discovery in the third aspect at the bottom of the triangle.

Opportunistic Situation - In this situation, shown in Figure 1.1, it is assumed that the measurement method and the deployment scenario are already established or in place (at the top of the triangle) and the objective is to find a target chemical signature that provides information to assist in answering the question under consideration.
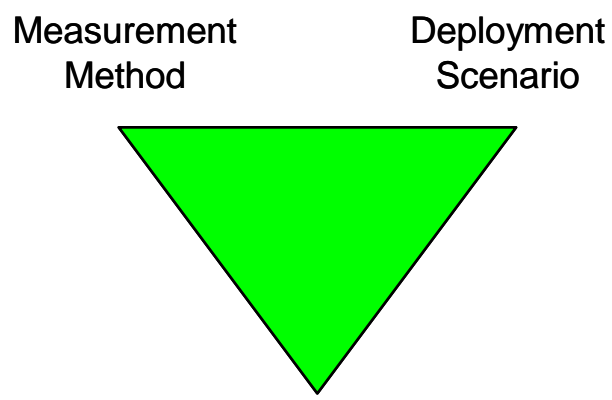

Target

Chemical

Figure 1.1. Measurement Method and Deployment Scenario Drive Target Chemical Selection

An example of an opportunistic situation would be an airport security system where it might become important to detect drug traffic. The airport screening technology is already in place for explosives detection (e.g., surface wipe and IMS analysis) and the deployment scenario is fixed (bag screening and passenger portals). The opportunistic question asks for an exploitable chemical signature for targeted narcotics that could be detected with the installed screening equipment by identifying additional IMS spectral peaks that could be monitored at the same time the explosives scans are performed.

Mature Situation - In this case, illustrated in Figure 1.2, an established measurement method is available for the detection of known, relevant process signatures and their target chemicals. The key question solicits a practical deployment scenario that could use the existing measurement system to obtain the required information for a specific application of interest. 
An illustration of this situation might be where both the chemical target and the measurement method have been used previously and a deployment scenario is devised to utilize the available assets.

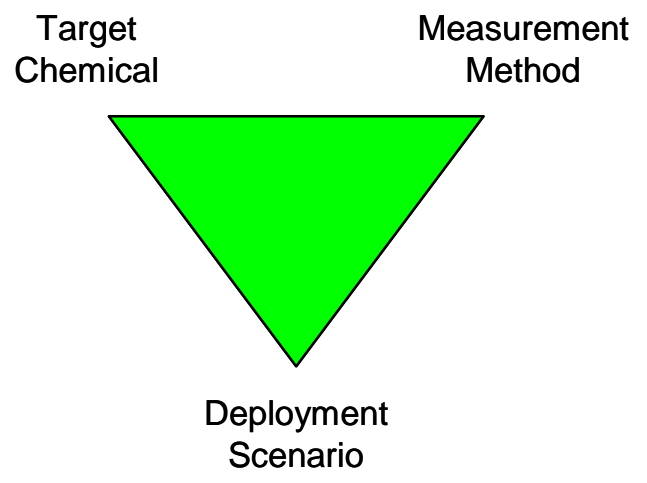

Figure 1.2. Target Chemical and Measurement Method Drive the Deployment Scenario

Development Situation - This situation is shown in Figure 1.3. Here the application requirements can not be suitably met with existing measurement technology options and available deployment scenarios. In this case, key chemical signatures are known and a limited number of practical deployment scenarios are available. The key question then becomes whether or not a suitable measurement method can be developed to obtain the required chemical information within the constraints of the available deployment scenarios.

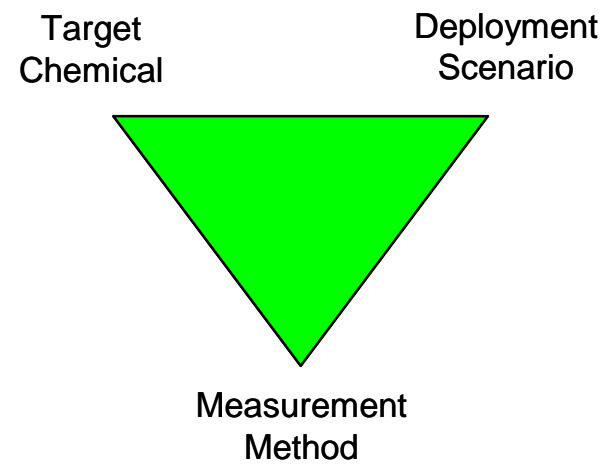

Figure 1.3. Target Chemical and Deployment Scenario Drive the Measurement Method

Under some deployment scenario constraints, available measurement methods and subsystems may not exist today that provide a suitable option to meet this requirement. When this occurs, the barriers that prevent deployment of suitable equipment represent technology gaps in either detection methods or in complementary subsystems (e.g., small footprint, long-life batteries, etc.).

This report focuses on the identification of high impact technology gaps driven by this last case, as applied to the less-than-remote detection of nuclear process detection using chemical signatures. 
Although the discussion focuses on the nuclear process example, the methodology is suitable for use on a broad spectrum of potential threat scenarios. For example, the same cases can be easily adapted to the detection of chemical warfare precursors. As long as the target chemical and deployment scenario options are clearly defined, the process can be adapted for the development of applicable measurement methods.

In an application-driven environment, where the target chemicals and the deployment scenarios are defined, the development of measurement technologies to fit the requirements is needed to solve the problem. This is also known as "application pull" (as opposed to "technology push" which is illustrated in the other two cases). This approach leads to the most applicable technology development, as the systems are built with the problem in mind from the outset. In the "technology push" cases, the measurement method is rarely optimal for a given application. For the purpose of this report, the "application pull" of chemical nuclear signature detection in potentially non-cooperative areas with difficult access define the situation in need of measurement technology development. This report delineates the process by which this development can be rationally approached for an optimal resolution. 


\subsection{General Methodology}

The general flow of the gap analysis process is represented in a linear sequence illustrated in Figure 2.1. The methodology begins with a key intelligence question and ends with the identification of technology gaps in equipment or methods. The general sequence is broken into four primary functional steps as indicated at the left-hand side of the figure.

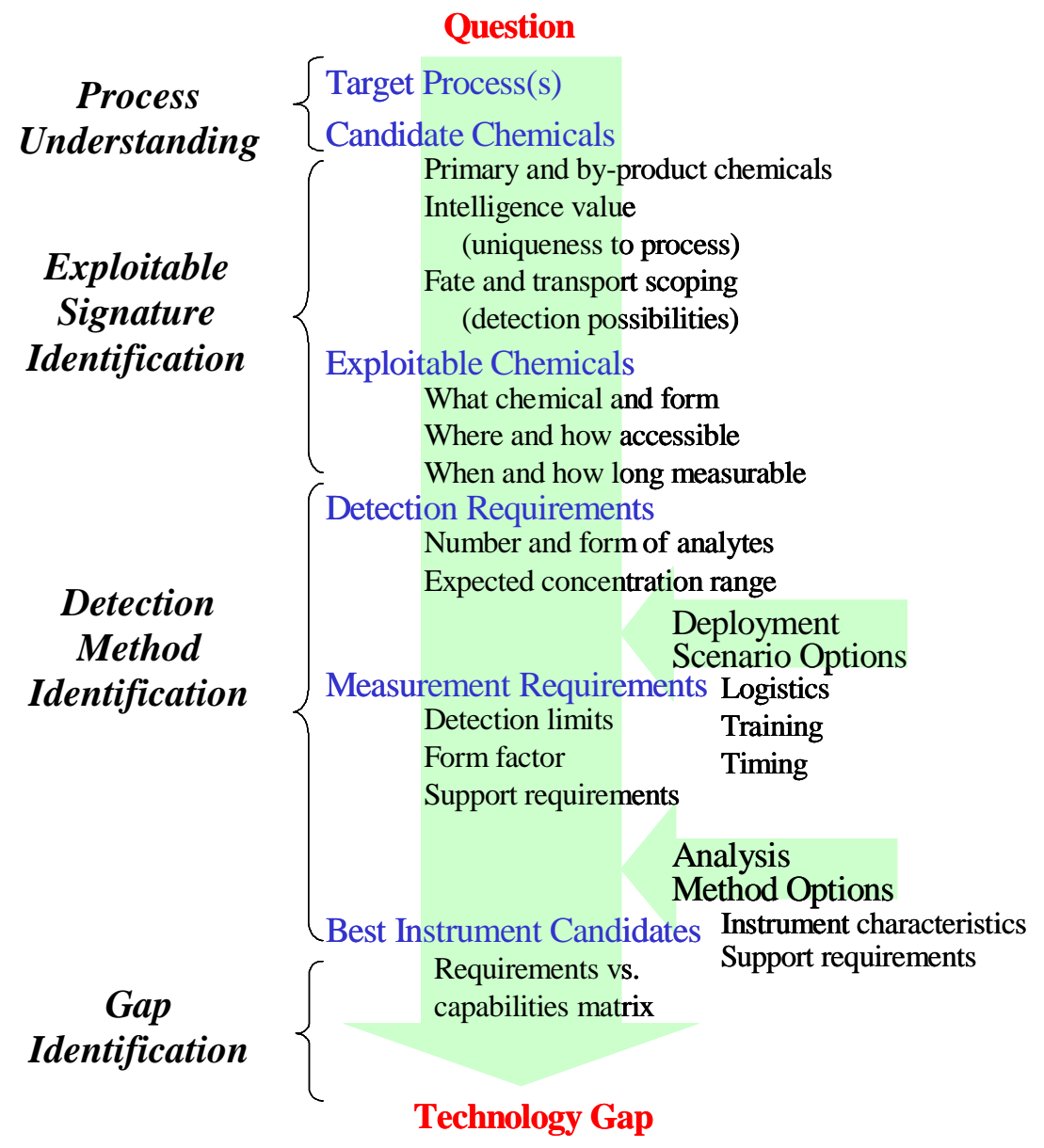

Figure 2.1. General Technology Gap Identification Methodology

- Process understanding - The processes associated with the intelligence question are identified and their candidate chemical signatures established as starting points for subsequent analyses.

- Exploitable signature identification - The ability to confirm (or deny) the existence of the processes requires the identification of definitive and unique signatures. Many chemicals used in processes may provide no useful intelligence value because of their lack of available signatures, short half life or their use in common commercial practice. 
- Detection method identification - Once the exploitable signatures have been identified and pertinent deployment constraints are established, suitable detection methods are identified and evaluated against analytical requirements and viable deployment scenarios.

- Gap identification - Measurement system technology gaps (if any) can then be identified by comparing available system capabilities against the analytical and operational requirements for the application.

For an end-user, the end point could be the identification of suitable measurement systems and the selection of the best candidates to meet the application requirement.

This technology gap identification methodology is based on the systematic consideration of important factors for the three complementary areas (i.e., target chemical signatures to be measured, operational deployment requirements, and available measurement technologies). This is illustrated schematically in Figure 2.2 where the activities in each column illustrate the sequential development and assessment of complementary data sets within each module, independent of the time line for the overall sequence.

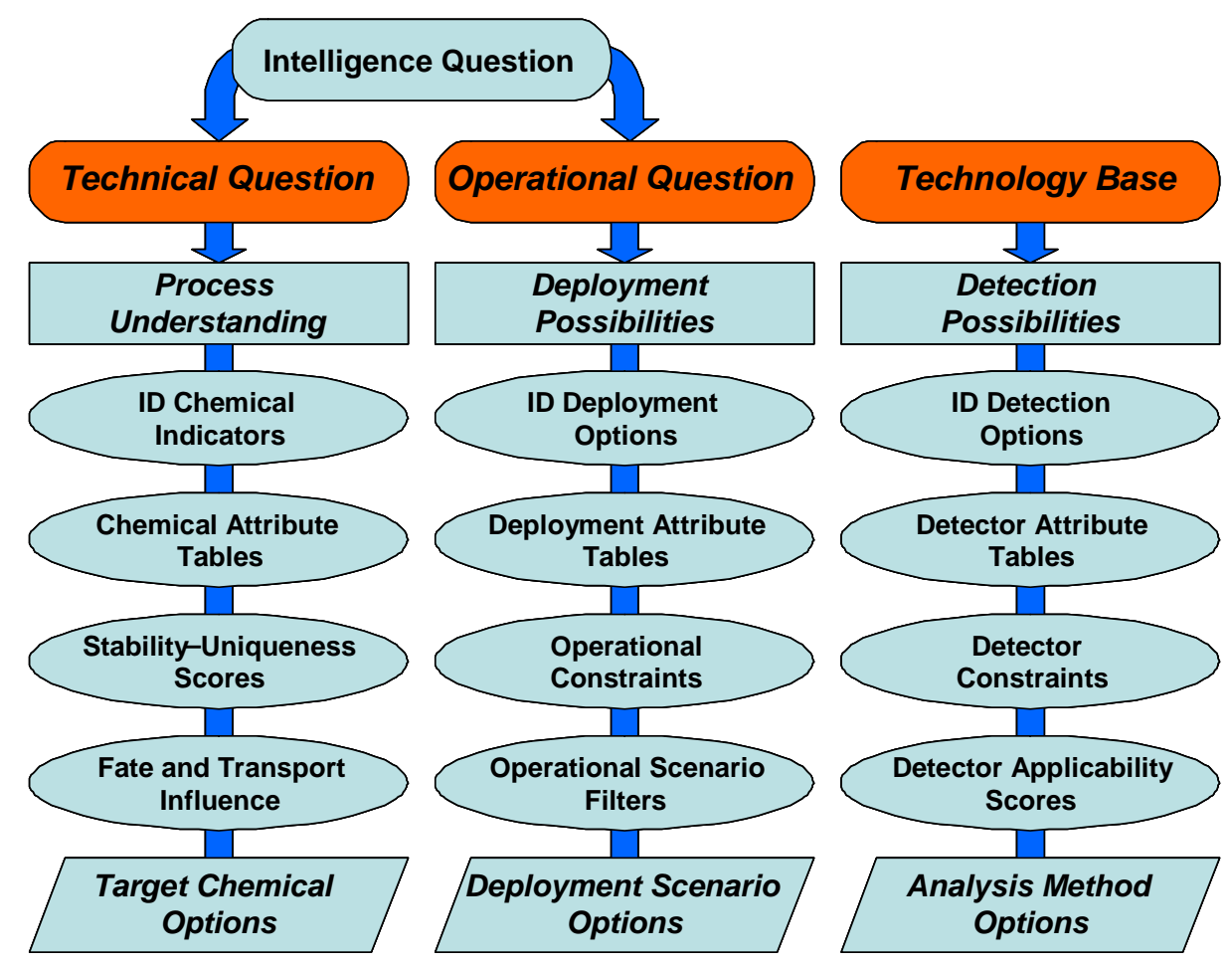

Figure 2.2. Considerations Feeding the Gap Identification Methodology 
The first two columns are driven by a key intelligence question.

- Target chemical options - understanding important processes and their associated chemical signatures that are definitive enough to confirm or deny the presence of a process with sufficient confidence to answer the intelligence question.

- Deployment scenario options - knowledge of the environmental variables, physical and operational constraints, and resource constraints that might be encountered in deployment of the analysis methods in less-than-remote application scenarios.

Information in the third column will come from the measurement technology (sensors and instrumentation) community.

- Analysis method options - knowledge of the detection methodology and the level of information that can be obtained via established or currently available measurement systems as well as insight into the strengths, weaknesses and maturity of these instruments and other techniques that might still be in development.

Figure 2.3 combines the topical activities from Figure 2.2 into the context of the overall process sequence introduced in Figure 2.1.

Activities from the first column of bubbles provide major inputs during the signature identification phase of the methodology and establish guidance for the analytical measurement requirements. Activities from the second column of bubbles provide key operational requirement information and establish measurement system constraints. Many methods that could meet the analytical requirements may NEVER meet the operational needs. Activities associated with the measurement system requirements information can then be compared with the information provided in the third column of bubbles establishing the available measurement methods. When measurement technology candidates cannot meet all of the analytical and operational requirements, a comparison of the system attributes and the requirements allows the identification of technology gaps that prevent successful system deployment in indicate development requirements.

Important technology gaps may range from:

- enabling technologies that could improve the performance of a number of measurement systems for a range of applications

to:

- a specific technical capability that is needed to allow successful system deployment for a single, very high-value application. 


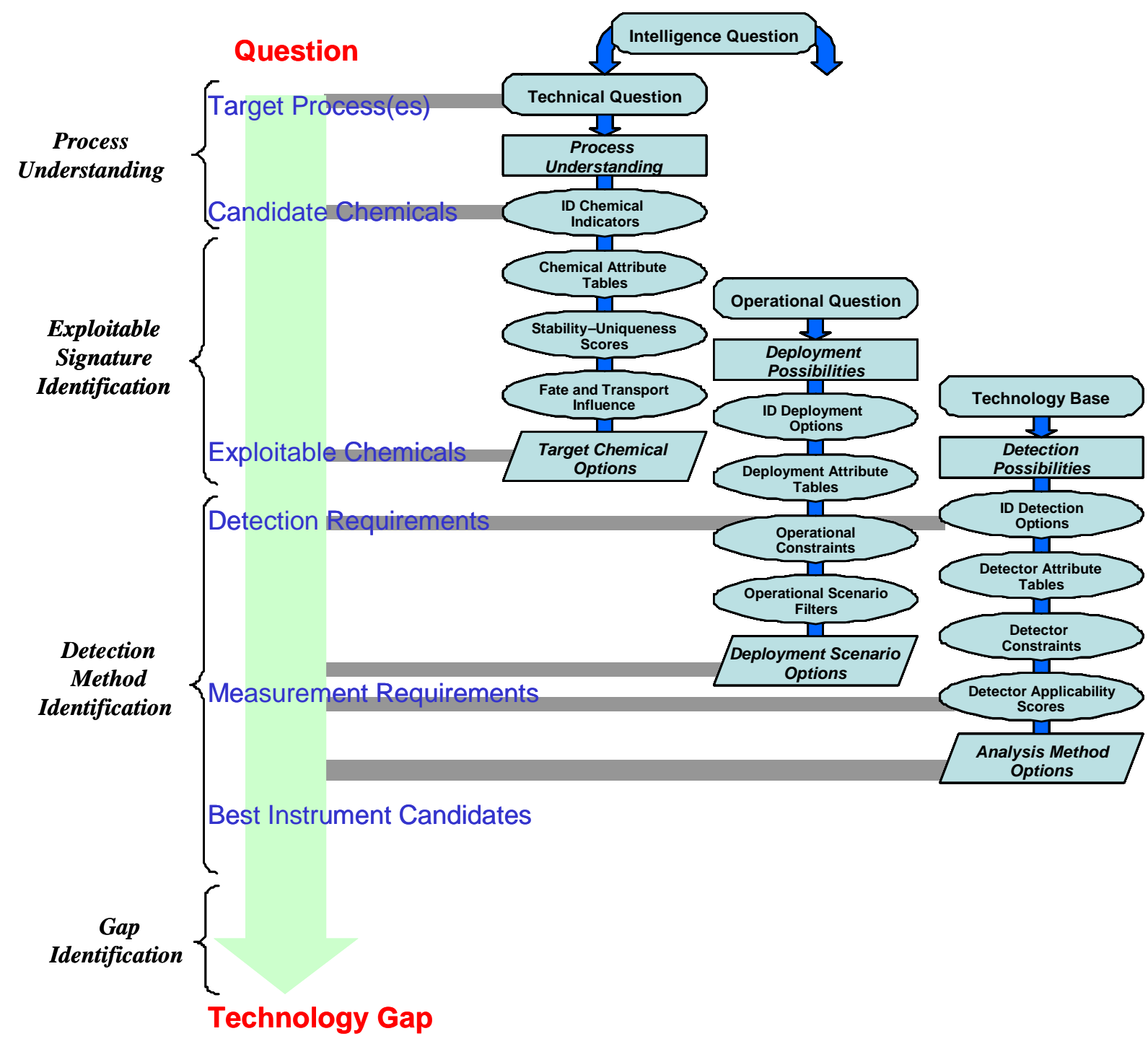

Figure 2.3. Overall Context of the General Methodology

These two cases represent opposite ends of the spectrum for applying this methodology. They illustrate the trade-off between broad case considerations and specific case assessment. Considering the number of basic measurement systems available, the second approach is analogous to examining a beach, one grain of sand at a time. For the purposes of this paper we will describe our effort to more directly determine technology gaps with broader applicability (and benefit if resolved) by considering classes of applications. It is recognized that this approach must be considered with representative application requirements to ensure that the findings are meaningful. If the application requirements are too generic, the findings are likely to be so generalized that they are of little value. The implications of these tradeoffs will be discussed within the context of the illustrative class of applications chosen for the initial test of the methodology. The test case described will be the detection of nuclear material production processes using less-than-remote methods to detect definitive chemical signatures. 


\subsection{Methodology Details}

A number of tables and visualization tools have been developed to facilitate data gathering and comparison of the requirements and attributes in each of the three areas contributing to the methodology (i.e., target chemicals, deployment scenarios and analytical methods). The physical format has been structured to aid in the concurrent use of the tables to allow rapid visual assessment of individual attributes against the technical and operational requirements. Measurement technology deficiencies identified in these comparisons represent technology gaps.

\subsection{Constructing Target Chemical Options}

For our case study, it is instructive to begin by identifying the exploitable chemical signatures that would allow the confirmation of the existence of the targeted illicit process. The implicit assumption in this case is that the chemical signature must not only be reliable for discriminating between similar processes, but also the signature must be suitable for reliable detection in the environment where the process is located. Key activities in identifying the target chemical options are shown in Figure 3.1.

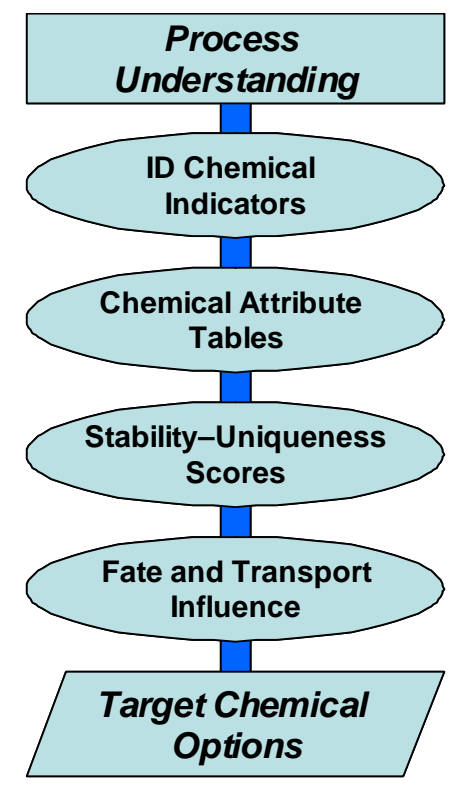

Figure 3.1. Key Chemical Signature Identification Method

\subsubsection{Process Understanding}

This sequence is driven by the key intelligence question that is under consideration. This question will provide the basis for experts in nuclear weapons production to identify probable processes that could be employed to produce the type of weapons under consideration. Identification of these candidate 
processes, knowledge of the key processing steps and specification of the feedstock and waste materials is the first step of the sequence.

\subsubsection{Identify (ID) Chemical Indicators}

Unique chemicals that offer the potential of definitive determination of the target process are identified. Many chemicals used in production processes will not support a definitive assessment. Chemicals that are commonly found in the environment due to their use for other purposes, either locally, regionally, or globally, often contribute to background levels which preclude any definitive interpretation of the assays relative to processes of interest. This evaluation step eliminates common chemicals from consideration early in the process in order to focus on a reduced number of signature options.

In this study, we leveraged the results of other PNNL studies that have been considered in nuclear material production processes. These studies have identified the chemical feed stocks used for a broad range of nuclear processes and evaluated the uniqueness of the each chemical based on its use in other known commercial production processes. This study is further confined to the semi-volatile chemicals, as they offer the greatest potential for exploitation by less-than-remote measurement methods.

\subsubsection{Chemical Attributes Tables}

Table 3.1 captures key information for individual chemicals (or families of chemicals) under consideration in order to facilitate systematic down-selection to exploitable chemical signatures. The top section of the table lists chemical property attributes versus applicable evaluation criteria that will be used to assess the relative impact of measurement options in the sampling environment. The bottom section of the table lists important attributes that relate to the value of the intelligence gained if the chemicals are detected.

The specific attribute descriptions and the reasons they are selected for Table 3.1 are discussed in detail in Appendix A. Evaluation criteria are provided for each attribute in the five right-hand columns in the table. The criteria increase in potential value progressing from the left to right side of the table. The large step criteria descriptions are intended to allow capture of broad attribute characteristics rather that focusing highly specific property values and assessments.

The first part of Table 3.1 can be converted via fate and transport modeling into parameters that give searchers some idea as to where and what quantities of residuals from a specific release are likely to be found. The disposition indicators are both time and environmentally sensitive but can be modeled for specific chemical, geophysical and climatological conditions.

The second part of Table 3.1 discusses the intelligence value of the chemicals. There is a host of information about a chemical that can give insights into its potential uses. For example, uniqueness is very important, as chemicals that are manufactured solely to be used in specific processes can be used to identify the potential presence of those processes with a high confidence. Another item, the cost (including waste disposal) of a chemical is important because the economics dictate that only the most 
important activities can justify the use of very high value chemicals. The attributes in the table are suggestive of the value of each in the elucidation of non-obvious processes.

Table 3.1. Chemical Attributes vs. Evaluation Criteria

\begin{tabular}{|c|c|c|c|c|c|c|}
\hline & Attribute & \multicolumn{5}{|c|}{ Criteria } \\
\hline \multirow{6}{*}{ 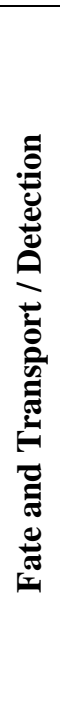 } & $\begin{array}{l}\text { Volatility / } \\
\text { Diffusion }\end{array}$ & $\begin{array}{l}\text { Very High } \\
\text { V.P. > } 50 \text { torr }\end{array}$ & $\begin{array}{c}\text { High } \\
\text { V.P. }=1-50 \text { torr }\end{array}$ & $\begin{array}{c}\text { Moderate } \\
\text { V.P. }=0.05-1 \\
\text { torr }\end{array}$ & $\begin{array}{c}\text { Low } \\
\text { V.P. }=0.05 \text { to } \\
0.001 \text { torr }\end{array}$ & $\begin{array}{l}\text { Very Low } \\
\text { V.P. }<0.001 \\
\text { torr }\end{array}$ \\
\hline & $\begin{array}{l}\text { Reactivity / } \\
\text { Stability }\end{array}$ & $\begin{array}{l}\text { Very High } \\
\mathrm{t}_{1 / 2}<1 \text { min }\end{array}$ & $\begin{aligned} & \text { High } \\
\mathrm{t}_{1 / 2}= & \min \text { to hrs }\end{aligned}$ & $\begin{array}{c}\text { Moderate } \\
\mathrm{t}_{1 / 2}=\text { hrs to days }\end{array}$ & $\begin{array}{c}\text { Low } \\
\mathrm{t}_{1 / 2}=\text { days to } \\
\text { month }\end{array}$ & $\begin{array}{c}\text { Very Low } \\
\mathrm{t}_{1 / 2}>\text { month }\end{array}$ \\
\hline & Water Solubility & $\begin{array}{c}\text { Very High } \\
100 \% \\
\text { miscible }\end{array}$ & $\begin{array}{c}\text { High } \\
10-100 \mathrm{~g} / 100 \mathrm{cc}\end{array}$ & $\begin{array}{c}\text { Moderate } \\
1-10 \mathrm{~g} / \\
100 \mathrm{cc}\end{array}$ & $\begin{array}{l}\text { Low } \\
0.001 \text { to } 1 \mathrm{~g} / \\
100 \mathrm{cc}\end{array}$ & $\begin{array}{l}\text { Very Low } \\
<0.001 \mathrm{~g} / \\
100 \mathrm{cc}\end{array}$ \\
\hline & $\begin{array}{l}\text { Bio Metabolized / } \\
\text { Breakdown Rate }\end{array}$ & $\begin{array}{c}\text { Very High } \\
\mathrm{t}_{1 / 2}<\mathrm{hr}\end{array}$ & $\begin{array}{c}\text { High } \\
\mathrm{t}_{1 / 2}=\mathrm{hr} \text { to day }\end{array}$ & $\begin{array}{c}\text { Moderate } \\
\mathrm{t}_{1 / 2}=\text { day to wk }\end{array}$ & $\begin{array}{c}\text { Low } \\
t_{1 / 2}=\text { wk to mo }\end{array}$ & $\begin{array}{l}\text { Very Low } \\
t_{1 / 2}>\text { mo }\end{array}$ \\
\hline & $\begin{array}{l}\text { Bio Stabilization / } \\
\text { Uptake Rate }\end{array}$ & $\begin{array}{c}\text { Very High } \\
\mathrm{t}_{1 / 2}>\mathrm{mo}\end{array}$ & $\begin{array}{c}\text { High } \\
\mathrm{t}_{1 / 2}=\text { wk to mo }\end{array}$ & $\begin{array}{c}\text { Moderate } \\
\mathrm{t}_{1 / 2} \text { day to wk }\end{array}$ & $\begin{array}{c}\text { Low } \\
\mathrm{t}_{1 / 2}=\mathrm{hr} \text { to day }\end{array}$ & $\begin{array}{c}\text { Very Low } \\
\mathrm{t}_{1 / 2}<\mathrm{hr} \\
\end{array}$ \\
\hline & $\begin{array}{l}\text { Organic } \\
\text { Adsorption } \\
\text { Tendency (KOW) }\end{array}$ & $\begin{array}{l}\text { Very High } \\
>4\end{array}$ & $\begin{array}{l}\text { High } \\
2 \text { to } 4\end{array}$ & $\begin{array}{l}\text { Moderate } \\
0 \text { to } 2\end{array}$ & $\begin{array}{l}\text { Low } \\
-2 \text { to } 0\end{array}$ & $\begin{array}{l}\text { Very Low } \\
<-2\end{array}$ \\
\hline & & & & & & \\
\hline & $\begin{array}{l}\text { Uniqueness of } \\
\text { Primary Chemical }\end{array}$ & $\begin{array}{c}\text { Very Low } \\
\text { Common } \\
\text { commercial } \\
\text { uses }\end{array}$ & $\begin{array}{c}\text { Low } \\
\text { Some } \\
\text { commercial, } \\
\text { research }\end{array}$ & $\begin{array}{l}\text { Moderate } \\
\text { Little } \\
\text { commercial, } \\
\text { research use }\end{array}$ & $\begin{array}{c}\text { High } \\
\text { No comm., } \\
\text { specialty use }\end{array}$ & $\begin{array}{c}\text { Very High } \\
\text { Specialized } \\
\text { processes } \\
\text { only }\end{array}$ \\
\hline$\stackrel{g}{\Xi}$ & $\begin{array}{l}\text { Uniqueness of } \\
\text { Degradation } \\
\text { Products }\end{array}$ & $\begin{array}{l}\text { Very Low } \\
\text { Common } \\
\text { commercial } \\
\text { uses }\end{array}$ & $\begin{array}{c}\text { Low } \\
\text { Some } \\
\text { commercial, } \\
\text { research }\end{array}$ & $\begin{array}{l}\text { Moderate } \\
\text { Little } \\
\text { commercial, } \\
\text { research }\end{array}$ & $\begin{array}{c}\text { High } \\
\text { No comm., } \\
\text { specialty use }\end{array}$ & $\begin{array}{c}\text { Very High } \\
\text { Specialized } \\
\text { processes } \\
\text { only }\end{array}$ \\
\hline Dू & Storage Stability & $\begin{array}{c}\text { Very High } \\
\text { No special } \\
\text { handling }\end{array}$ & $\begin{array}{c}\text { High } \\
\text { Some special } \\
\text { handing }\end{array}$ & $\begin{array}{c}\text { Moderate } \\
\text { Requires } \\
\text { special handling }\end{array}$ & $\begin{array}{c}\text { Low } \\
\text { Careful special } \\
\text { handling }\end{array}$ & $\begin{array}{l}\text { Very Low } \\
\text { Prepared at } \\
\text { time of use }\end{array}$ \\
\hline 莺 & $\begin{array}{l}\text { Safety / } \\
\text { Transportation } \\
\text { Constraints }\end{array}$ & $\begin{array}{c}\text { Very Low } \\
\text { No special } \\
\text { handling }\end{array}$ & $\begin{array}{c}\text { Low } \\
\text { Some } \\
\text { precautions }\end{array}$ & $\begin{array}{l}\text { Moderate } \\
\text { Special } \\
\text { transport } \\
\text { conditions }\end{array}$ & $\begin{array}{c}\text { High } \\
\text { Critical special } \\
\text { transport }\end{array}$ & $\begin{array}{l}\text { Very High } \\
\text { Not } \\
\text { transportable }\end{array}$ \\
\hline & $\begin{array}{l}\text { Cost Including } \\
\text { Waste Disposal }\end{array}$ & Very Low & Low & Moderate & High & Very High \\
\hline & Toxicity & $\begin{array}{l}\text { Very Low } \\
\text { PEL }>\%\end{array}$ & $\begin{array}{l}\text { Low } \\
\text { PEL high to } \\
\text { medium }\end{array}$ & $\begin{array}{l}\text { Moderate } \\
\text { PEL mid to } \\
\text { high }\end{array}$ & $\begin{array}{c}\text { High } \\
\text { PEL high }\end{array}$ & $\begin{array}{l}\text { Very High } \\
\text { No exposure } \\
\text { allowed }\end{array}$ \\
\hline
\end{tabular}




\subsubsection{Stability-Uniqueness Scores}

Two chemical properties that are extremely important for consideration for in situ applications under this project are stability and uniqueness.

- Stability: High scoring chemicals will survive for extended periods in the environment and can be detected long after they escape as process effluents. Chemical concentrations can build up in the environment if they are released by a process over an extended period of time and do not become highly dispersed in the environment. The chemical will receive a low score if it is fairly unstable in the environment (e.g., undergoes rapid hydrolysis or photolysis after release, etc.). Chemicals with low environmental stability must be detected and measured quickly after release or they may be converted to a chemical by-product that is not useful for the process identification. The Probasco et al. (2002) study cited previously also reported results of a similar stability/uniqueness assessment for volatile effluents from nuclear material processing.

- Uniqueness: When a chemical is routine for commercial, industry or agricultural applications, it may score a low uniqueness value because of high concentrations in the environmental background and it may offer little value for the detection of illicit processes. At the other extreme are chemicals that have no known commercial applications (beyond the nuclear processing application) are given high uniqueness scores and their detection at or near a suspect site is a strong indicator of a potential illicit process.

Tables 3.2 and 3.3 provide a summary view of the chemical uniqueness (directly related to intelligence value of information) and the stability (how long will it survive in the environment after release) for a number of chemical families employed in nuclear material production processes. Table 3.2 is for semi-volatiles compounds, Table 3.3 covers the volatiles.

The specific chemicals have been grouped into generic classifications for this paper with the specific number of chemicals identified in parenthesis. High value chemical targets are located to the upper, righthand corner of these tables. A comparison of Tables 3.2 and 3.3 reveals that the semi-volatiles offer far more chemical signatures with both high uniqueness and stability.

\subsubsection{Fate and Transport Effects}

Fate and transport effects are important to consider because different effluents can behave very differently in the environment following release. Some effluents may tend to rapidly disperse in the environment, others may undergo rapid destruction or transformation, while others may tend to deposit near the point of release and remain stable for long periods. Understanding the basic fate and transport tendencies/effects for key effluents can provide guidance regarding the probable survival and location of a given chemical (or family of chemicals) in the environment. There is no point in looking for chemicals that are rapidly transformed after release (e.g., lost to rapid hydrolysis, photolysis, microbial breakdown, etc.) and it may be fruitless to look for chemicals in low probability regions of the environment long after their release (e.g., highly volatile and reactive chemicals on nearby surfaces long after release, etc.). 
Table 3.2. Stability vs. Uniqueness of Semi-Volatile Chemical Classes for Nuclear Processes

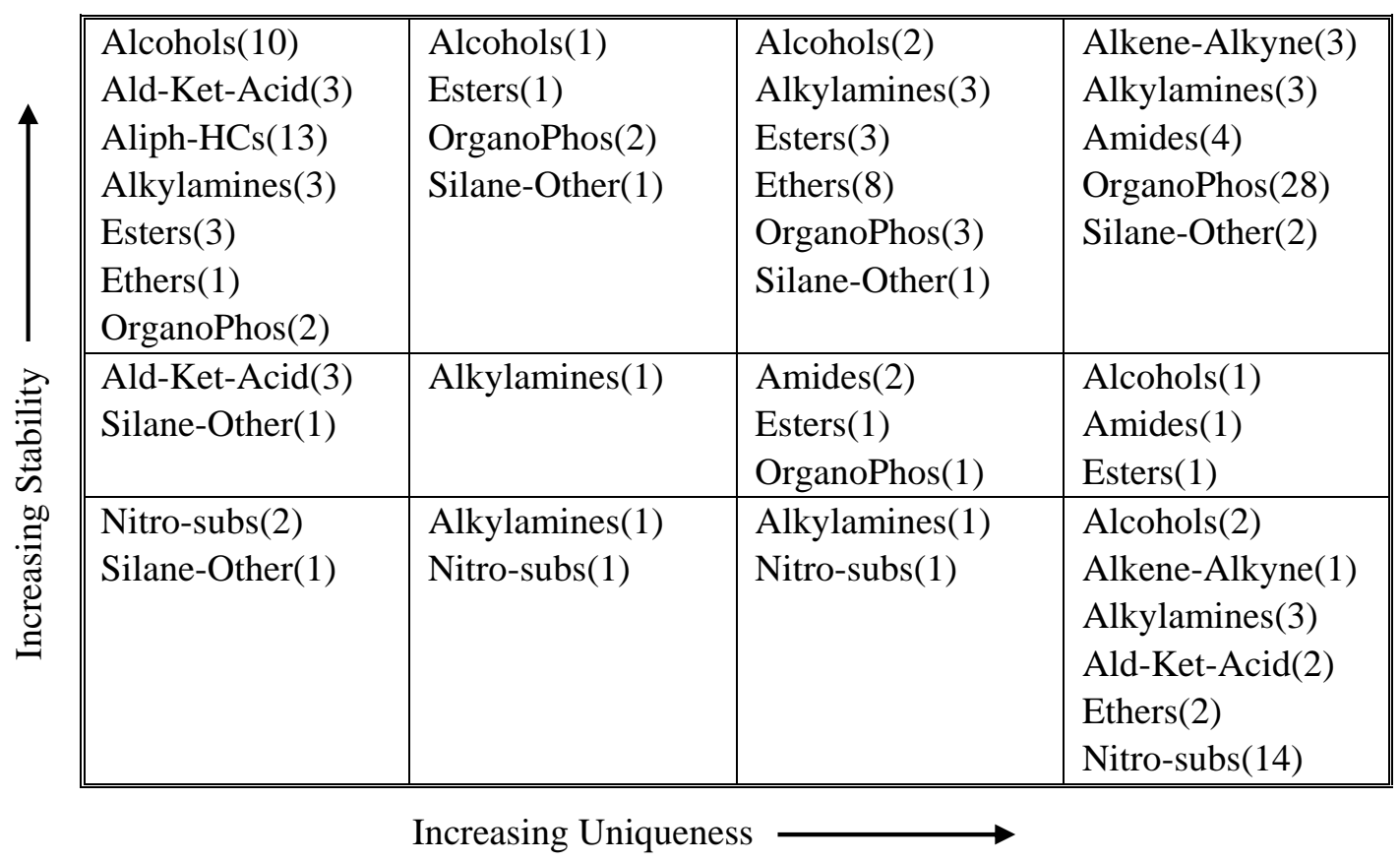

Table 3.3. Stability vs. Uniqueness of Volatile Chemical Classes for Nuclear Processes

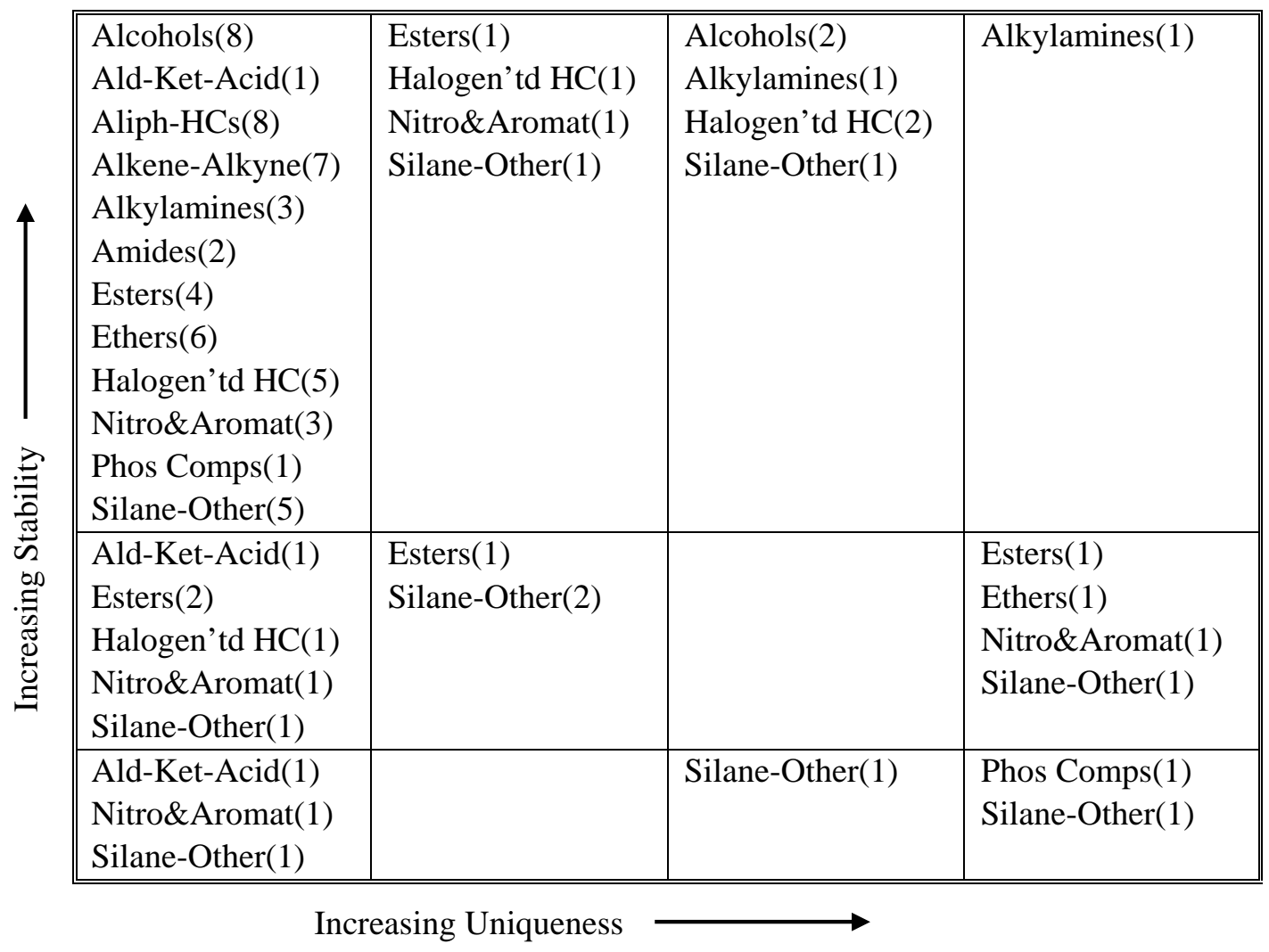


For the purposes of this initial technology gap evaluation, a few representative examples of fate and transport predictions were conducted based on previous literature modeling assumptions (MacKay 2001; MacKay et al. 2001). To understand the potential variability in selecting possible sample collection locations, ${ }^{(1)}$ three key parameters were examined as illustrated in Figure 3.2 for three distinct types of semi-volatile chemicals (based on their properties). These parameters and the reasons for selection are:

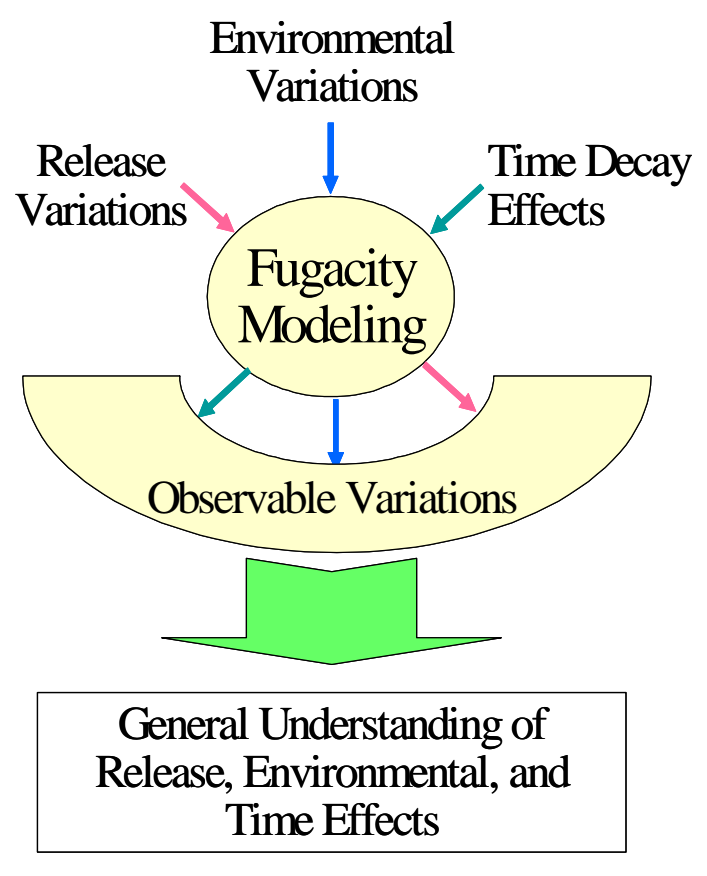

Figure 3.2. Parameters Evaluated in the Fugacity Model

- Release variations were examined to determine if the release path for process effluents strongly affect the final location of the chemical in the environment. For example, determinations were made concerning final partitioning and whether these changed significantly if the release is varied between the air (e.g., stack emissions.), the ground (e.g., spills on the ground, in soil cribs, or burial in the soil as done in the early years at Hanford), or the surface water (e.g., drainage into a pond or stream).

- Environmental variations were examined to determine if climate (e.g., temperature variations, humidity, precipitation), vegetation, and soil type strongly effect the final location of chemicals in the environment.

- Time decay effects were examined to determine if a chemical is stable in the environment and how important measurement timing is for the detection of a chemical in various environmental partitions.

(1) See for example http://www.trentu.ca/cemc/CEMC200102.pdf 
If the variations found are modest, then the results provide broad implications for the required measurement technologies. If the results show large variability, then caution must be exercised in testing measurement methods against specific application conditions and case-specific analyses should be considered prior to establishing detection and measurement approaches for specific applications.

A number of fate and transport models have been developed to meet a variety of application objectives. Some models have been developed to study the long-term behavior of effluents in the environment with the objective of understanding industrial and agricultural releases and their ultimate impact on environmental and human risks. Typically, these models consider effluent releases over large areas, over long time periods, and calculate average fate and transport effects using average regional environmental and climate factors. The models do not address seasonal and daily variations in environmental parameters (e.g., sunlight, temperature, humidity, wind conditions, etc.) or highly specific local geography or topography effects (e.g., the presence of hills or valleys, proximity to rivers, lakes, or ocean, etc.).

The CalTOX ${ }^{\mathrm{TM}}$ code $^{(1)}$ was developed in this vein to support key environmental risk studies in California and other locations. Caution dictates that this and similar codes generally are not suitable for highly specific assessments that include site-specific topographies, meteorology, and other complicating factors (e.g., complimentary emissions that might result in specific effluent altering interactions.). In addition, the codes generally have not been developed to handle relatively short transient events. With that caveat, a number of these codes have been successfully vetted for important long-term, regional applications. Other models have been developed to address smaller scale effects and can accommodate site-specific topography features, meteorology, and transient events.

To explore and illustrate the importance of fate and transport, we have conducted a scoping analysis using the CalTOX code. The analysis was conducted for several representative semi-volatile chemicals to estimate the time averaged chemical partitioning. The code considers exchange rates of chemicals between various regions of the environment based on the chemical's properties, the properties of the local environment (e.g., soil type, etc.), and climate conditions. This general modeling approach has been vetted in a number of different applications with varying degrees of success.

The scoping results are intended to provide the reader an awareness of the insights that can be provided by such models while at the same time providing some perspective on the importance of various factors on the reliability of the results. It should also be noted that there are numerous modeling packages that will provide fate and transport predictions similar to those discussed in this report. For example, the MEPAS (Whelan et al. 1992) and TaPL3 (Webster et al. 1998; 2003) can be used to develop similar data sets as those developed with CalTOX in this report.

Briefly, the CalTOX model is based on the exchange rates and exchange pathways between the eight environmental compartments that are shown schematically in Figure 3.3. The model partitions the

(1) CalTOX, a Multimedia Total-Exposure Model for Hazardous-Waste Sites, Part II: The Dynamic Multimedia Transport and Transformation Model, December 1993. Further information available at: http://www.dtsc.ca.gov/ScienceTechnology/ftp/techman2.pdf 
chemical into the liquid, gas and solid phases of each compartment for the calculation. The flow between compartments and the ultimate fate of the chemical are calculated based on known (or estimated) transfer rates and environmental conditions. See footnote for discussions of the various partitions and the exchange/loss mechanisms.

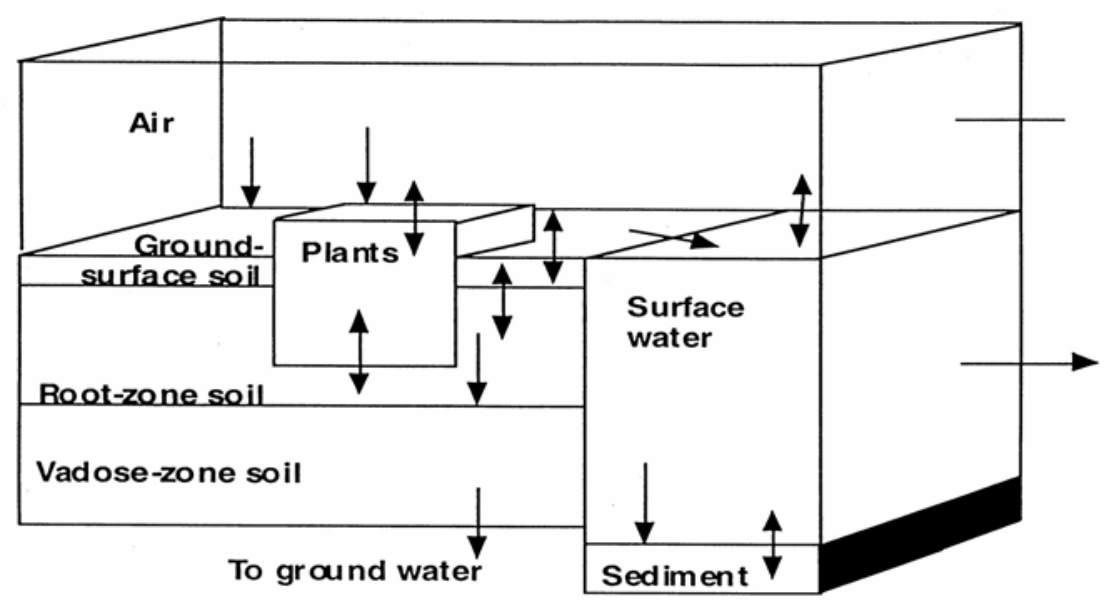

Figure 3.3. CalTOX Model Compartments ${ }^{(1)}$

As most commonly used for long-term release analyses, CalTOX models the steady-state concentration of the effluents in the various environmental partitions (compartments). The code also allows time-dependent calculations to evaluate the decay of effluent concentrations in the various compartments once effluent releases have ended. The time-dependent calculations assume that the initial chemical concentration in the environment is in the soil compartment because chemicals in the other primary compartments (air and water) are assumed to migrate out of the calculation region early in the relatively long-term decay calculation. For this and other reasons, the CalTOX documentation recommends only using the model for time periods of months and years. But with this caveat in mind, we have considered shorter times with the understanding that the results should only be considered as temporal trend indicators and that the actual decay rates may vary considerably. Figure 3.4 illustrates not only the compartments but the interactions between the compartments (transport).

(1) CalTOX, a Multimedia Total-Exposure Model for Hazardous-Waste Sites, Part II: The Dynamic Multimedia Transport and Transformation Model, December 1993. Further information available at: http://www.dtsc.ca.gov/ScienceTechnology/ftp/techman2.pdf 


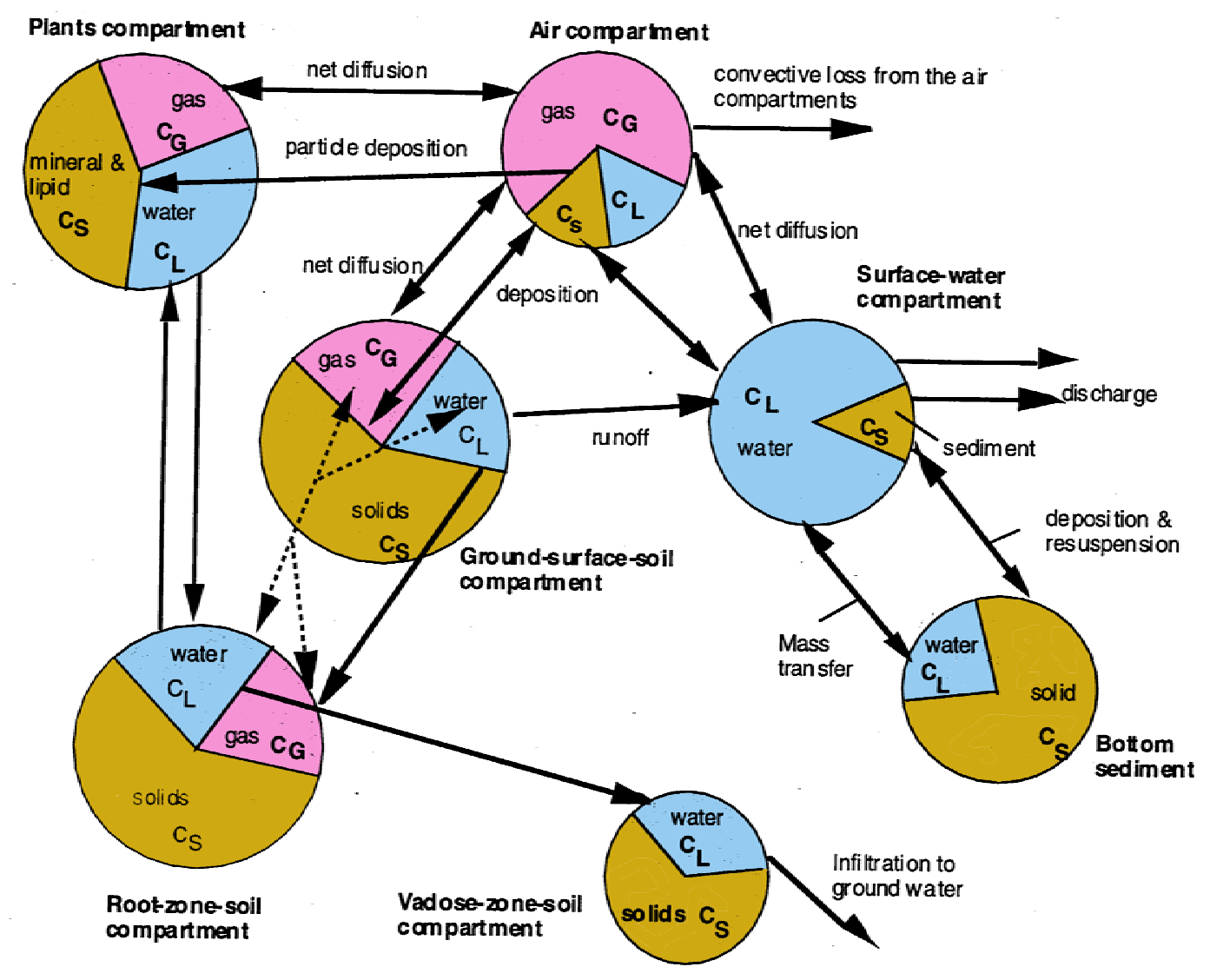

Figure 3.4. CalTOX Fugacity Model Compartment and Transport Diagram

CalTOX was not developed to predict the dynamic partitioning of effluents following the onset of effluent releases (i.e., prior to the time that the chemicals reach steady-state distributions in the various environmental compartments). Thus it is not entirely appropriate to use the code to model the effects of short-term transient air releases as might occur with an infrequent off-normal or accidental effluent release from a production process. However, if an accident results in a spill into the soil or surface waters, CalTOX can be used to model the subsequent dispersal and decay by using the estimated soil loading from the spill as an initial condition for the decay modeling.

Even excellent models are only as good as the input parameters that are used as the basis for the calculations. For the chemical fate and transport question, many key parameters for lesser used chemicals are often not well known or understood for different types of soil and environmental stressors (Carlson 1996). In fact key properties and environmental parameters for many important process and potential effluent chemicals have not been measured and are NOT available in the literature.

In this work, we have used the model to assess general trends, showing roughly the expected chemical concentration in each partition, rather than a quantitative predictor. Primary observations are focused on the relative loading in various partitions to determine which partition would offer the best 
opportunity to detect an effluent signature in the environment. Exact partitioning may vary greatly and should be considered carefully by mission planners.

\subsubsection{Chemical Signature Properties}

The specific chemical properties of the signature compounds under investigation play a significant role in the fate and transport activities. In order to investigate the differences in chemical properties, three classes of chemicals were selected and a representative compound from each class was chosen to be used in the example calculations. These semi-volatile compounds were selected from the the CalTOX database, based on the listed properties. The compound properties have been heavily researched and reliable values have been determined. It should also be noted that compounds were selected that fall into the semi-volatile category. Numerous compounds which fit the compound class selection criteria were not used if they had a vapor pressure of greater than $2 \mathrm{~Pa}$. High vapor pressure compounds are amenable to remote sensing, and are therefore outside the in situ project goals. The three compound classes and selected example chemicals are as follows:

- Non-polar/hydrophobic - anthracene

- Polar/hydrophobic - N-nitrosodiphenylamine

- Polar/water soluble - catechol

Table 3.4 illustrates a number of important properties of the selected compounds (values extracted from the CalTOX database; the complete property set can be viewed there).

Table 3.4. Selected Properties of Example Compounds from CalTOX Database

\begin{tabular}{|l|c|c|c||}
\hline & anthracene & $\begin{array}{c}\text { N- } \\
\text { nitrosodiphenylamine }\end{array}$ & catechol \\
\hline Molecular weight $(\mathrm{g} / \mathrm{mol})$ & 178.22 & 192 & 110 \\
\hline Octanol-water partition coefficient $\left(\mathrm{K}_{\mathrm{ow}}\right)$ & 30300 & 1348.9 & 7.5 \\
\hline Melting point $(\mathrm{K})$ & 488.15 & 339.65 & 377.15 \\
\hline Vapor Pressure in $(\mathrm{Pa})$ & 0.0118 & 0.089 & 1.34 \\
\hline Solubility in mol/m ${ }^{3}$ & 0.000316 & 0.1822 & 4194 \\
\hline Henry's law constant (Pa-m $\left.{ }^{3} / \mathrm{mol}\right)$ & 4.28 & 0.506 & 0.00031 \\
\hline Organic carbon partition coefficient $\left(\mathrm{K}_{\mathrm{oc}}\right)$ & 22200 & 1200 & 118 \\
\hline Octanol/air partition coefficient & $1.7 \times 10^{7}$ & $6.4 \times 10^{7}$ & $5.8 \times 10^{7}$ \\
\hline Partition coefficient in ground/root soil layer & 345.41 & 18.67 & 1.83 \\
\hline Partition coefficient in vadose-zone soil layer & 67.87 & 3.66 & 0.36 \\
\hline Reaction half-life in air (days) & 0.0475 & 0.053 & 0.196 \\
\hline Reaction half-life in surface soil (days) & 568.34 & 34.16 & 7.08 \\
\hline Reaction half-life in ground water (days) & 509 & 44 & 8 \\
\hline Reaction half-life in surface water (days) & 0.0475 & 15.45 & 1.75 \\
\hline Reaction half-life in sediments (days) & 945 & 229.16 & 22.91 \\
\hline Reaction half-life in the leaf surface (days) & 568.3 & 34.1 & 7.08 \\
\hline
\end{tabular}


The first evaluation was to investigate the partitioning of the three example chemicals from a continuous low level release into a hot/wet environment. Alabama was chosen as the example environment. It should be noted that CalTOX has integrated climatological data for each of the 50 states in the database for use in the calculations. Thus, in this report, mention will be made of various state environments; that is to bring attention to the fact that the typical climate values for that state are being used in the example calculations. Figure 3.5 typifies the results.

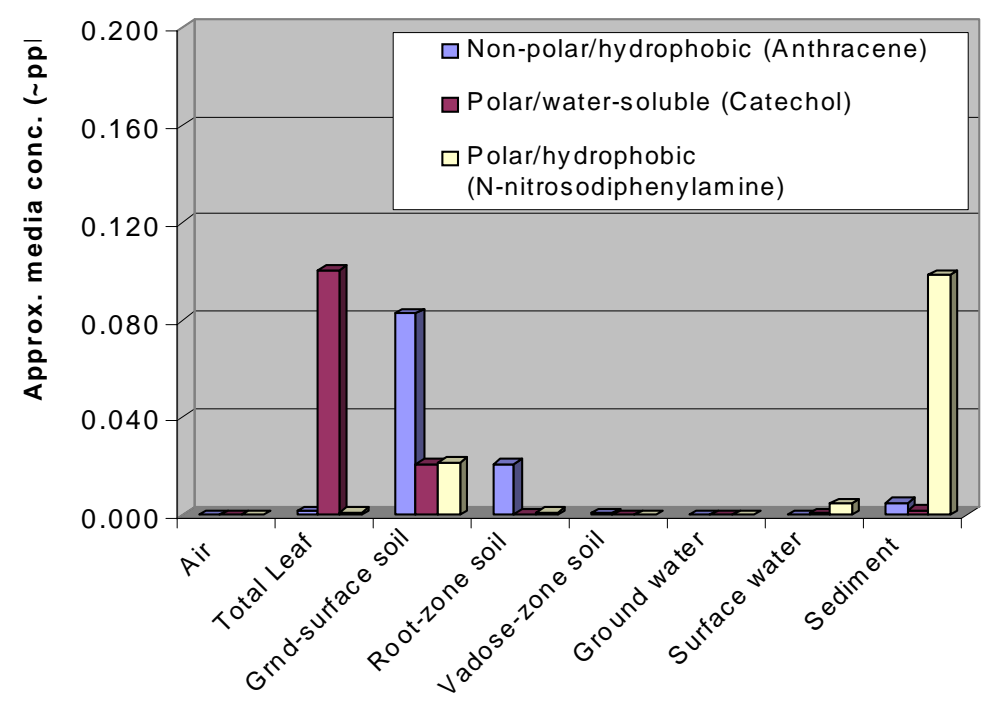

Figure 3.5. Relative Equilibrium Concentrations of Example Chemicals in Each Compartment for Continuous Emission into a Hot/Wet Environment (Alabama) at a 65-25-10 (air-water-soil) Ratio

The results are consistent with an intuitive evaluation of the release scenario:

- Anthracene - The non-polar, hydrophobic nature of the compound should cause sequestration in soils and sediments, as transport is limited. Any water-based release should quickly result in transport into the sediments due to limited solubility. This is consistent the modeled results in Figure 3.5.

- Catechol - The polar, water soluble nature of this compound should make it very mobile and bioavailable. Figure 3.5 illustrates reduced soil concentrations and greatly enhanced leaf concentrations. The only oddity is that there is no discernable concentration in ground and surface waters, which would seem likely due to the highly soluble nature of the compounds. However, in Table 3.4 it can be seen that the ground and surface water half lives of catechol are low, which limits any concentration build-up in these compartments.

- N-nitrosodiphenylamine - This polar, yet somewhat hydrophobic compound should address transport properties somewhere between the two more extreme examples of anthracene and catechol. Soil concentrations are reduced to the levels of that of catechol. However, the compound does show up in surface water and strongly in sediments. The behavior here is complex. Although the water solubility is low, it is still nearly 3 orders of magnitude higher than that of anthracene which would 
partially explain the attenuated soil concentrations. The much smaller soil half life value (from Table 3.4) would explain the remainder of the soil attenuation question. The large value in the sediments is described by the partial water solubility and the fairly long half life in the sediments. Although anthracene also has a fairly long soil half life, its extremely low water solubility limits the transport into waters where it can interact with sediments for sequestration there.

\subsubsection{Local Environmental Factor Effects}

Three disparate locations and average environments were also chosen to evaluate the sensitivity to soil conditions and climatological effects. The locations and associated environmental parameters are available as standard cases within the CalTOX data base. The parameters are summarized in Table 3.5 with the chemical initially partitioned into the soil, water, and air in a 65-25-10 ratio. Release totals were $20 \mu$ moles per $\mathrm{m}^{2}$ per day into a $100 \mathrm{~m}$ by $100 \mathrm{~m}$ sample space.

Table 3.5. Environmental and Location Effects Modeled

\begin{tabular}{||l|l|l||}
\hline & Nominal Location & \multicolumn{1}{c|}{ General Features } \\
\hline Hot/wet & Alabama & clay \& sediment soils, warm humid climate \\
\hline Hot/dry & Nevada & sandy soil, arid variable climate \\
\hline Cool/wet & Minnesota & rocky \& loamy soils, moist cool climate \\
\hline Cool/dry & Montana & rocky \& loamy soils, cool dry climate \\
\hline
\end{tabular}

Figure 3.6 shows the partitioning effects with respect to diverse geographical areas chosen. It should be noted that the climate types are averages for the entire state. Thus, the conditions are moderated somewhat by climatic diversity within the state. For example, although Nevada can be considered a hot/dry state, the northwestern areas of the state near Reno would moderate the temperature extremes of the Las Vegas area deserts. These climates are used only for example purposes, and it is expected that any potential sensor deployment into a specific environment would include a detailed climatic study.

For some chemicals and locations, it is also important to consider anomalous effects that may occur in nature that are not represented in the models. An example of this is the role of small fog droplets in the secondary pick up of some chemicals from the surfaces of the soil and plants (after initial deposit following release) and subsequent transport in the environment (Glotfelty et al. 1987). In this case, fogbased enrichment factors of over 1000 have been shown for some compounds.

Local environmental effects conclusions -

- Major concentration variations in the soil may result if local organism populations dramatically affect the chemical half-life in individual compartments.

- The octanol-water partition coefficient (KOW) value has an important impact on the effects of precipitation for moving chemical residue down into the soil column. 

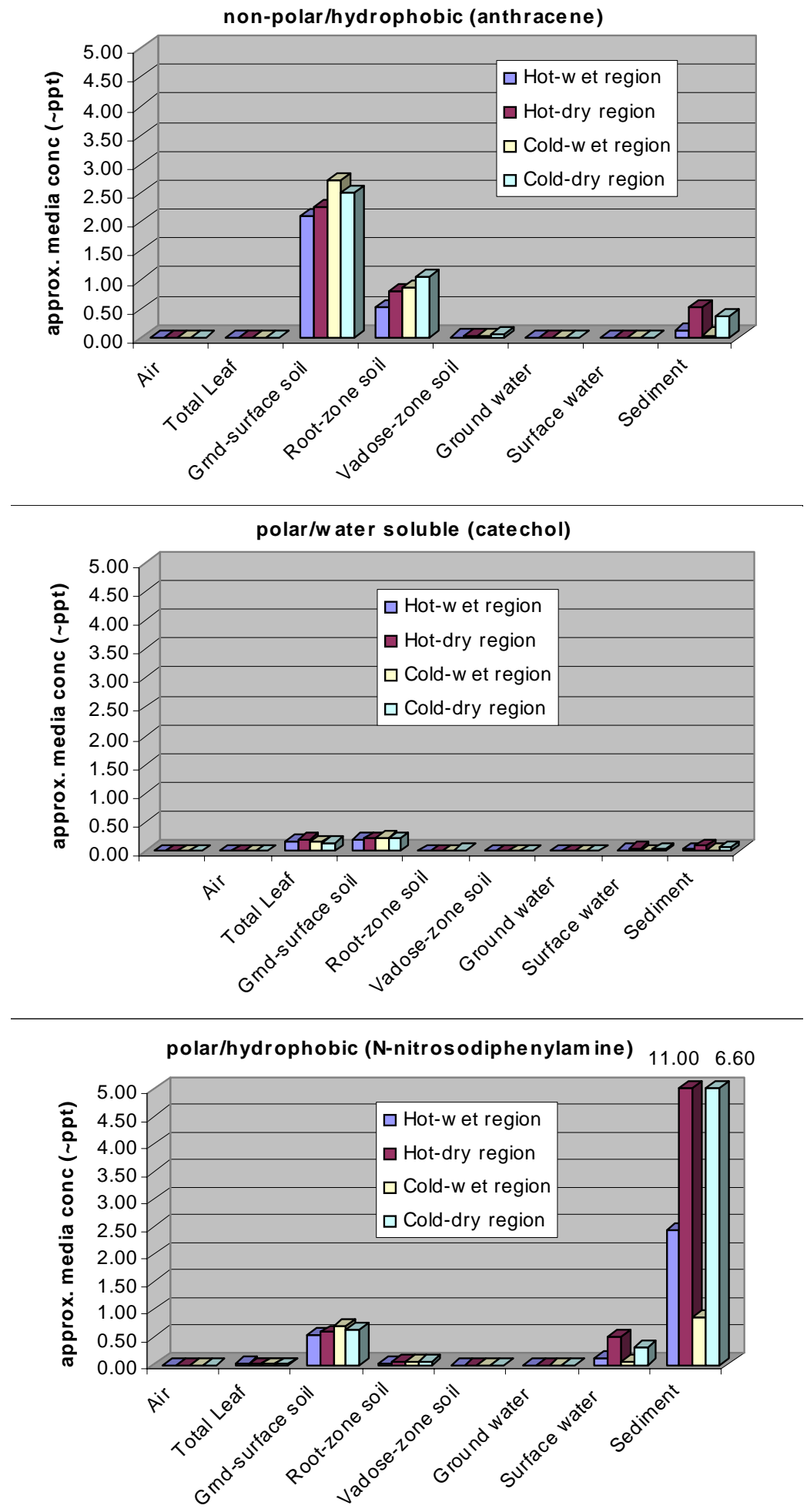

Figure 3.6. Relative Equilibrium Concentrations of Example Chemicals in Each Compartment for Continuous Emission (65-25-10 air-water-soil release rate ratio) into four Different Climate Regions 
- Water solubility values will greatly influence transport in wet environments.

- Reaction half-lives of compounds in the specific media can skew results away from intuitive transport conclusions.

\subsubsection{Effluent Release Mode Effects}

Four release mode variations were modeled in order to illustrate the partitioning sensitivity to these variations as summarized in Table 3.1. The results of the calculations are shown in Figures 3.7 and 3.8 for both the absolute quantities and the relative $\%$ of chemical release and taken up in each partition. Figure 3.7 illustrates the hot/dry (Alabama) climate results and Figure 3.8 shows the cool/wet (Minnesota) climate results. In these cases, the releases are assumed to be steady state with a total of 20 micromoles per day per square meter.

Table 3.6. Chemical Release Conditions Modeled

\begin{tabular}{|l|c|c|c|}
\hline \hline & Release to Air - (\%) & Release to Soil - (\%) & Release to Water - (\%) \\
\hline Case 1 & $20 \mu$ moles $/$ day $/ \mathrm{m}^{2}(100 \%)$ & $0-(0 \%)$ & $0-(0 \%)$ \\
\hline Case 2 & $0-(0 \%)$ & $20 \mu \mathrm{moles} / \mathrm{day} / \mathrm{m}^{2}(100 \%)$ & $0-(0 \%)$ \\
\hline Case 3 & $0-(0 \%)$ & $0-(0 \%)$ & $20 \mu \mathrm{moles} / \mathrm{day} / \mathrm{m}^{2}(100 \%)$ \\
\hline Case 4 & $13 \mu \mathrm{moles} /$ day $/ \mathrm{m}^{2}(65 \%)$ & $5 \mu \mathrm{moles} / \mathrm{day} / \mathrm{m}^{2}(25 \%)$ & $2 \mu \mathrm{moles} / \mathrm{day} / \mathrm{m}^{2}(10 \%)$ \\
\hline
\end{tabular}

Practical release modes for specific applications must be considered carefully for individual chemicals as the chemical's properties may preclude or limit practical releases via certain paths.

- For example, a highly volatile chemical that escapes from a process as a fugitive emission is very likely to be released to the air. It would take intentional dumping or burial to effect significant longterm releases of this type of chemical to the soil or the water.

- Conversely, a low volatility, sticky chemical with a relatively low boiling point would be very difficult to release to the air. Chemicals like this often tend to stick to surfaces and materials where they have exposure. For example, it has been reported that attempts to release chemicals of this type to the atmosphere through exhaust stacks have resulted in very little release to the air. Post-test analysis found the chemicals adsorbed onto the stack walls. Practical release to the air was found to require heating the stack walls to temperatures that inhibited the chemical adsorption in the stack during transit. 

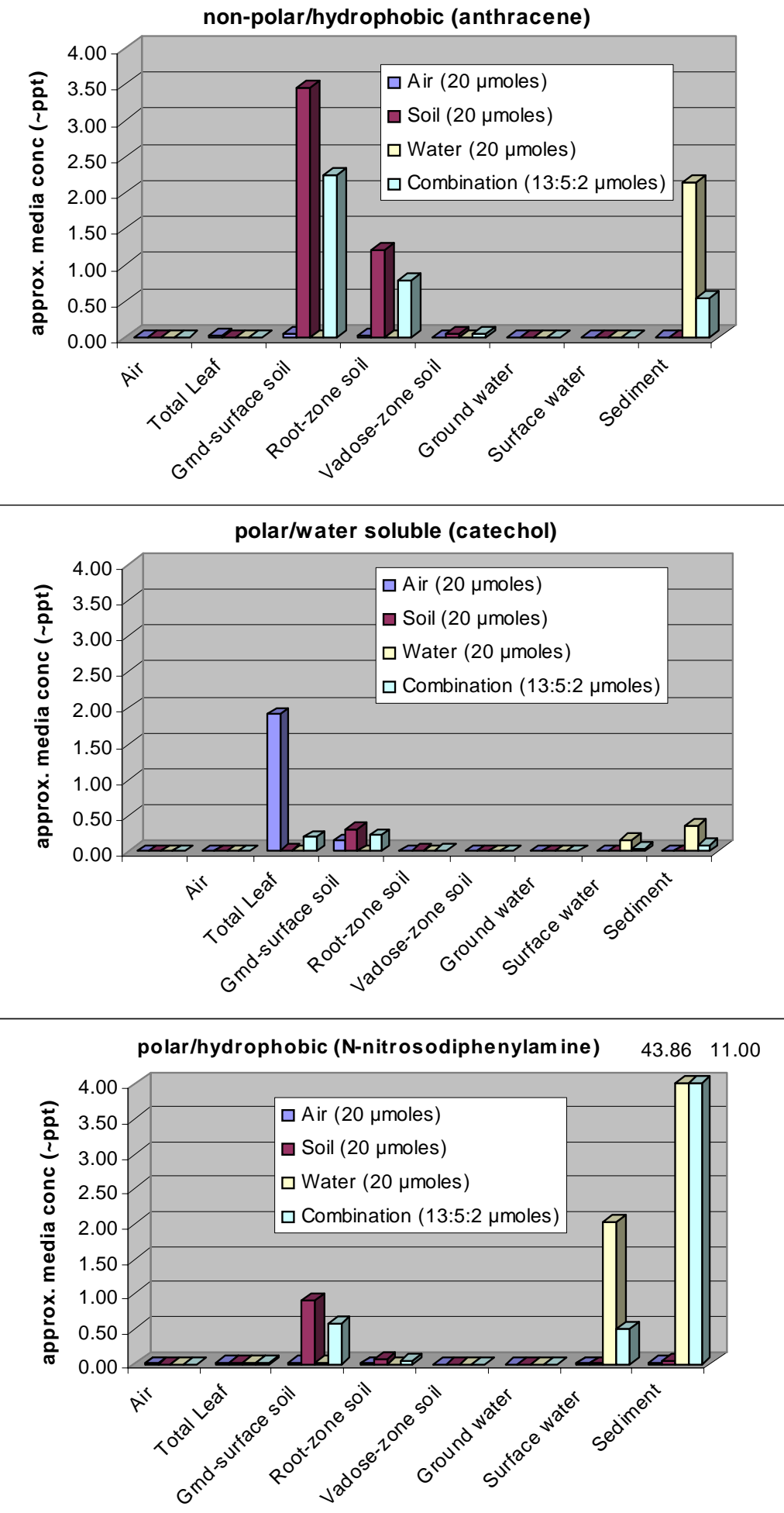

Figure 3.7. Relative Equilibrium Concentrations of Example Chemicals in Each Compartment for Continuous Emission with Different Release Mechanisms into a Hot/Dry Climate 

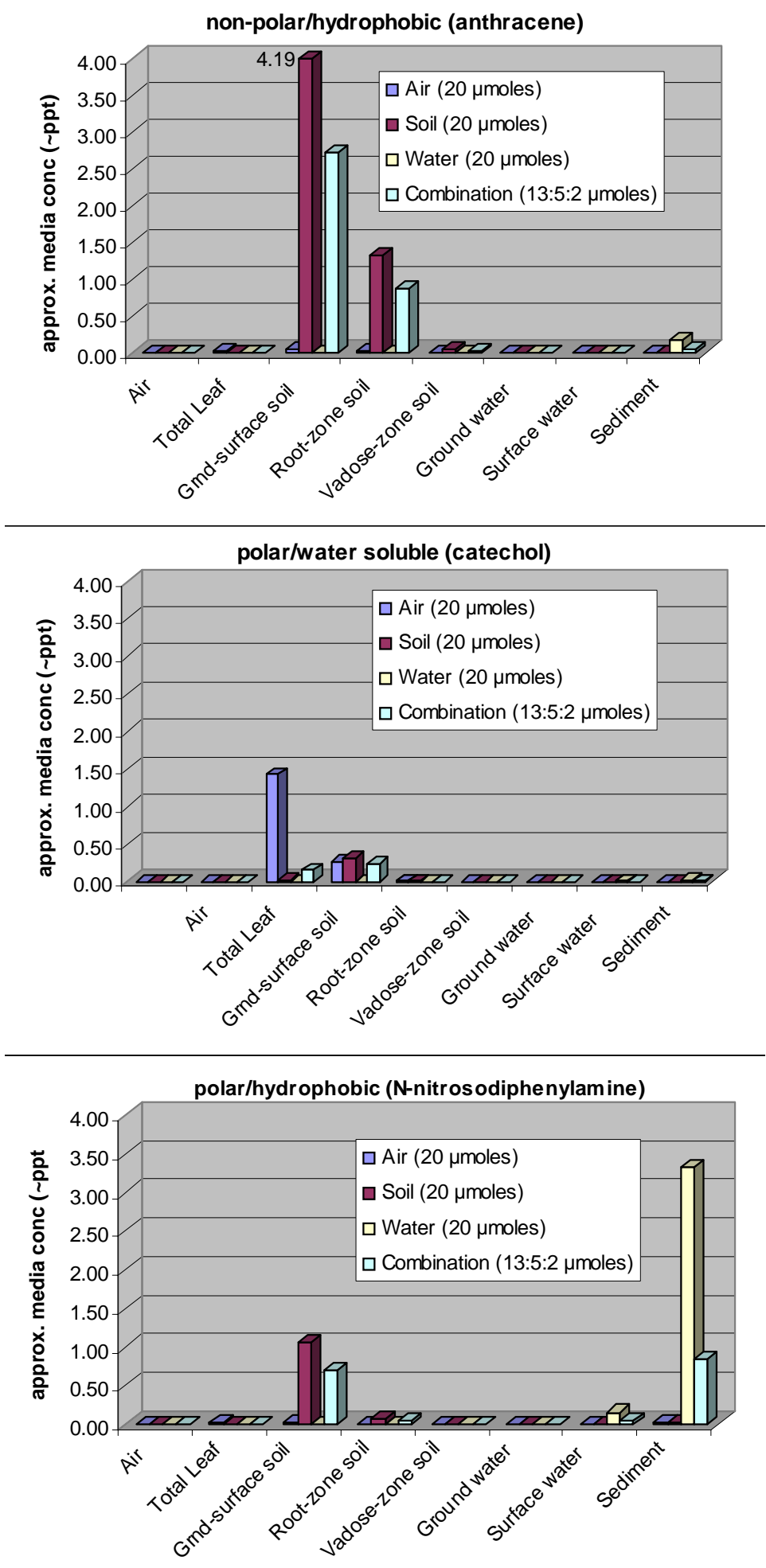

Figure 3.8. Relative Equilibrium Concentrations of Example Chemicals in Each Compartment for Continuous Emission with Different Release Mechanisms into a Cool/Wet Climate 
Effluent release mode effect conclusions -

- Variations in the release mode can have dramatic effects on the resulting partitioning between various environmental compartments. Thus care should be taken to establish the probable release mode for cases of interest before conducting any modeling. If release modes cannot be established with sufficient confidence, bounding cases should be modeled to provide estimates of the partitioning under the various conditions (this recommendation is consistent with the work of McKone and others and has been clearly documented in their reports and publications). "In all cases the model is very sensitive to source terms." ${ }^{(1)}$

\subsubsection{Temporal Decay Effects Following Cessation of Effluent Releases}

The effects of chemical signature temporal decay were evaluated by considering four different time periods from cessation of a release (30,60, 120, and 360 days). The post release modeling considered the amount of chemical in the soil at the cessation of the releases and allowed those concentrations to time decay based on the fugacity calculations. The release function consisted of $20 \mu$ moles/day for 365 days/year over 5 years and spread evenly over 10,000 sq $\mathrm{m}$ to a depth of $0.1 \mathrm{~m}$ depth. The chemical loads in the air and water were not considered as they will rapidly migrate out of the model space after the end of release. ${ }^{(2)}$ Figure 3.9 and Figure 3.10 show the results of the calculations for two different environments.

The results of these example fugacity calculations provide useful insights into how the fugacity analysis can provide valuable guidance for measurement method developers and for mission planners.

Temporal decay effect conclusions -

- It is necessary to have representative chemical half-life values for input data as changes greatly affect decay rates as should be expected.

- CalTOX decay rate analysis uses partition loading as starting point and predicts decay and dispersal.

\subsubsection{Summary Observations from CalTOX Scoping Analyses}

Predictions for semi-volatile chemicals indicate partitioning into the soil and sediments after release to the environment. Specifically, for the semi-volatile chemical examples presented above, key implications include:

(1) "CalTOX, A Multimedia Total-Exposure Model for Hazardous-Waste Sites, Part II: The Dynamic Multimedia Transport and Transformation Model," page 10, December 1993. Available at http://www.dtsc.ca.gov/ScienceTechnology/ftp/techman2.pdf

(2) This followed the recommendation of Thomas McKone, a lead developer of the CalTOX code personal communication. 

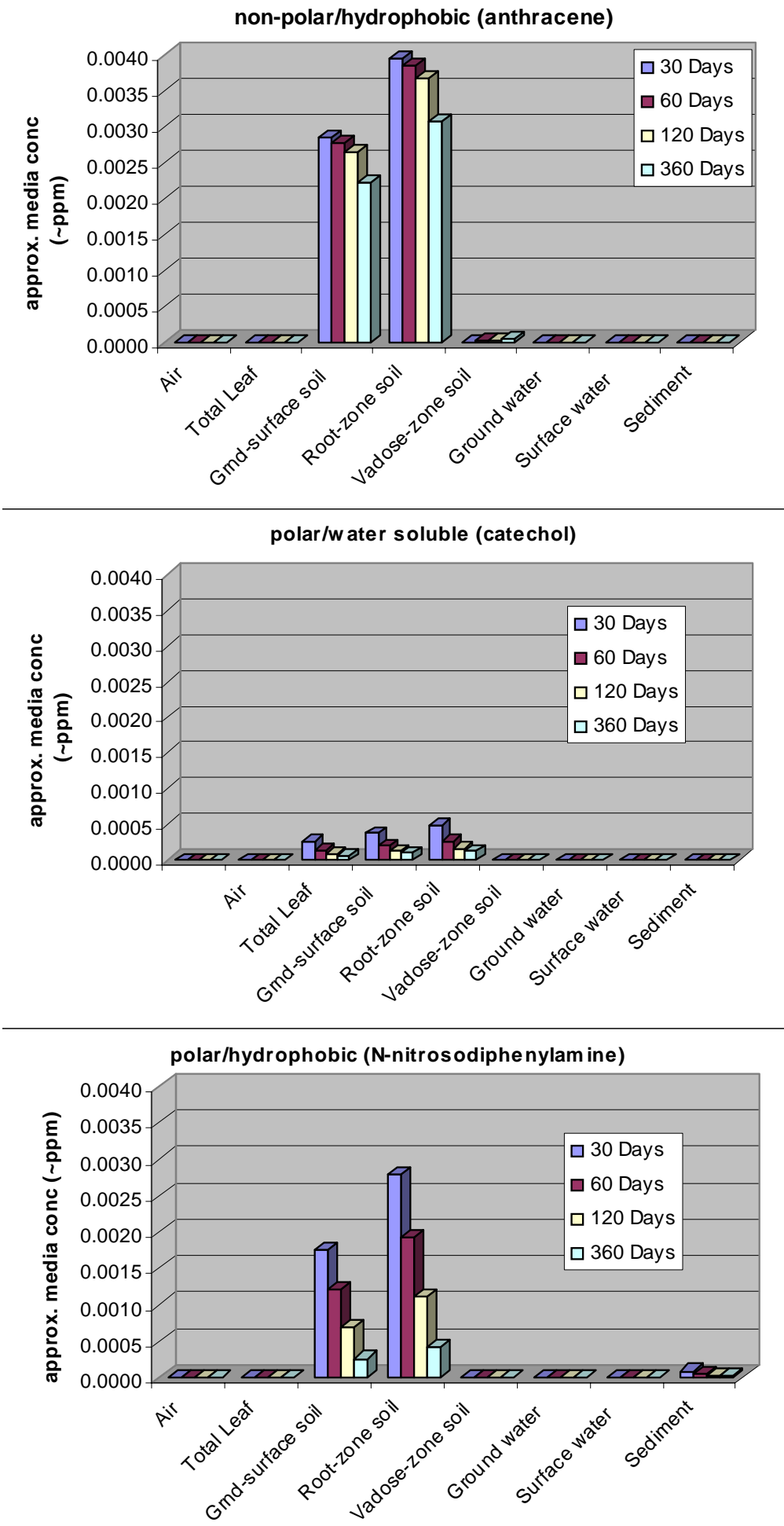

Figure 3.9. Relative Equilibrium Concentrations of Example Chemicals in Each Compartment for a Discontinued Release and Subsequent Time Decay for a Hot/Dry Climate 

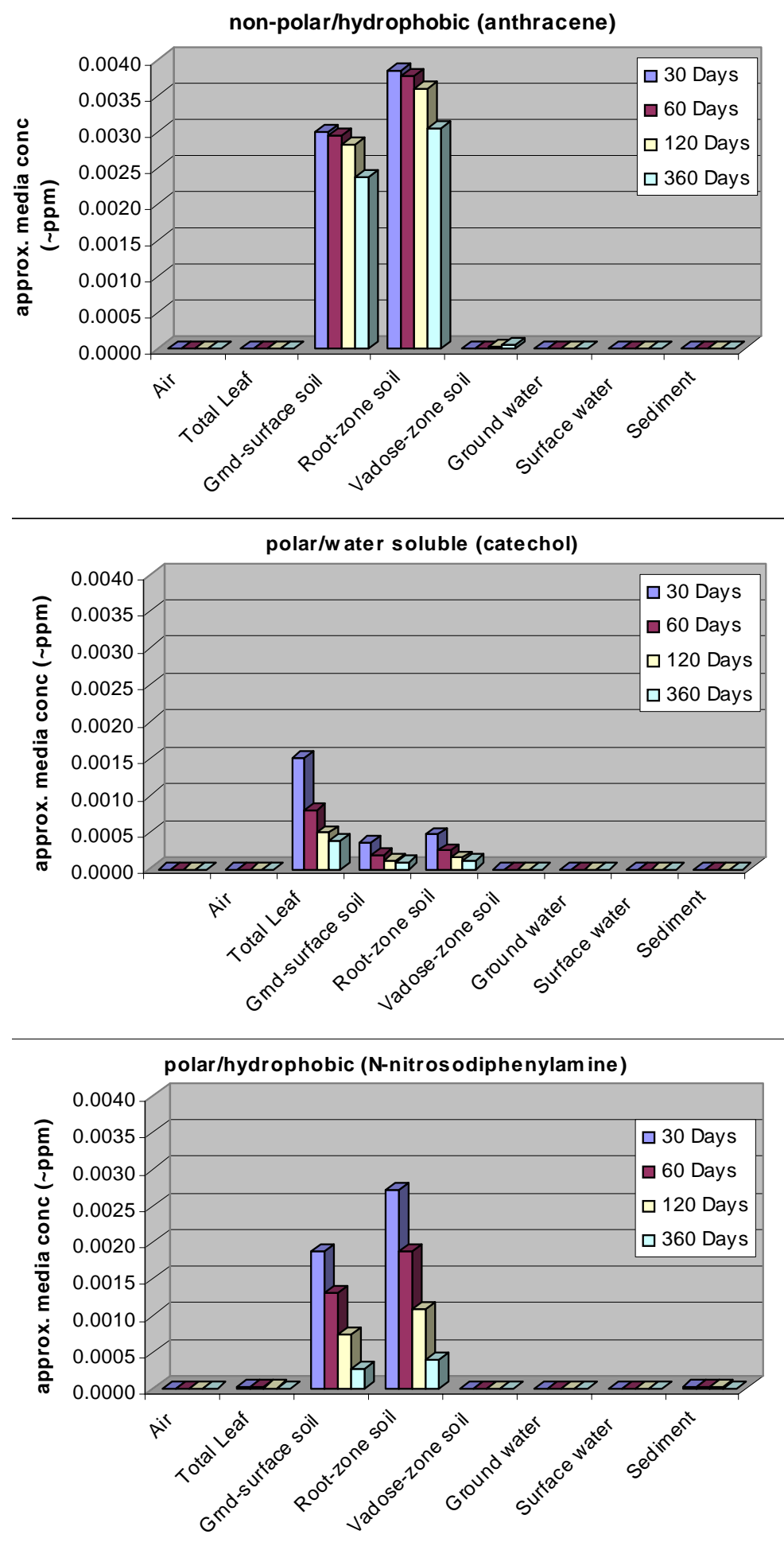

Figure 3.10. Relative Equilibrium Concentrations of Example Chemicals in Each Compartment for a Discontinued Release and Subsequent Time Decay for a Cool/Wet Climate 
- Primary chemical presence in the environment will be found in the plant material, the near surface ground soil and the sediment for a sustained release depending on how it was released.

- Location and climatic variations resulted only in modest variations in the chemical partitioning in the environment for the general cases tested. However, it is known that the micro climates and terrain variations can affect the results greatly in some cases.

- Chemical decay rates in the environment indicate that the example chemicals are expected to remain in the environment for significant times after the cessation of chemical releases, but they will redistribute into different partitions.

The same model codes can be applied to specific chemicals and applications by adding appropriate site-specific information on climate, meteorology, terrain, local confounding issues and so forth, but extensive evaluation for specific insertion options is beyond the scope of this effort.

\subsubsection{Conclusion from Fugacity Modeling}

Stay alert for specific chemical and environmental effects that can impact the predictions.

Experimental studies have found that some combinations of chemicals and environmental conditions can produce fate and transport effects that would not be anticipated based on the modeling. Generally this occurs when the chemical/environmental conditions result in interaction mechanisms becoming important that have not been built into the models and/or result in significant changes to chemical-environmental interaction parameters that are used in the models (e.g., half-life in the soil, etc.). An example of such a chemical-environmental effect has been observed with aerosol and particulate-enhanced transport of some chemical effluents (Bidleman 1988). Models are good at making generalizations, but potential compound class specific deviations should be investigated. As the refinement of the specific scenario progresses, detailed examination of the end case set can be done to verify feasibility and adequacy of the conclusions to the scenario requirements.

Although the CalTOX model works well for the prediction of the equilibrium media compartment location (air, soil, sediment, surface water, etc.) for a chemical set of interest, the model does not provide spatial dispersion information. Thus, the CalTOX model has little value in the development of concentration gradients with respect to distance in the case of a point source term. Fortunately, efforts have taken place to study characteristic travel distances of semi-volatile compounds (Bennett et al. 1998; Beyer et al. 2000). From these studies, models have been developed to predict characteristic travel distances based on chemical properties for semi-volatile compounds. ELPOS and TaPL3 are examples of such models (Beyer and Matthies 2002; Webster et al. 2003). Information from these models, used in conjunction with the partitioning assessments gained from the CalTOX model, can provide additional insight into the appropriate areas/media to apply additional analytical techniques for detection of desired signature compounds. 


\subsubsection{Target Analyte Options}

Successful completion of the activities outlined above will determine if there are key exploitable chemical signatures for detection of the target process(es) and where in the environment it will be most effective to take measurements.

\subsection{Constructing Deployment Scenario Options}

The activities shown in Figure 3.11 are designed to identify suitable deployment options, requirements and constraints. These will serve as the basis for identifying candidate measurement methods and evaluating the measurement system options against the user criteria. If suitable technology options are available, the method can be used to select the preferred measurement system option. If suitable measurement technologies are not available, this evaluation can identify technology gaps that must be addressed to meet the application requirement.

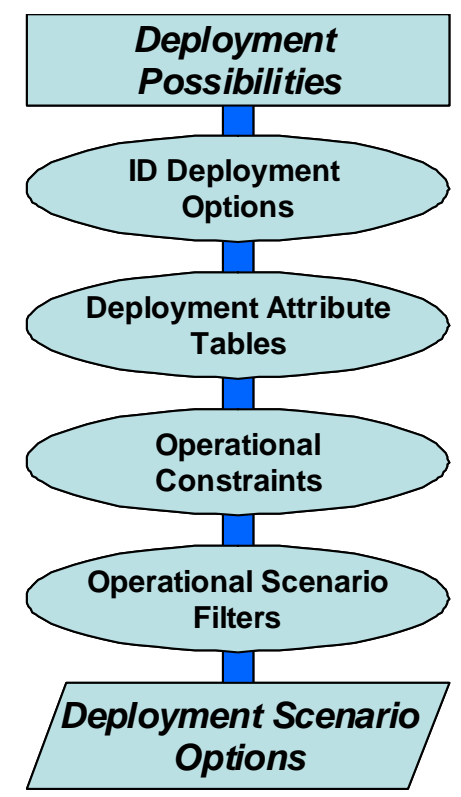

Figure 3.11. Deployment Scenario Options Identification Process

\subsubsection{Deployment Possibilities}

Deployment scenario options are driven by the socio-geo-political environment of the area where the data is required and by the agency responsible for the insertion of the asset used to make the measurement.

Rather than speculate on what is politically and physically possible in a specific instance, the approach has been taken to identify some generic traits associated with a broad range of scenarios that 
will have impact on the type of measurement system deployed. The intention is to vet these generic traits in an appropriate forum without the necessity of tying specific traits to specific scenarios and agencies.

\subsubsection{Identify Deployment Options}

The first step in the process is to develop a possible list of deployment options ranging from covert single person stealth insertion with highly portable, concealed instrumentation to fully overt "bring in the entire laboratory in the back of an air ride semi-trailer with an accompanying power unit" scenario.

\subsubsection{Deployment Attribute Tables}

The next step is to extract and tabulate the generic attributes from these possible scenarios. This has been done in Table 3.7. The table includes key attributes that relate to the detection properties for the chemical measurement options in the actual deployment environment, attributes that relate to the timing requirements of the deployment, attributes that relate to logistical considerations for the deployment measurement equipment, and attributes that relate to the type of technical training required to successfully make a reliable measurement. The attributes are ranked into generic criteria of increasing measurement instrument complexity as shown (increasingly demanding of the measurement system as you move to the right-hand column).

\subsubsection{Operational Constraints}

Practical operational constraints for a particular insertion scenario will usually dictate the criteria needed to complete a specific insertion mission. For example, it might be determined that detection of a single analyte is required at the ppb level and the expected dynamic range is moderate and confidence level needs to be high. Once the deployment agency examines all the operational constraints relevant to any number of deployment scenarios, the next step is to construct operational scenario filters.

\subsubsection{Operational Scenario Filters}

Once the operational constraints are understood, one can construct a block/pass filter that shows the attributes that are acceptable for a particular deployment scenario. This is done for a notional example for four representative attributes in Table 3.8. The required performance levels for the various attributes are designated by either a shaded bar or by locating a "R" (i.e., Requirement) in the appropriate box (depending on the detail level of the graphic desired). For practical cases, this information would be ideally provided by an end-user to describe the requirement of a deployment scenario of interest.

Identifying the needed level of performance in each attribute row will have major impact on the cost and near-term availability of viable technologies to meet the application requirements. For example, if a scenario requirement is set by arbitrarily marking the most demanding level of performance in each row, there may be no technology options that meet the requirements. This is analogous to the infamous StarTrek "tricorder" - small, measure everything, robust, long operating time, no sample preparation, stand-off sensing, fully processed answers, etc. If lower levels of performance would be sufficient for 
Table 3.7. Deployment Scenario Attributes vs. Evaluation Criteria

\begin{tabular}{|c|c|c|c|c|c|c|}
\hline & Attribute & \multicolumn{5}{|c|}{ Criteria } \\
\hline \multirow{4}{*}{ 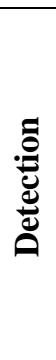 } & $\begin{array}{c}\text { Number of } \\
\text { analyte(s) }\end{array}$ & $\begin{array}{l}\text { Single } \\
\text { analyte }\end{array}$ & Single class & $\begin{array}{c}\text { Multiple } \\
\text { classes }\end{array}$ & $\begin{array}{c}\text { Broad } \\
\text { spectrum }\end{array}$ & Universal \\
\hline & $\begin{array}{l}\text { Detection limits } \\
\text { required }\end{array}$ & $>\%$ & $\begin{array}{l}\text { ppth } \\
10^{-3}\end{array}$ & $\begin{array}{l}\mathrm{ppm} \\
10^{-6}\end{array}$ & $\begin{array}{l}\mathrm{ppb} \\
10^{-9}\end{array}$ & $\begin{array}{l}<\mathrm{ppt} \\
10^{-12}\end{array}$ \\
\hline & $\begin{array}{c}\text { Sampling } \\
\text { dynamic range }\end{array}$ & $\begin{array}{c}\text { Very Low } \\
<10^{1}\end{array}$ & $\begin{array}{c}\text { Low } \\
10^{1} \text { to } 10^{2}\end{array}$ & $\begin{array}{l}\text { Moderate } \\
10^{2} \text { to } 10^{4}\end{array}$ & $\begin{array}{c}\text { High } \\
10^{4} \text { to } 10^{6}\end{array}$ & $\begin{array}{c}\text { Very High } \\
>10^{6}\end{array}$ \\
\hline & $\begin{array}{c}\text { Confidence } \\
\text { uniqueness reqs }\end{array}$ & $\begin{array}{c}\text { Very low } \\
10 \\
\end{array}$ & $\begin{array}{l}\text { Low } \\
10^{2} \\
\end{array}$ & $\begin{array}{c}\text { Moderate } \\
10^{3} \\
\end{array}$ & $\begin{array}{l}\text { High } \\
10^{4} \\
\end{array}$ & $\begin{array}{c}\text { Very high } \\
10^{5} \\
\end{array}$ \\
\hline \multirow{4}{*}{ 菖 } & & & & & & \\
\hline & $\begin{array}{l}\text { Sampling time } \\
\text { analysis time }\end{array}$ & $>1$ day & $1 \mathrm{hr}$ to 1 day & $5 \mathrm{~min}$ to $1 \mathrm{hr}$ & 1 to $5 \mathrm{~min}$ & $<1 \mathrm{~min}$ \\
\hline & $\begin{array}{c}\text { Time to } \\
\text { deployment }\end{array}$ & $>1$ year & 6-12 months & 1-6 months & 1-30 days & $<1$ day \\
\hline & $\begin{array}{c}\text { Mission time } \\
\text { allowance }\end{array}$ & $<1$ day & 1-30 days & $1-12$ months & $1-10$ years & $>10$ years \\
\hline & & & & & & \\
\hline \multirow{3}{*}{. } & $\begin{array}{c}\text { Power } \\
\text { requirement }\end{array}$ & $\begin{array}{l}\text { High volt } \\
\text { High current }\end{array}$ & $\begin{array}{c}\text { Standard Line / } \\
\text { generator }\end{array}$ & $\begin{array}{c}\text { Vehicle Lead / } \\
\text { acid }\end{array}$ & $\begin{array}{l}\text { Alkaline } \\
\text { NiCd, Li }\end{array}$ & $\begin{array}{l}\text { Passive/ } \\
\text { parasitic }\end{array}$ \\
\hline & $\begin{array}{l}\text { Portability } \\
\text { requirement }\end{array}$ & $\begin{array}{l}\text { Prepared } \\
\text { facility } \\
\text { required }\end{array}$ & $\begin{array}{l}\text { Laboratory } \\
\text { bench scale }\end{array}$ & $\begin{array}{c}\text { Vehicle } \\
\text { deployable }\end{array}$ & $\begin{array}{c}\text { Man } \\
\text { portable }\end{array}$ & Handheld \\
\hline & $\begin{array}{c}\text { Ruggedness / } \\
\text { transportability }\end{array}$ & $\begin{array}{c}\text { Very fragile, } \\
\text { controlled } \\
\text { transport }\end{array}$ & $\begin{array}{c}\text { Fragile, } \\
\text { transport } \\
\text { precautions req }\end{array}$ & $\begin{array}{c}\text { Moderate, } \\
\text { normal } \\
\text { precautions }\end{array}$ & $\begin{array}{l}\text { Minimal } \\
\text { Mil-spec } \\
\text { hardened }\end{array}$ & Bombproof \\
\hline 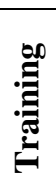 & $\begin{array}{c}\text { Training level } \\
\text { allowance }\end{array}$ & $\begin{array}{c}\text { Extensive } \\
\text { and } \\
\text { specialized }\end{array}$ & $\begin{array}{c}\text { High skill, } \\
\text { trained operator }\end{array}$ & $\begin{array}{c}\text { Well trained } \\
\text { operator }\end{array}$ & $\begin{array}{c}\text { Minimal } \\
\text { trained } \\
\text { operator }\end{array}$ & $\begin{array}{l}\text { Unskilled, } \\
\text { untrained }\end{array}$ \\
\hline
\end{tabular}

some of the rows, the more demanding level of scoring has the effect of unnecessarily reducing the technology options that will be considered for the application and likely increasing the cost and complexity of the system. A structured approach for encouraging end-users to develop practical requirements tables will be discussed later in this report.

\subsubsection{Deployment Scenario Options}

Once constructed, a set of these deployment scenario masks can be overlaid on the appropriate equivalent attributes for specific measurement instrument masks to determine if matches exist or gaps are present for either the deployment scenarios or the measurement options under consideration. 
Table 3.8. Operational Scenario Mask Developed from Table 3.7. The "R" represents the required performance level and the shaded regions represent excess capability.

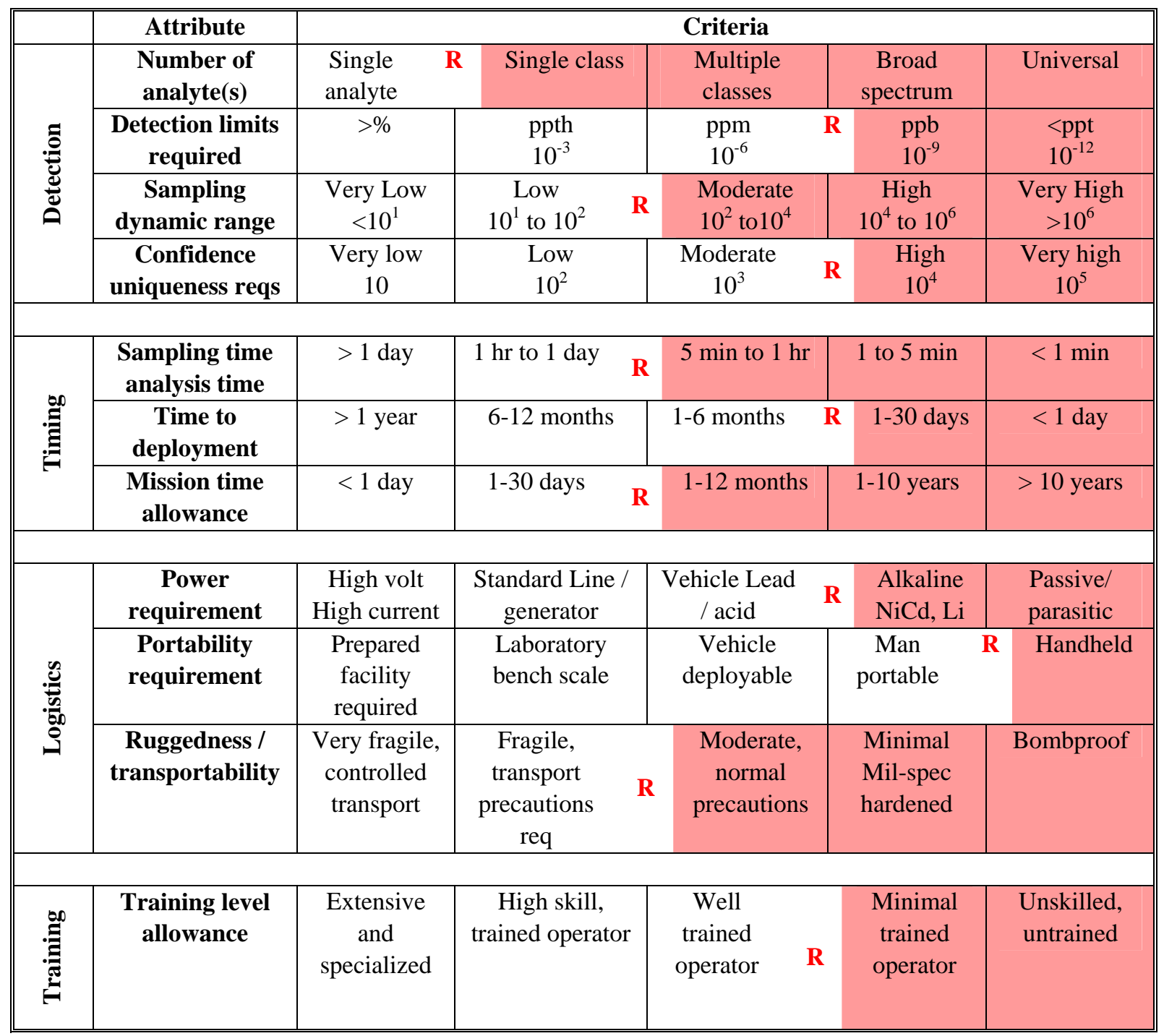

\subsection{Constructing Analysis Methods Options}

The third step in the process is to examine the potential analysis methods. This process is illustrated in Figure 3.12. It begins with a general knowledge of the detection methods and instrumentation available and ends with analysis method options. The evaluation process is complicated by ongoing research activities pursuing new and improved measurement methods. This includes not only incremental improvements on existing technologies, but new detection schemes and devices. Thus, the analysis method options are a large and highly dynamic set of diverse techniques that can be difficult to assess. 


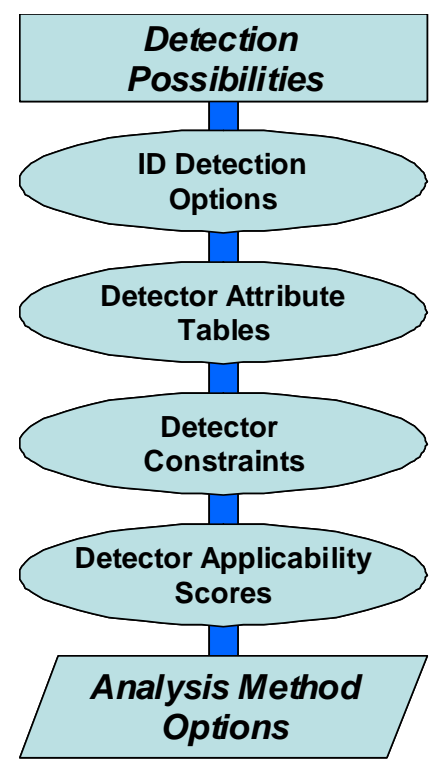

Figure 3.12. Analysis Method Options Identification Process

\subsubsection{Detection Knowledge}

A general knowledge of what detection technologies are currently available is the starting point for this activity. One can also consider techniques that are in the process of development or have been conceived but not yet reduced to practice; however, in these cases, the actual technical performance and applicability can be difficult to define, making evaluation problematic. It can be very difficult to extrapolate the performance of a laboratory prototype to potential field-deployed operation. Detection methodology includes not only the sensor system used, but also the sample collection apparatus, separations methods, concentration methods, transduction methods, and the interpretation of the raw data to yield the chemical information being sought. This makes the evaluation highly complex. For example, there can be a number of sample preparation techniques applicable to a given sensor technology, and each permutation provides different system performance while having different deployment criteria.

\subsubsection{Identify Detection Options}

The first step in the process is to distill a list of those methods and instruments that might be applicable to meet the specific need from the general knowledge base of available methods and instruments.

\subsubsection{Detector Attribute Tables}

Each of the detection methods identified can then be generally summarized in a generic attribute versus performance criteria table. Table 8 was developed for that purpose. For ease of comparison, the attributes were separated into five groups. The first group of attributes is detection related, the second is timing related, the third is logistics related, the fourth is training related, and the fifth is cost related. As 
the tables of each of the measurement methodologies are completed (masks developed as described in the previous section), they will yield a library of table masks to match against specific scenario requirements. In this format, they actually overlay many of the scenario requirements.

Table 3.9. Measurement System Attributes vs. Evaluation Criteria

\begin{tabular}{|c|c|c|c|c|c|c|}
\hline & Attribute & \multicolumn{5}{|c|}{ Criteria } \\
\hline \multirow{4}{*}{ } & $\begin{array}{l}\text { Number of } \\
\text { analyte(s) }\end{array}$ & $\begin{array}{l}\text { Single } \\
\text { analyte }\end{array}$ & Single class & $\begin{array}{l}\text { Multiple } \\
\text { classes }\end{array}$ & $\begin{array}{c}\text { Broad } \\
\text { spectrum }\end{array}$ & Universal \\
\hline & $\begin{array}{c}\text { Sensitivity / min } \\
\text { detect }\end{array}$ & $>\%$ & $\begin{array}{c}\text { ppth } \\
10^{-3}\end{array}$ & $\begin{array}{c}\text { ppm } \\
10^{-6}\end{array}$ & $\begin{array}{l}\mathrm{ppb} \\
10^{-9}\end{array}$ & $\begin{array}{l}<p p t \\
10^{-12}\end{array}$ \\
\hline & Dynamic range & $\begin{array}{l}\text { Very Low } \\
<10^{1}\end{array}$ & $\begin{array}{c}\text { Low } \\
10^{1} \text { to } 10^{2}\end{array}$ & $\begin{array}{l}\text { Moderate } \\
10^{2} \text { to } 10^{4}\end{array}$ & $\begin{array}{c}\text { High } \\
10^{4} \text { to } 10^{6}\end{array}$ & $\begin{array}{c}\text { Very High } \\
>10^{6}\end{array}$ \\
\hline & $\begin{array}{l}\text { Selectivity / } \\
\text { confidence }\end{array}$ & $\begin{array}{l}\text { Very low } \\
10\end{array}$ & $\begin{array}{c}\text { Moderate low } \\
10^{2}\end{array}$ & $\begin{array}{l}\text { Moderate } \\
10^{3}\end{array}$ & $\begin{array}{l}\text { High } \\
10^{4}\end{array}$ & $\begin{array}{l}\text { Very high } \\
10^{5}\end{array}$ \\
\hline & $\begin{array}{l}\text { Analysis time } \\
\text { per sample }\end{array}$ & $>1$ day & $1 \mathrm{hr}$ to $1 \mathrm{day}$ & $5 \mathrm{~min}$ to $1 \mathrm{hr}$ & 1 to $5 \mathrm{~min}$ & $<1 \mathrm{~min}$ \\
\hline . & $\begin{array}{c}\text { Time to } \\
\text { deployment }\end{array}$ & $>1$ year & 6-12 months & 1-6 months & 1-30 days & $<1$ day \\
\hline & $\begin{array}{l}\text { System life } \\
\text { expectancy }\end{array}$ & $<1$ day & $1-30$ days & $1-12$ months & $1-10$ years & $>10$ years \\
\hline & $\begin{array}{c}\text { Power } \\
\text { requirements }\end{array}$ & $\begin{array}{c}\text { High volt } \\
\text { High current }\end{array}$ & $\begin{array}{c}\text { Standard Line / } \\
\text { generator }\end{array}$ & $\begin{array}{c}\text { Vehicle Lead / } \\
\text { acid }\end{array}$ & $\begin{array}{l}\text { Alkaline } \\
\mathrm{NiCd}, \mathrm{Li}\end{array}$ & $\begin{array}{l}\text { Passive/ } \\
\text { parasitic }\end{array}$ \\
\hline & $\begin{array}{l}\text { Size / weight } \\
\text { total system }\end{array}$ & $\begin{array}{l}\text { Prepared } \\
\text { facility } \\
\text { required }\end{array}$ & $\begin{array}{l}\text { Laboratory } \\
\text { bench scale }\end{array}$ & $\begin{array}{c}\text { Vehicle } \\
\text { deployable }\end{array}$ & $\begin{array}{c}\text { Man } \\
\text { portable }\end{array}$ & Handheld \\
\hline & $\begin{array}{c}\text { Ruggedness / } \\
\text { transportability }\end{array}$ & $\begin{array}{c}\text { Very fragile, } \\
\text { controlled } \\
\text { transport }\end{array}$ & $\begin{array}{c}\text { Fragile, } \\
\text { transport } \\
\text { precautions }\end{array}$ & $\begin{array}{c}\text { Moderate, } \\
\text { normal } \\
\text { commercial }\end{array}$ & $\begin{array}{l}\text { Minimal } \\
\text { Mil-spec } \\
\text { hardened }\end{array}$ & Bombproof \\
\hline .气્ב & $\begin{array}{c}\text { Environmental } \\
\text { op stability }\end{array}$ & $\begin{array}{c}\text { Poor, } \\
\text { difficult to } \\
\text { operate with } \\
\text { any changes }\end{array}$ & $\begin{array}{c}\text { Low, affected } \\
\text { by minor } \\
\text { changes }\end{array}$ & $\begin{array}{l}\text { Moderate, } \\
\text { affected by } \\
\text { major change }\end{array}$ & $\begin{array}{c}\text { High, } \\
\text { affected by } \\
\text { extremes }\end{array}$ & $\begin{array}{c}\text { Very high, } \\
\text { works always }\end{array}$ \\
\hline & $\begin{array}{l}\text { Consumables / } \\
\text { support } \\
\text { requirements }\end{array}$ & $\begin{array}{l}\text { Extensive } \\
\text { multi- } \\
\text { component } \\
\text { logistics }\end{array}$ & $\begin{array}{l}\text { Substantial } \\
\text { supplies / } \\
\text { disposables }\end{array}$ & $\begin{array}{c}\text { Moderate } \\
\text { supplies / } \\
\text { disposables }\end{array}$ & $\begin{array}{c}\text { Minimal } \\
\text { supplies / } \\
\text { disposables }\end{array}$ & $\begin{array}{l}\text { No ancillary } \\
\text { supplies, self } \\
\text { contained }\end{array}$ \\
\hline & $\begin{array}{l}\text { Waste disposal } \\
\text { requirements }\end{array}$ & $\begin{array}{c}\text { Extensive, } \\
\text { harmful, } \\
\text { special } \\
\text { storage }\end{array}$ & $\begin{array}{l}\text { Substantial, } \\
\text { easy but } \\
\text { controlled }\end{array}$ & $\begin{array}{c}\text { Moderate } \\
\text { quantity and } \\
\text { risk }\end{array}$ & $\begin{array}{l}\text { Minimal, } \\
\text { easily } \\
\text { managed }\end{array}$ & None \\
\hline
\end{tabular}


Table 3.9. Continued

\begin{tabular}{|c|c|c|c|c|c|c|}
\hline & Attribute & \multicolumn{5}{|c|}{ Criteria } \\
\hline \multirow{3}{*}{ 胞 } & $\begin{array}{c}\text { Collection / } \\
\text { sample prep } \\
\text { requirements }\end{array}$ & $\begin{array}{c}\text { Extensive } \\
\text { multi-step, } \\
\text { long time }\end{array}$ & $\begin{array}{c}\text { Substantial } \\
\text { operator } \\
\text { involvement }\end{array}$ & $\begin{array}{l}\text { Moderate } \\
\text { operator } \\
\text { interaction }\end{array}$ & $\begin{array}{c}\text { Minimal } \\
\text { operator } \\
\text { interaction }\end{array}$ & $\begin{array}{l}\text { Automatic } \\
\text { operation }\end{array}$ \\
\hline & $\begin{array}{c}\text { Calibration } \\
\text { requirements }\end{array}$ & $\begin{array}{l}\text { High, multi- } \\
\text { point, } \\
\text { constant } \\
\text { attention }\end{array}$ & $\begin{array}{c}\text { Substantial, } \\
\text { multi-point, } \\
\text { frequent } \\
\text { interval }\end{array}$ & $\begin{array}{c}\text { Moderate, } \\
\text { single point, } \\
\text { high frequency }\end{array}$ & $\begin{array}{l}\text { Low, single } \\
\text { point, low } \\
\text { frequency }\end{array}$ & $\begin{array}{c}\text { Very low, no } \\
\text { calibration or } \\
\text { self } \\
\text { calibration }\end{array}$ \\
\hline & $\begin{array}{c}\text { Training level } \\
\text { allowance }\end{array}$ & $\begin{array}{l}\text { Extensive } \\
\text { and } \\
\text { specialized }\end{array}$ & $\begin{array}{l}\text { High skill, } \\
\text { trained operator }\end{array}$ & $\begin{array}{l}\text { Well trained } \\
\text { operator }\end{array}$ & $\begin{array}{c}\text { Minimal } \\
\text { trained } \\
\text { operator }\end{array}$ & $\begin{array}{l}\text { Unskilled, } \\
\text { untrained }\end{array}$ \\
\hline & & & & & & \\
\hline$\vec{n}$ & $\begin{array}{c}\text { Capital cost of } \\
\text { system }\end{array}$ & $>\$ 250 \mathrm{~K}$ & $\$ 75 \mathrm{~K}-\$ 250 \mathrm{~K}$ & $\$ 15 \mathrm{~K}-\$ 75 \mathrm{~K}$ & $\$ 1 \mathrm{~K}-15 \mathrm{~K}$ & $<\$ 1 \mathrm{~K}$ \\
\hline 0 & $\begin{array}{c}\text { Cost of sample } \\
\text { analysis }\end{array}$ & $>\$ 25$ & $\$ 5-\$ 25$ & $\$ 1-\$ 5$ & $\$ 0.10-\$ 1$ & $<\$ 0.10$ \\
\hline
\end{tabular}

\subsubsection{Detector Constraints}

The operating characteristics for each attribute of the possible detection methodologies are entered into the tables. The end goal is to devise a visual method of comparing the realistic performance parameters of the instruments against the application and deployment requirements. The constraints may dictate that a method is totally unsuitable, marginally useful, or ideally suited to the application.

As the measurement system attributes are described, a "mask" can be developed on the evaluation graphic (Table 3.9) which can be used to describe the system and interact with the masked graphic done for the scenario. This is where gap information is developed and visualized. This is shown in Table 3.10, which is developed in a similar manner to that shown for the operational scenarios in Table 3.8.

Table 3.10. Simplified Measurement System Evaluation Derived from Table 3.9 with Added Mask Information

\begin{tabular}{|c|c|c|c|c|c||}
\hline & \multicolumn{5}{|c|}{ Criteria } \\
\hline Attribute & Easy & & Mid & & Hard \\
\hline$\# 1$ & & & & S & \\
\hline$\# 2$ & & S & & & \\
\hline$\# 3$ & & & S & & \\
\hline$\# 4$ & & S & & & \\
\hline$\# 5$ & & & S & & \\
\hline S designates current performance level. \\
\hline
\end{tabular}





\subsection{Technology Selection and Gap Identification Process}

The assessment tables introduced above provide the basis for:

- evaluation and selection of existing technologies to meet immediate application requirements

- identification of technology gaps preventing the deployment of measurement technologies required to meet application requirements

- assessment of trade-offs to determine where technology development efforts could provide the greatest advantage for meeting future requirements.

This is accomplished by comparing an application requirement table (provided by an end user) and a measurement technology capability table (provided by a technologist). There are several ways to combine these, depending on the desired analysis as shown in Figure 4.1.

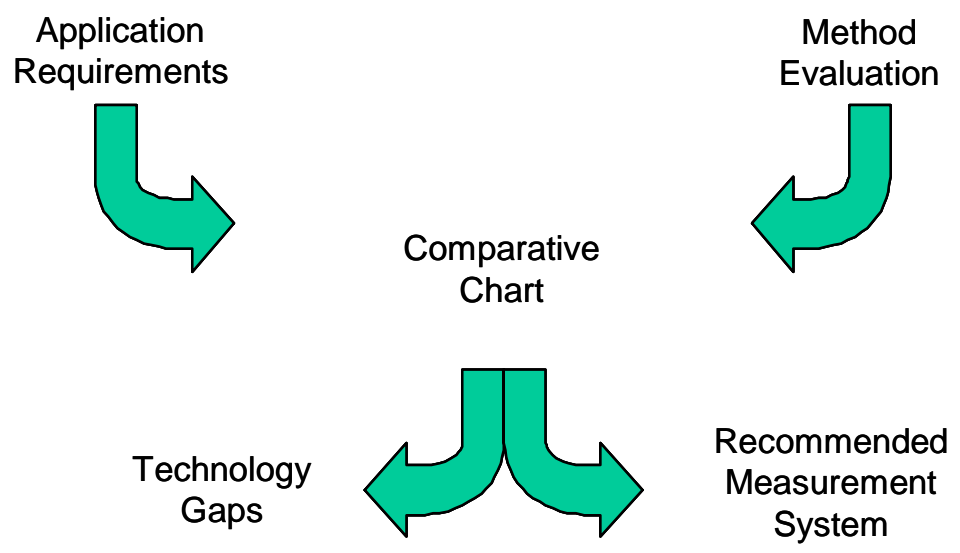

Figure 4.1. Comparative Examination of Measurement System Performance and Application Requirements Yields Technology Gaps and Measurement System Recommendations

\subsection{Evaluations for Immediate Applications Using Discrete Criteria (Simple Analysis)}

Evaluating technologies for immediate use (i.e., no time for technology development or adaptation) requires an assessment of existing measurement system options against the application requirements. This is a go/no-go type evaluation based on requirements and current system capabilities. An existing system can either meet the criteria or not-there is no wiggle room for "it could work if we improved this." This case represents the simplest application for the tools already introduced. 


\subsubsection{Technology Evaluation for Immediate Applications}

To illustrate this type of evaluation, consider the tables shown in Figure 4.2. The upper tables represent the Deployment Scenario Requirements Criteria (left side) and the current Measurement System Performance Level (right side) for a specific sensor candidate.

Deployment Scenario Requirements
\begin{tabular}{|c|c|c|c|c|c|}
\hline Attribute & \multicolumn{5}{|c|}{ Criteria } \\
\hline & Easy & & Mid & & Hard \\
\hline 1 & & & & & R \\
\hline 2 & & $\mathrm{R}$ & & & \\
\hline 3 & $\mathrm{R}$ & & & & \\
\hline 4 & & & & $\mathrm{R}$ & \\
\hline 5 & & & $\mathrm{R}$ & & \\
\hline
\end{tabular}

Measurement System Requirements
\begin{tabular}{|c|c|c|c|c|c|}
\hline Attribute & \multicolumn{5}{c|}{ Criteria } \\
\hline & Easy & & Mid & & Hard \\
\hline 1 & & & & S & \\
\hline 2 & & S & & & \\
\hline 3 & & & S & & \\
\hline 4 & & S & & & \\
\hline 5 & & & S & & \\
\hline
\end{tabular}

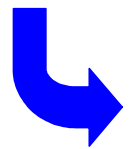

Deployment and Measurement Requirements

\begin{tabular}{|c|c|c|c|c|c|}
\hline Attribute & \multicolumn{5}{|c|}{ Criteria } \\
\hline & Easy & & Mid & & Hard \\
\hline 1 & & & & S & R \\
\hline 2 & & RS & & & \\
\hline 3 & R & & S & & \\
\hline 4 & & S & & R & \\
\hline 5 & & & RS & & \\
\hline
\end{tabular}

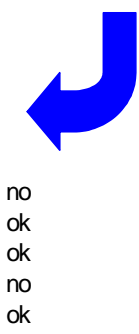

Figure 4.2. Derivation of Deployment Scenario vs. Measurement System Performance Criteria Table

When the two datasets are combined in the bottom table, it allows an easy comparison of the requirements and the performance levels. The sensor candidate meets the requirements for Attributes 2 and 5 and significantly exceeds the requirements for Attribute 3 . However, the sensor candidate fails to meet the requirements for Attributes 1 and 4. The vertical red lines on the chart for attributes 1 and 4 indicate technology barriers that prevent the candidate system from meeting the criteria for these attributes. Thus, this sensor candidate would not be suitable for the immediate application.

Note that this illustration was a "black and white" assessment. The application requirements and the sensor performance levels were definitively assigned to individual boxes in the assessment tables. This is fine for assessments against immediate needs if a suitable measurement technology candidate can be found. However, if a suitable candidate cannot be found to meet all requirements, this "black and white" method does not help making trade-off decisions that could be important for selecting the best compromise candidate to address the application requirements.

\subsubsection{Technology Gap Identification}

For technologies that fail to meet the requirements for the immediate application, the combined table shown at the bottom of Figure 4.2 provides immediate indication of where technologies gaps exist that prevented the measurement technology from meeting the requirements. The figure can also provide useful insights regarding how system adaptation or additional technology development could be addressed to meet comparable requirements at some future time. 
Figure 4.3 is the combined table from the bottom of Figure 4.2 which has been marked to highlight the technology gaps in this example. Recall that Attributes \#1 and \#4 failed to meet the requirements, indicating technology gaps. From the figure, the gap for Attribute \#1 is likely smaller (one cell on the table) than the gap for Attribute \#4 (two cells on the table).

Deployment and Measurement Requirements

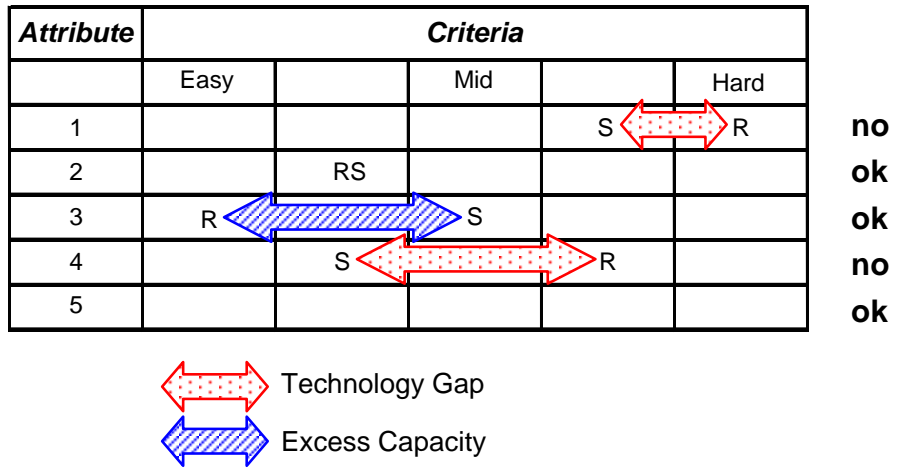

Figure 4.3. Illustration of Technology Gap Magnitude as Illustrated by the Red (Dotted) Arrows ${ }^{(\mathbf{1})}$

\subsubsection{Technology Selection for Immediate Applications if No Technologies Meet All Requirement Criteria}

If no measurement technologies fully meet the user application requirements, it may be necessary to select a measurement system that represents the best compromise to meet the overall requirements and mission objectives. The use of discrete requirements (the black and white box checking in the Figures 4.2 and 4.3) is not well suited to this as it does not provide supplementary information about the relative importance of the various performance levels that would be needed to make logical trade-off assessments for various attributes for the candidate measurement technologies. Some performance criteria levels may be "must haves" (e.g., detection limits, etc.) while others are desirable but compromises could be made (e.g., battery lifetime, sensor weight, etc.) while still meeting the overall application requirements. This supplementary information can be included by considering a graduated scale evaluation of the requirements for each attribute (as compared to single point designation illustrated above).

\subsubsection{Graduated Scale for Performance Requirement Criteria}

The graduated requirement scoring allows end-users to provide useful supplementary guidance on their application requirements. The scale ranges from "no value for this application" to "performance beyond any of our needs." Specific grading steps are:

(1) CalTOX, a Multimedia Total-Exposure Model for Hazardous-Waste Sites, Part II: The Dynamic Multimedia Transport and Transformation Model, December 1993. Further information available at: http://www.dtsc.ca.gov/ScienceTechnology/ftp/techman2.pdf 
- No value for application requirements

- Minimum useful requirement

- Desired level of performance

- Beneficial added performance

- No additional benefit for increased performance (overkill)

An example of a situation where there would be no advantage to improving performance might be detection limits for an instrument. If current technology can provide $10 \mathrm{ppb}$ detection levels and the local background levels for the analyte are at that level, then improving the detection limit provides no benefit because the background levels in the environment would mean that you would not see process-related effluent levels below the current detection limits.

As mentioned previously, over specifying requirements will unnecessarily eliminate potentially viable measurement technologies from consideration and is likely to increase the cost and delay the availability of needed measurement systems.

Figure 4.4 illustrates the graduated scale for the same target performance levels considered earlier in Figures 4.2 and 4.3 .

\section{Deployment Scenario Requirements}

\begin{tabular}{|c|c|c|c|}
\hline \multirow[t]{2}{*}{ Attribute } & \multicolumn{3}{|c|}{ Criteria } \\
\hline & Easy & Mid & Hard \\
\hline 1 & & & \\
\hline 2 & & & \\
\hline 3 & & & \\
\hline 4 & & & \\
\hline 5 & & & \\
\hline
\end{tabular}

Performance Level

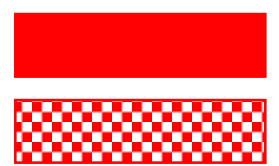

No value for application

Minimum useful performance

Desired level of performance

Beneficial added performance

Significant overkill

Figure 4.4. Graded Scale Requirements Map 
The use of these application requirement tables offers several distinct benefits. Technology end-users can provide substantive summary needs information in a manner that does not expose sensitive information in a specific-case scenario or link that information to the interested agency (if provided through an independent third party). Thus, the application requirements matrices provide needed information to the system technology developers while maintaining a firewall that protects the end-users and their most sensitive information. In addition, the requirements information in the matrices could be tremendously valuable to NA-22 staff evaluating investment options and for the technology developers. In both cases, the information would help focus development efforts on key end-user needs issues.

This graduated scale deployment scenario information, when combined with the measurement system performance level information, can provide the basis for a more useful evaluation of technologies if compromises must be made to meet immediate application requirements. In Figure 4.5, the deployment scenario requirements information is located in the upper half of each attribute row (as the primary driver)

\section{Deployment/Measurement Requirements}

\begin{tabular}{|c|c|c|c|c|c|}
\hline \multirow[t]{2}{*}{ Attribute } & \multicolumn{5}{|c|}{ Criteria } \\
\hline & Easy & & Mid & & Hard \\
\hline \multirow{2}{*}{1} & & & & & \\
\hline & & & & $\mathrm{S}$ & \\
\hline \multirow{2}{*}{2} & & & & & \\
\hline & & $S$ & & & \\
\hline \multirow{2}{*}{3} & & & & & \\
\hline & & & S & & \\
\hline \multirow{2}{*}{4} & & & & & \\
\hline & & $S$ & & & \\
\hline \multirow{2}{*}{5} & & & & & \\
\hline & & & $S$ & & \\
\hline
\end{tabular}

\section{Performance Level}

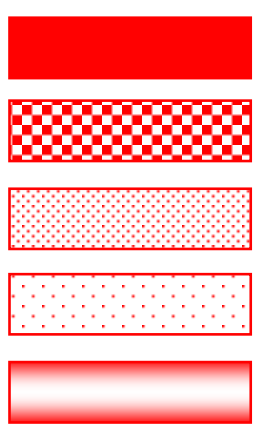

No value for application

Minimal useful performance

Desired level of performance

Beneficial added performance

Significant overkill

Figure 4.5. Combined Scenario Requirements and Measurement System Performance 
and the corresponding measurement system performance status for the same attribute is located in the bottom half of the attribute row. This over-under arrangement will be followed in the coming sections as well.

Based on this representation, the following observations can be made:

- The candidate sensor system performance meets the desired level performance for Attributes \#2 and \#5.

- The candidate sensor performance exceeds the desired performance level for Attribute \#3 by so much that some of the extra capability is beyond the useful range. But since the performance is already at that level and there is no additional cost for it, it can be used for the application.

- While the candidate sensor performance for Attribute \#1 does not meet the desired criteria, the sensor does provide sufficient performance to yield some value for the application. So the candidate might warrant additional consideration against other candidates if it can meet all other criteria.

- But the candidate sensor performance is so deficient for Attribute \#4 that it offers NO value for the application.

Thus this sensor candidate would be rejected based on the total failure against Attribute \#4 criteria.

However, this example does illustrate how the graduated requirements information can be useful for supporting an objective assessment of alternative technology candidates in the case where no system can immediately meet all application requirement criteria.

\subsubsection{Consideration of Relative Importance of Individual Attribute for Specific Applications}

An additional factor to consider is that all deployment scenario attributes identified in Table 3.7 may not be of equal importance for every application. For example, in the notional illustration above, if Attribute \#4 was of minor or no importance for the application, the candidate sensor system failure to meet this criterion would be of no consequence and the candidate should be considered further for the application. At the same time, if the attribute were not a consideration for the application, the end-user may have opted to enter no criteria for this attribute.

\subsection{Technology Evaluations for Future Applications Where Time will Allow Technology Development and Adaptation}

The previous discussion in Section 4.1 focused on immediate applications where time constraints prevented any significant technology adaptation or development. Not all applications fall into the immediate response category. The tools described in this report also offer significant advantages for evaluating other future need situations as described in this section. 


\subsubsection{Snapshot of Current Sensor Capabilities}

In the discussion above, sensor performance tables were introduced to capture the current capability status of individual measurement systems. These capability assessments presented in an individual table represent the performance for candidate systems that includes the measurement method (sensor), any required sample collection and preparation components, power system, etc. Once a system had been defined for a target application, the performance status information can be provided by a knowledgeable technologist. This information is essential and sufficient for the evaluation of technology options against immediate needs but it is not sufficient for considering technology options to meet future needs.

\subsubsection{Graduated Assessment of Sensor Capability Potential}

When considering technology options for future applications, it is important to understand where the technology is today (i.e., current snapshot information) and also to understand the potential for performance improvement. In order to capture both the current status and the future potential insights, a graduated performance scale is introduced below. Individual system performance will be evaluated with this graduated grading scale using the sensor performance criteria introduced previously.

The graduated measurement system performance assessment allows technologists to provide useful supplementary guidance on individual measurement systems. Specific grading steps are:

- No value for application

- Minimal useful performance

- Can meet requirement with significant adaptation

- Can meet requirement with minimal modifications

- Meet requirements with no changes.

The intended purpose for providing this information is to allow the technology option assessments to be performed with an awareness of where performance improvement might be available with modest effort and where it would require major effort and significant breakthroughs (or miracles). Figure 4.6 illustrates this grading system applied to the same example discussed above.

In this illustrative figure, some attributes are shown with good potential for performance improvements with further development (i.e., light shading) but other attributes indicates that a fundamental barrier may exist that would prevent continued improvement to the top level of performance for this measurement system (i.e., dark shading).

This graduated scale information, when combined with the application requirements information (Figure 4.5) provides the basis for a more useful evaluation of technologies potential and the identification of technology gaps. Figure 4.7 shows the scenario requirements information located in the upper half of each attribute row (as the primary driver) and the measurement technology status and potential for the same attribute in the bottom half of the attribute row. 
Method Capability Assessment

\begin{tabular}{|c|c|c|c|}
\hline \multirow[t]{2}{*}{ Attribute } & \multicolumn{3}{|c|}{ Criteria } \\
\hline & Easy & Mid & Hard \\
\hline 1 & & & \\
\hline 2 & & & \\
\hline 3 & & & \\
\hline 4 & & & \\
\hline 5 & & & \\
\hline
\end{tabular}

\section{Method Applicability}

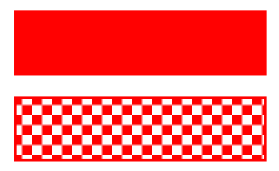

No value for application

Minimal useful performance

Can meet requirement with significant adaptation

Can meet requirement with minimal modifications

Meets requirements with no changes

Figure 4.6. Graded Estimation of Measurement System Performance Gap

The graduated information in these figures provides the basis for an informed analysis of the tradeoffs associated with technology options to meet future application requirements. The trade-off considerations can assess the relative benefits to the end-users and the anticipated technical development practicalities for advancing a given measurement system forward to meet more demanding performance criteria. This analysis can allow the selection of key technology gaps for technical development. 


\section{Deployment/Measurement Requirements}

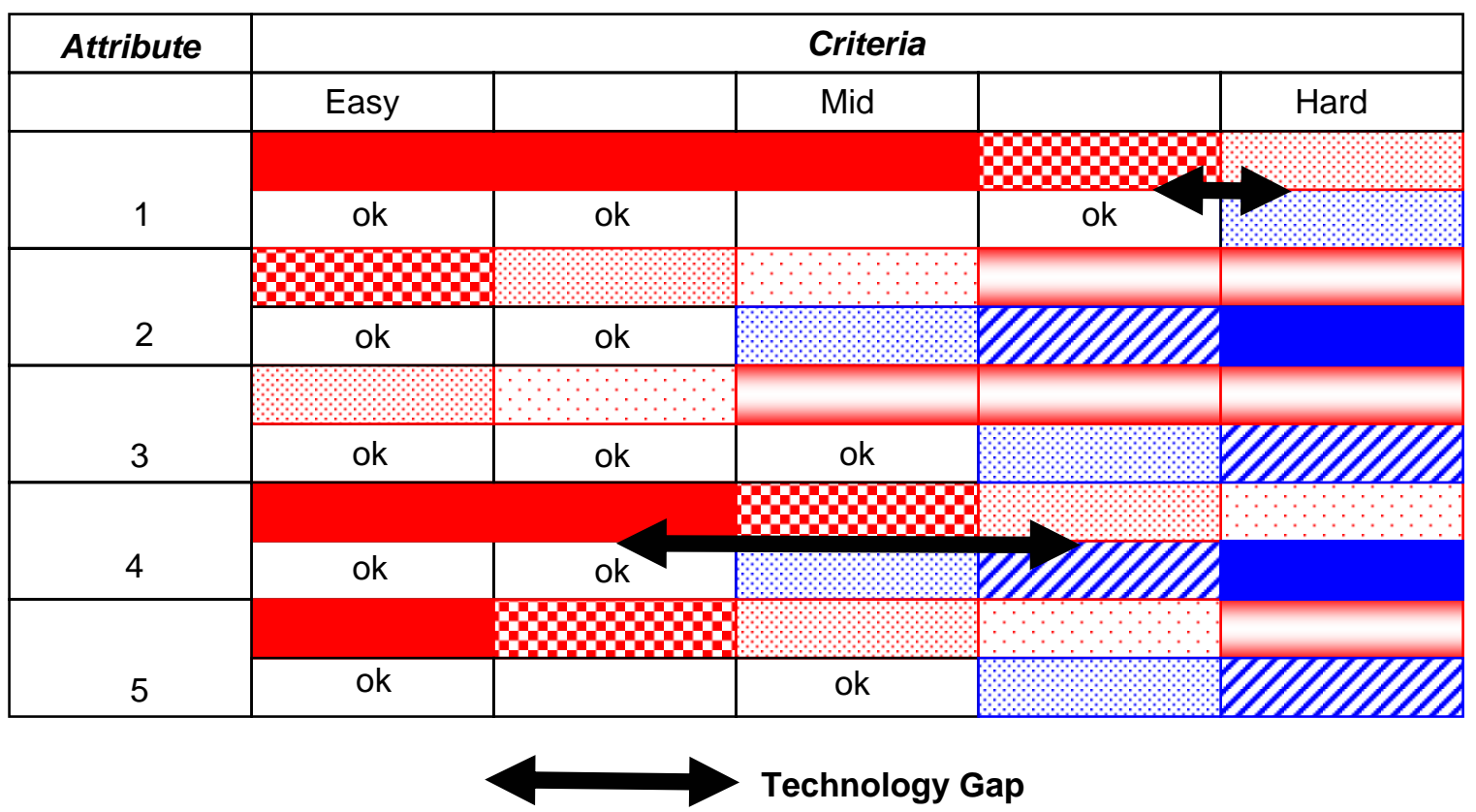

Performance Level (Upper)

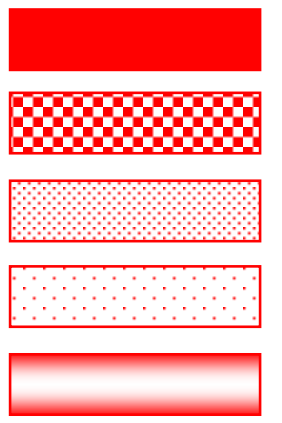

No value for application

Minimum useful performance

Desired level of performance

Beneficial added performance

Significant overkill
Requirement Level (Lower)

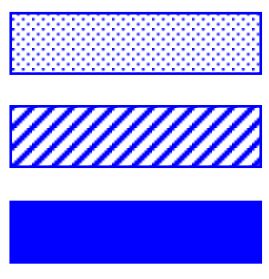

Can meet requirement with minimal modifications Can meet requirement with significant modifications Unlikely to meet useful portion of requirement even with significant advances

Figure 4.7. Merging Graduated Information on Scenario Requirements and Measurement System Performance to Qualify Technology Gaps 



\subsection{Application Requirements Assessment by End-Users}

The previously introduced Table 3.7 serves as the basis for documenting measurement system requirements for various application scenarios. The table describes various performance level requirements for a number of important scenario attributes.

Based on some past calls for sensor development from user organizations, it appears that the frequently requested solution requires the most demanding qualifications in each row. In this case, any application requiring less performance could still be met with the same sensor system. However, in the practical world of sensor and measurement technology, systems that meet all criteria at the most demanding levels may be non-existent. In general there are no "Tricorders" that can measure everything in a small, robust, totally self-contained package that requires no operator training and never needs a new battery.

While some applications may only be met by high-end systems, it is generally beneficial to the endusers to provide the most realistic requirements definition possible, usually through a process of selecting the best trade-offs. Over-specifying the requirements will eliminate the consideration of some potentially useful technologies and is very likely to unnecessarily increase the system cost and complexity and to delay the availability of a suitable instrument. Under-specifying the requirements could result in the selection of a measurement system that will ultimately fail to meet the actual mission requirements. Selection of an inadequate system would prevent the acquisition of needed data/information, waste time and money, delay timely access to a suitable system, and potentially put field staff at risk with little potential of obtaining the needed information.

The key question becomes,

How do we obtain realistic user requirements that represent a suitable balance between the desire for a perfect measurement system and the negative aspects of over-specifying the requirements?

\subsection{Budgeted Point System Method}

One approach that encourages end-users to realistically establish their mission requirements is to ask them to evaluate their requirements under a budgeted point concept. This approach is beneficial in that it encourages user prioritization of the perceived requirements. The results can be used to build filters that assist in the selection of acceptable measurement system alternatives and identify the highest priority technology for meeting the user's requirements. The filters can also be used to identify key technology gaps that, if resolved, would allow for the deployment of superior sensor systems.

The budgeted point approach presents users with choices and trade-off decisions that are very analogous to financial decisions that everyone faces at work and at home when trying to maximize the 
benefits of our expenditures while living with a limited financial budget. For many individuals, "wants" far exceed real needs and actual purchasing power.

Several factors are taken into account when setting up a budgeted point approach:

- First, it becomes increasingly difficult to achieve the attribute performance levels moving from left to right on any row in Table 3.7. This increase in difficulty is represented by assigning higher multiplier values to higher performance requirements. (The multiplier is a cost surrogate - we expect to pay more for better performance.) Using this method essentially results in a user considering a cost performance trade-off for each attribute as they determine required performance levels. The assignment of multiplier values is ideally chosen based on the relative difficulty in obtaining it. The scale can be quite non-linear for a gap evaluation.

- Second, not all attributes in Table 3.7 are of equal importance to a user for a given application or scenario and attribute priorities may change from one scenario to another. The scoring method should capture user insights by recognizing higher priority attributes. It will be important to meet higher priority needs first, before spending time on attributes of lesser value, even if these latter attributes are easier to achieve.

Development of a single method that is best suited to this application has been elusive, as detailed choices in the method may be well suited to some end-users while not meeting the requirements for others. The question that seems to be at the root of preferences/concerns for alternate methods focuses on how to take into account the relative importance of the various attributes and how to make the method sufficiently flexible to meet realistic end-user needs. Therefore, two embodiments of the budgeted point approach are discussed and compared.

Both methods are based on a single scoring matrix that represents the relative difficulty for achieving more demanding performance on any of the attributes. For each of the attributes in Table 3.7, a multiplier value (or "cost") has been assigned to each of the increasingly difficult performance criteria. As mentioned above, this is not a linear scale so the more demanding levels have been assigned increasingly higher values. The actual values chosen are subjective and can be tailored for a specific application. This is illustrated in Table 5.1.

The differences in the two methods discussed relate to how the relative importance of individual attributes is taken into account and how the final budget limitations and scoring are treated. As mentioned, not all attributes are equally important for a given scenario. For example, mission planners may be able to accommodate less demanding targets for sensor size or operating training level but they may have no flexibility to obtain useful data if the sensor detection limits are too low. These application importance factors can be represented in several ways. 
Table 5.1. Attribute/Performance Table Scoring Methods

\begin{tabular}{|c|c|c|c|c|c||}
\hline & \multicolumn{5}{|c|}{ Performance Criteria Level } \\
\hline Attribute & Level 1 & Level 2 & Level 3 & Level 4 & Level 5 \\
\hline A & & & & & \\
\hline B & & & & & \\
\hline C & & & & & \\
\hline D & & & & & \\
\hline E & & & & & \\
\hline F & & & & & \\
\hline$\ldots$ & Level 1 & Level 2 & Level 3 & Level 4 & Level 5 \\
\hline \multicolumn{7}{|l|}{} & $\begin{array}{l}\text { Least } \\
\begin{array}{l}\text { Performance } \\
\text { Level }\end{array}\end{array}$ & & & & Demanding \\
\hline $\begin{array}{l}\text { Multiplier } \\
\text { Value (Cost) }\end{array}$ & 1 & 2 & 4 & 7 & 10 \\
\hline \hline
\end{tabular}

- Attribute priority values - Simply assign rank order numbers to the various attributes in the table based on importance for the given scenario. Rank numbering in inverse order (highest priority gets the highest number) provides a priority number that is indicative of attribute importance.

- User assigned attribute weighting values - Weighting values are assigned to each attribute by the enduser to represent the relative importance of the attribute for the scenario. This allows equal weighting of comparable attributes and emphasis (de-emphasis) of high (low) priority attributes for the scenario.

- User assigned importance of meeting performance criteria - This is an importance scoring scale for meeting the performance level designated in Table 5.2.

Table 5.2. Performance Level Scores

\begin{tabular}{|c|l||}
\hline $\begin{array}{c}\text { Performance } \\
\text { Score }\end{array}$ & \multicolumn{1}{|c|}{ Performance Importance Criteria } \\
\hline 5 & Necessary for mission success \\
\hline 4 & Very important for mission success \\
\hline 3 & Moderate importance for mission success \\
\hline 2 & Desired but not necessary \\
\hline 1 & Minor importance \\
\hline
\end{tabular}




\subsubsection{Method 1 - Limited Point Budgeting Approach using Performance Importance Criteria}

This method utilizes the attribute scoring table and the performance importance criteria values introduced above.

In Table 5.3, the multiplier (cost) for each attribute is determined from the level of performance checked in the table. The corresponding multiplier (cost) value is taken from the last row of Table 5.2. The performance importance values are assigned by the user based on the criteria descriptions shown above and their knowledge of the application scenario. The attribute scores are the product of the multiplier and performance importance values for each attribute. The total score is the simple sum of the attribute scores.

Table 5.3. Scoring Using the Performance Importance Criteria

\begin{tabular}{|c|c|c|c|c|c||}
\cline { 2 - 6 } \multicolumn{1}{c|}{} & \multicolumn{5}{c||}{ Performance Criteria Level } \\
\hline Attribute & Level 1 & Level 2 & Level 3 & Level 4 & Level 5 \\
\hline A & & & X & & \\
\hline B & & X & & & \\
\hline C & & & & X & \\
\hline D & & & X & & \\
\hline E & & & & & X \\
\hline F & & & & X & \\
\hline$\ldots$ & & & & & \\
\hline
\end{tabular}

\begin{tabular}{|c|c|c|}
\hline $\begin{array}{l}\text { Multiplier } \\
\text { (Cost) }\end{array}$ & $\begin{array}{c}\text { Performance } \\
\text { Importance }\end{array}$ & $\begin{array}{c}\text { Attribute } \\
\text { Score }\end{array}$ \\
\hline 4 & 5 & 20 \\
\hline 2 & 4 & 8 \\
\hline 7 & 4 & 28 \\
\hline 4 & 3 & 12 \\
\hline 10 & 5 & 50 \\
\hline 7 & 4 & 28 \\
\hline & Total Score & 146 \\
\hline
\end{tabular}

Budgeting comes into play when a budget point ceiling is introduced. In this example, with six attributes to consider, there was a maximum point total possible of 300 points ( 6 attributes $\times$ a maximum performance score of 10 for each attribute $\times$ a maximum performance importance score of 5 ). So if the budget limit was set at 150 points (50\% of the possible points), this example would be within the allowed budget. However, if the end-user had specified more demanding requirements for any attribute, the assignments would have exceeded the budget and the user would be encouraged to re-examine the selections to determine if additional trade-offs could be made without compromising the success of the scenario.

Strengths of this method - Operation with a real point budget encourages end-users to consider practical trade-offs for the sensor system attributes.

Issues - The assignment of the allowed point budget is arbitrary. It could just as easily be assigned at $60 \%$ or $75 \%$ of the maximum allowed points. A lower budget encourages hard consideration of practical needs and possible trade-offs. However, for some scenarios, a lower budget could mean that end-users simply could not specify meaningful scenario needs within the budget. End-users need to be able to declare their actual requirements, even beyond the budget limits, for demanding scenarios. 


\subsection{Normalized Scoring Using Attribute Rank Ordering}

The concept is illustrated in Figure 5.1 below.

\begin{tabular}{|c|c|c|c|c|c|c|c|c|}
\hline \multirow{2}{*}{\begin{tabular}{|c|} 
Attribute \\
$A$
\end{tabular}} & \multicolumn{5}{|c|}{ Criteria } & \multirow{2}{*}{$\begin{array}{c}\text { Multiplier } \\
4\end{array}$} & \multirow{2}{*}{$\begin{array}{c}\text { Ranking } \\
3\end{array}$} & \multirow{2}{*}{$\begin{array}{c}\text { Score } \\
4\end{array}$} \\
\hline & & & & & & & & \\
\hline$B$ & & & & & & 1 & 10 & 3 \\
\hline C & & & & & & 2 & 5 & 3 \\
\hline$D$ & & & & & & 10 & 4 & 13 \\
\hline$E$ & & & & & & 7 & 7 & 16 \\
\hline$F$ & & & & & & 4 & 2 & 3 \\
\hline$\ldots$ & & & & & & & & \\
\hline & & & lier & & & Total & Total & Total \\
\hline & 1 & 2 & 4 & 7 & 10 & 28 & 31 & 42 \\
\hline & & & $\operatorname{anc}$ & $=$ & igh & & 10 high & $M^{\star} R$ norm \\
\hline
\end{tabular}

Figure 5.1. Concept of Normalized Scoring Using Attribute Rank Ordering

- Start with the masked operational scenario Attribute vs. Criteria table seen previously in Table 3.7. Individual Attributes are shown on successive rows in the table. Criteria are in the columns in increasing Performance Levels from left to right.

- Performance levels in the shaded areas are unacceptable for the scenario under consideration.

- Multiplier Values are assigned to each Criteria level as shown below the chart. The lowest level of acceptable performance determines the Multiplier for that particular Attribute which is placed in the first column to the right of the table.

- The second column to the right of the table is the Ranking contributed by the user. It is a number between one and ten with 10 being the highest value. It represents the user's estimation of the relative importance of the Attribute for a particular scenario. The normalized ranking for a specific attribute is determined by dividing its assigned ranking value by the sum of all the ranking values provided by the end-users ( 31 in this case).

- The Score shown in the third column to the left of the table is calculated by multiplying the normalized Ranking by $10 \times$ the attribute Multiplier rounded to the nearest whole number. In the example for Attribute A, the calculation is $(3 / 31) \times(4 * 10)=4$. Attribute D is $(10 / 31) \times(4 * 10)=13$.

Large scores represent high difficulty; high importance attribute gaps will be significant if they cannot be attained. 
Strengths - This approach does not require the assignment of an arbitrary point budget which the enduser must work within.

Issues - The absence of a point budget ceiling does not require/encourage end-users to consider tradeoffs that might be very appropriate for meeting the requirements for a given scenario. 


\subsection{Measurement Method Options}

There are a wide variety of analytical measurement systems that are commercially available. Some of these are as simple as paper strips that respond with a color change to specific compound classes, others are highly complicated, such as multi-hyphenated instrument systems with sample preparation, separation (e.g., chromatography), and complex detection systems all engineered into one package. The scenario requirements of the in situ project will limit the applicability of systems either through deployment parameters such as size/weight/power constraints or through technique shortfalls in sensitivity or selectivity. Although each individual scenario will require a survey of available relevant techniques, there are a number of specific deployment parameters that will greatly affect the choice of techniques that are applicable.

The analytical measurement system as a whole needs to be considered in light of the scenario deployment requirements. Although emphasis is often placed on the actual detection mechanism, the more mundane areas of sample collection and handling can have profound adverse effects on the analytical results if not properly addressed. In considering potential measurement options, the system performance attributes listed in Table 3.7 can be used as a guide to identify performance criteria which can be met by existing equipment and which criteria might require further development for deployment (technology gap). The complexity in the evaluation occurs in the consideration of all the criteria, as it is apparent that certain techniques will be strong in some areas (such as the logistical items: size/weight, power, etc.) while being weak in other areas (such as the detection items of sensitivity and selectivity). Thus, a prioritization will be necessary to resolve deployment issues.

The fact that deployment decisions are based upon scenario variables and instrument characteristics is not a new concept. One of the more popular implementations of this concept is the receiver operator characteristic (ROC) curve (Egan 1975; Hanley 1989; Swets 1988), with an example shown in Figure 6.1. A ROC curve is a plot of the true positive rate against the false positive rate. ROC curves are routinely used to evaluate detection equipment, as they illustrate the tradeoff between sensitivity and specificity. Although useful, ROC curves do not address a wide range of variables involved in making a measurement system deployment decision.

The nature of the measurement scenario puts specific constraints on certain measurement system attributes. Semi-volatile compounds and their associated degradation products have a low vapor pressure and can be polar, leading to an enhanced complexity in the sample handling and preparation. Based on scoping analysis performed using CalTOX, semi-volatile chemicals are likely to be found in the soil and sediments for a time after release. Removing polar compounds from soil and sediment samples for analysis requires a lot of energy (either through heating or addition of solvents); this detail has profound effects on the system attributes. A tradeoff becomes immediately obvious, as extra energy can be used to enhance analyte extraction, thus augmenting detection limits at the cost of an increased power need. Reducing the power input to the extraction can make a system more field-deployable; however, detection limits may have to be sacrificed (through reduced extraction yield). The necessity for extraction steps to remove polar compounds from the sample matrix for analysis has additional effects besides power. The addition of a sample extraction module (whether it be thermal desorption, solvent extraction, or laser 


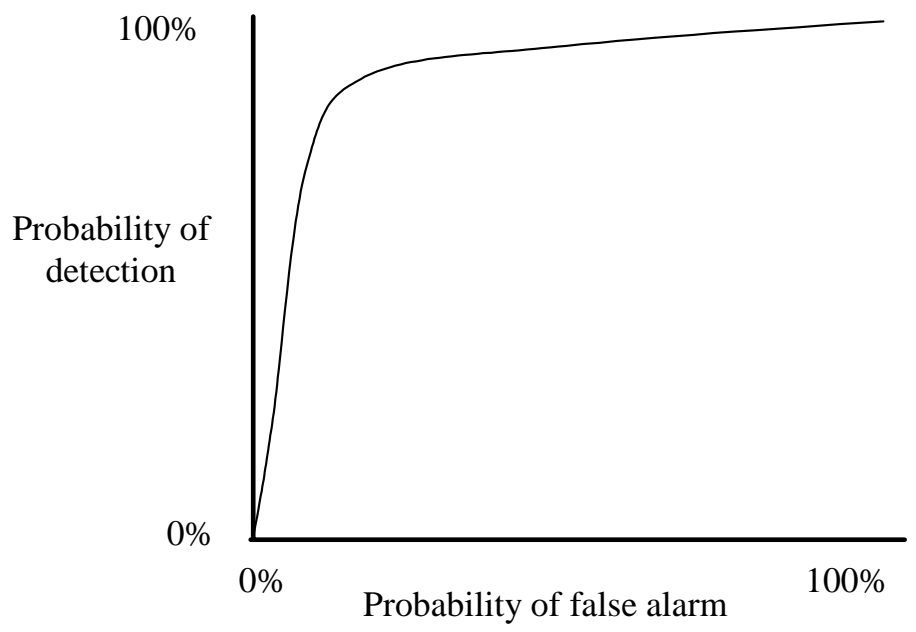

Figure 6.1. Example of a Receiver Operator Characteristic (ROC) Curve

ablation) before a detection technique can add to the capital cost of the system, will increase the system size and weight, may increase consumables and per sample operation costs (especially for solvent extraction), and will increase analysis time in addition to the added power requirements. Thus, the technology evaluation (and subsequent gap determination) is highly dependent on end-user input concerning the deployment requirements and the data needs. If a prioritization of these requirements takes place, measurement systems can be selected (or excluded) based on tangible criteria, and the result is an objective evaluation of technologies useful to the end-user and the illumination of weaknesses (technology gaps) where research investments may be necessary to solve a measurement difficulty.

Table 6.1 illustrates an evaluation of a number of measurement technologies against the example scenario to be defined in the next section. It is presented here such that the criteria used to appraise a measurement technique can be explained. This table does not present an exhaustive study of all available measurement techniques that might be applicable to the example scenario, but instead reveals a strong cross-section of methods that have been pre-screened to provide a reasonable set. Once the attributes are evaluated against the criteria listed in Table 3.7, they can be evaluated with consideration given to the specific chemical compound issues as well as the deployment constraints. These evaluations can be used to determine whether a technique meets a requirement based on a comparison with the method evaluation in Table 6.1, or whether technology development is needed to fill a gap in performance to meet scenario requirements.

\section{Detection}

- Numbers of analytes - In evaluating the process of interest, one can identify compounds related to the process that can be targeted for measurement. By applying the stability/uniqueness criteria discussed earlier, efforts can be focused on the optimal compound set for potential measurement. This evaluation for a specific process (such as nuclear processing signatures) will typically lead to a very small final signature set of one or a few similar chemicals. Thus, for this scenario, the criteria level most applicable in Table 3.7 is the "single class" entry. 
Table 6.1. Example Methodologies and Attribute Applicability for Example Scenario

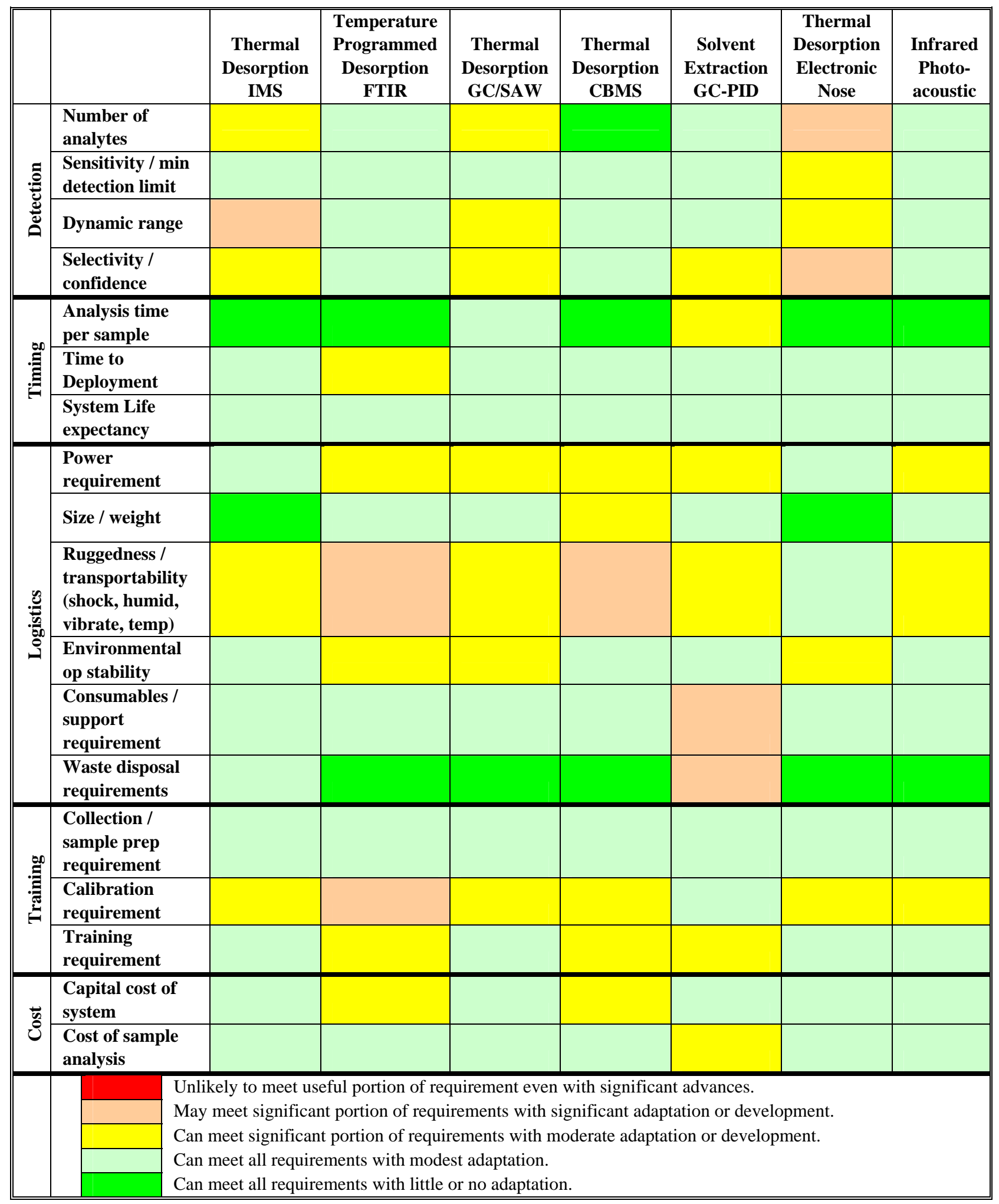


- Sensitivity/minimum detection limit - Rogue nuclear processing is typically a clandestine operation, and thus emissions will be heavily controlled in most cases. Monitoring for target chemicals will usually be done to exploit either a low level fugitive emission or an upset condition. Although the in situ project focuses on less-than-remote methods, the non-cooperative nature of rogue nuclear processing limits access to the site of emission. Thus, monitoring activities will most likely need to take place hundreds of meters from the suspected site. Fate and transport evaluation (fugacity modeling) of the identified chemicals will not only give insight into which targets will survive long enough to be measured, but will also provide clues into the best medium to find the target chemicals, and how dispersed they may be. Concentration levels drop with distance from a point release; thus, very high sensitivity will be required of a measurement system in this scenario. The criteria level

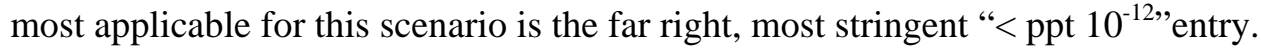

- Dynamic range - The dynamic range aspects of this scenario are not difficult. Given the unique nature of the compound class of interest, there should be little to no background level. Thus, the measurement will not include the detection of a low level in the presence of a high background of similar chemicals. Also, there is not a need to quantitatively determine the concentration levels of the

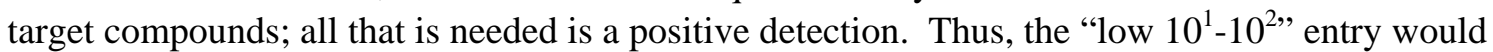
suffice, and the "very $<10^{1 \text { " }}$ entry may even be adequate in this application.

- Selectivity/confidence - Given the severe political implications of rogue nuclear processing, a high confidence measurement is required. However, if multiple sample analyses can be performed, this can enhance the confidence level of the detection (remove the potential of a spurious false alarm) without requiring an extreme level of measurement system selectivity. This should be a very viable approach to the detection of semi-volatile compounds which will persist for additional measurements once released (persistence for multiple measurements is a weakness in detecting volatile signatures). However, lower resolution techniques may lead to false alarms that are not spurious, but are measurement system responses to other classes of chemicals due to phenomena such as non-specific adsorption to selective materials, poor optical dispersion, or similar ionization potentials. This is an interference issue that is typically well documented for various chemical detection systems. In this

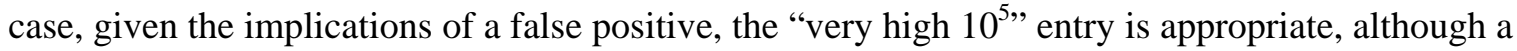

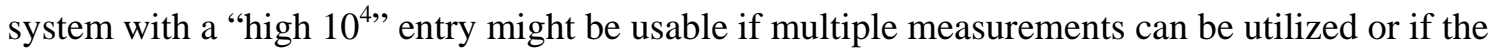
appropriate scientific talent is available to provide additional interpretation of the datasets.

\section{Timing}

- Analysis time per sample - The analysis time required is highly scenario-dependent. If the measurement system can be covertly deployed, longer analysis times may be acceptable. However, if human assets are required to operate the system non-covertly in a non-cooperative environment, time will be of the essence. Given the hands-on nature of most of the techniques shown in table 13, it will be assumed that embedded, covert operation will be nearly impossible in most cases. Thus, the " 5 min to 1 hr" entry is most likely the minimum acceptable criteria, with the more stringent entries being desirable. 
- Time to deployment - The volatile nature of world politics related to rogue nuclear processing dictates that systems be put into place as quickly as possible after intelligence information provides insight into potential measurement locations. Granted, a system can be assembled ahead of time and be ready for use "off the shelf." However, the differences in requirements of each deployment scenario may dictate further system modification before deployment. The persistence of semi-volatile signatures make it possible to take measurements for a time period after an event (upset release); however, even these have a limited lifetime (as illustrated by the CalTOX modeling). Thus, the "1-6 months" entry would be considered the minimum, with the shorter time frame entries being much more optimal.

- System operating life expectancy - It is difficult to deploy measurement devices into a noncooperative environment for long periods of time. In many cases, intelligence information is used to focus an effort on obtaining a high confidence signature detection. This may require only an hour of device operation time. However, given that multiple sample measurements will most likely be needed to find a signature chemical and to verify the response, a "1-30 days" entry would be considered reasonable. Extension of the operation life may be valuable, but it is not worth the sacrifice of other attributes. In cases where a longer term covert deployment may be possible for persistent monitoring, this value should move towards the "1-10 years" entry.

\section{Logistics}

- Power requirements - Power requirements can greatly hamper the mobility and covert level of the deployment. In most non-cooperative scenarios, AC line current is not considered a reasonable option. At a minimum, AC operation via a generator or vehicle inverter may be possible-battery operation is desirable. Thus, the "vehicle/lead acid" entry should be considered the minimum entry, with "alkaline, NiCd, Li" a more optimal entry.

- Size/weight (total system) - Because the system needs to be transported into a non-cooperative situation, as well as deployed, a reasonable size and weight is required to meet this. The "vehicle deployed" entry would be considered the absolute minimum acceptable, with smaller/lighter systems such as the "man portable" entry or the "handheld" entry being much more appropriate.

- Ruggedness/transportability - The need to transport the system a long distance and then deploy into a non-cooperative situation requires that the device be rugged beyond normal commercial shipping requirements. Transportation to the final deployment site will most likely not take place on paved roads and may need to survive an airborne drop. Thus, the "minimal mil-spec hardened" entry would be considered the minimum starting point.

- Environmental operating stability - Non-cooperative deployment situations are usually very heavily coordinated and scheduled in advance. Thus, it is difficult to control factors such as the weather when the measurement opportunity window opens. Also, there are situations (such as the fog transport example mentioned earlier) where adverse weather events can enhance the measurement. It is imperative then to deploy a measurement system that will not be adversely affected by swings in 
temperature, humidity, barometric pressure, etc. The "moderate, affected by major change" would be the absolute minimum acceptable entry.

- Consumables/support requirements - System consumable items not only increase the costs of analysis, but complicate the logistics of deployment. Consumables often must be handled carefully to avoid contamination (such as gas scrubbers and sampling media) and are often loose items that must be packaged for proper storage and accessibility in the field. Some "consumable" items can be considered support issues, such as gas cylinders and/or solvents. These items can have large impacts on the deployment logistics that are not always apparent when reviewing the technique specifications.

- Waste disposal requirements - Waste disposal can take many forms from a measurement system, including solvents, solid sampling media, gases, and reaction by-products. In a non-cooperative environment, appropriate waste disposal is a must. Evident waste forms should not be visible, especially those that can be tied directly to the analysis. All evident waste must be removed or destroyed, and there are logistical issues with both approaches that must be considered.

\section{Training}

- Collection/sample preparation requirements - An analytical system is only as effective as the weakest link in the system chain; in many cases, the weak link is sampling. Although much research and development effort has been put into detection equipment, the capabilities of a state-of-the-art detector can be compromised by a poor sampling approach. Thus, it is important that the users be trained and effective in the specific sampling preparation methods required. The complexities and difficulties inherent in the sample preparation method cannot only affect the final analytical results, but can also add a logistical burden to the operation.

- Calibration requirements - Device calibration has a direct impact on data reliability and technique sensitivity. To maintain the highest quality measurements, detection devices must be properly calibrated. Since calibration will most likely take place in the field-deployed scenario, the effort level needed to calibrate the system will be important to consider.

- Training requirements - In a non-cooperative environment, it is often difficult to embed highly trained scientists to operate equipment. In many cases, detection equipment will be deployed by military personnel and operatives with no formal scientific education. Thus, the level of training needed to set up and operate a field-deployed instrument becomes a major issue.

\section{Cost}

- Capital cost of system - The initial costs related to the procurement or building of the detection system. This value needs to be considered with respect to the "per sample" costs, as a high initial capital cost can be offset by a low "per sample" cost if a large number of measurements are taken.

- Cost of sample analysis - These are costs related to the ongoing operation and amortized maintenance costs of the system on a per sample basis. 


\subsection{Technology Gap Analysis}

The ultimate purpose of this entire process is to identify technology gaps in less-than-remote detection of semi-volatile signature compounds. To that end, a process which objectively evaluates all aspects of the detection process (signature identification and evaluation, scenario definition, and methodology applicability) has been delineated in a way that limitations in current approaches can be highlighted. The use of requirements and applicability matrices allows for a direct comparison between needs and potential solutions through an overlay approach. When the requirements matrix is built using direct input from end-users, the gaps revealed in the overlay process allow the end users to not only determine the limitations of current technologies but also lend insight into where research investments can be made to directly impact future operations.

\subsubsection{Overlay of Scenario Requirements vs. Measurement Instrumentation vs. Unique Signature Semi-Volatiles}

To determine the efficacy of the process, it must be challenged by a "real world" example, and the results compared against a direct analysis of the scenario. Thus, a legitimate example scenario must first be crafted. The underlying focus of this report is to evaluate technologies for less-than-remote nuclear signature detection; thus, the example scenario will be based on a hypothetical detection requirement.

The PUREX process is a well-known method used to selectively extract uranium and plutonium from spent nuclear fuel (Fecht et al. 1955; Hopkins 1955). The main extraction component of the PUREX process is the organic solvent tributylphosphate (TBP). Obviously, any use of this process by splinter groups and rogue nations would be of interest to the world community. Thus, a non-cooperative detection scenario can be envisioned that targets the main chemical from this process (TBP). TBP is a semi-volatile organic chemical that has a limited water solubility and limited vapor dispersion potential. Since the equilibrium vapor pressure is $<0.1 \mathrm{mbar} @ 20^{\circ} \mathrm{C}$, vapor concentrations will be quite low, except in the event of a very large-scale upset. Thus, vapor-based detection schemes, such as stand-off optical systems (e.g., hyperspectral imaging), are of extremely limited utility for this detection scenario. Less-thanremote in situ analysis methods are required to provide useful detection information. The most likely logistical path would be to implant a small team into the area near the suspected facility which would then utilize supplied detection equipment to make measurements. In many cases it may be preferable to only gather samples to be returned for high-quality laboratory analysis; however, there is some risk to this approach. For example, unless a large, broad scale sampling effort is undertaken, the samples returned may not be representative or contain the target chemicals. With a field-deployed instrument, samples can be run until the target chemical is located and sampling can proceed with this guidance. This ensures that samples returned to the laboratory contain detectable quantities and greatly reduce the need to return for additional samples. Also, there can be issues with sample lifetime. In some cases, signature compounds may degrade with time, due to hydrolysis, photolysis, or microorganism activity. Samples collected in a non-cooperative environment may take days or even weeks to return to a laboratory. Field-deployed analysis offers nearly instant feedback on signature chemical levels and locations and can guide further actions. 
If one further envisions this deployment scenario, parameter requirements become clearer. A noncooperative less-than-remote deployment will necessitate techniques that are portable, rugged, and, in most cases, require minimal power. Sensitivity will be a key. As the vapor pressure and water solubility are low, transport from the emission site will be limited. Therefore, concentrations will drop off quickly from the point of emission. It is thus imperative to have the capability to deploy measurement devices as close as possible to a suspected facility. Table 3.7 was introduced earlier as a presentation of a number of critical scenario requirements for measurement systems with the associated rough categorizations that can be used to classify and compare techniques. Given the limitations defined by the scenario description, the techniques under consideration for deployment can be reduced substantially from the pool of all available analytical methods.

\subsubsection{Example Gap Determinations}

The specific nature of semi-volatile compounds strictly limits the measurement technologies that can be employed for detection. For example, since semi-volatile compounds do not tend to stay airborne with reasonable vapor concentrations, only techniques that can access surface amounts (such as adsorbed onto soils) or accumulated quantities (such as uptake into plants) will be successful. These techniques must, in most cases, remove the analytes of interest from the matrix, which can be a daunting task in itself, before any analysis can take place. Even techniques that can make measurements directly without removal of the analytes from the matrix (such as reflective optical techniques) will need to contend with a wide variety of sample matrix backgrounds and environmental interferents. The matrix effects cannot be understated, as specificity in measurement is nearly always a high priority in dealing with proliferation issues. A high false positive rate can lead to serious complications in making treaty compliance decisions. Thus, high selectivity is required; this step often includes the separation of the analytes from the matrix in addition to the selectivity of the measurement technique itself.

As our example of the PUREX process signature measurement is further considered, the analysis illustrated in Table 6.1 becomes significant. We originally reduced the signature compound set down to TBP within a short time frame of release ( $<90$ days). Longer times to deployment (such as a year) would require reconsideration of the chosen signature (such as the environmental fate products) or whether an appropriate signature still exists at all.

Table 6.1 illustrates the applicability of a number of analytical methods against the specific requirements of example scenario. The colors are derived from the evaluation criteria illustrated in Table 3.7 and scored for the example scenario. Many conclusions can be drawn from this graphic, including the strengths of individual techniques and the scenario requirements that are difficult to meet with any technique (technology gaps). Three of the attribute rows stand out as having broad technology gaps as they contain a significant number $(>5)$ of non-green blocks. The attributes that stand out as having weaknesses include ruggedness/transportability, power requirements, and calibration requirements. In contrast, the attribute of analysis time shows few weaknesses, suggesting that research and engineering efforts in this area have been successful in addressing the analysis time issues of deployment. 
The technology gaps revealed in the analysis have origins in both the difficult nature of the scenario and the shortcomings in the migration of laboratory analytical techniques to the field. For example, the gaps associated with ruggedness and calibration are somewhat related. Modern sensitive analytical techniques do not handle shock or temperature stress very well; these things are a fact of life for fielddeployed devices. Calibration issues are often related to environmental stresses such as shock or temperature swings. Although these issues are usually controlled in the laboratory environment, that level of control is difficult to achieve in field-deployed devices, and may require demands in other areas such as size and weight or power increases to fulfill the required performance level. Thus, investment into hardening analytical techniques would be beneficial, if it can be done without adversely impacting other attributes.

A simple identification of a technology gap can yield significant insight upon further analysis. This is the case for the power requirement attribute. When one considers all the measurement methods under consideration, it is not usually the actual detection device which is problematic, but the sample handling technique which prepares the sample for analysis. For example, five of the seven measurement systems listed in Table 6.1 have a thermal desorption step. This step is critical to remove the analyte of interest from the matrix and prepare it for the detection mechanism. Thermal desorption is an energy intensive process, especially when done with resistive heating. Although ion mobility spectrometry and surface acoustic wave detection devices can typically be run with very little power consumption, the addition of the thermal desorption step to provide an appropriate vapor sample to these detectors adds a huge power burden to the system. Although the main identified gap is the power requirement, it can be suggested after further analysis that the true technology gap is in sample handling of adsorbed semi-volatile compounds. Many detectors require a vapor sample, and the separation of the matrix components (whether through simple desorption or chromatographic means) are energy-hungry processes. Thus, when considering technology investments to overcome the identified power requirement gap, improved batteries are only a part of the solution. The development of methods that can remove analyte molecules from soil and plant material without significant energy expenditures (or excessive solvent usage, which would negatively impact other attributes) would also be considered key in solving the power requirement issues. Also, advanced chemical separation methods (such as novel chromatographic techniques) would also be useful in overcoming the shortfalls in the power requirements, but care must be taken not to adversely affect other attributes. For example, although micro-scale gas chromatography (GC) brings an advantageous separation dimension to a sample with only a minor increase in power demands, the sensitivity attributes begin to suffer because of the low sample capacity of such devices. Also, many detectors are not useful with micro-scale GC because of the low flows and dead volume issues involved. It is important to keep the entire attribute set in mind as one attempts to fill technology gaps associated with a specific measurement scenario.

By systematically defining desirable chemical properties to reduce the potential signature set and identifying the important variables in a given scenario, the evaluation of current measurement technologies and elucidation of gaps becomes a relatively straightforward process. Given that a specific process may have hundreds of chemical signatures and a scenario may have thousands of operational variables, it would be difficult to begin matching measurement technologies with the appropriate uses, let alone identify areas for improvement, if the process was not systematically evaluated. This report provides a framework for such an evaluation, and allows for the targeted deployment of measurement 
technologies as well as insight into needed research and development investments to solve measurement technology gaps. 


\subsection{Summary and Conclusions}

A strong case can be made for implementation of "less-than-remote" or in situ measurement technologies for the detection, monitoring and characterization of illicit or clandestine manufacturing and testing operations that are associated with nuclear, chemical or biological processes. The benefits over remote monitoring for deriving accurate quantitative assessments from either ongoing and residual events and processes are readily apparent especially when considering those based on semi-volatile compounds as indicators. By examining likely chemical observables, the end user deployment constraints and available measurement technologies in a systematic way, we have developed a structured process to identify implementation barriers and assess technology gaps in order to assist potential users in evaluating the applicability of technology and prioritize development to fully utilize the in situ tools.

While generally applicable for identifying many classes of processes and their byproducts, we have confined our illustration to methods with general classes of chemicals associated with various nuclear materials processes. Specifically, we have concentrated on that substantial set of chemicals that are not limited to volatile compounds normally associated with remote or stand-off detection, but rather those chemicals that are of unique intelligence value that often rapidly localize in the environment and migrate via non-atmospheric pathways.

The first step in the method is to examine the processes of interest and develop a highly qualified list of chemicals and their byproducts that are both associated with the process and not found in other common processes that could provide misleading results. We have emphasized the necessity of understanding those migration pathways following a release (controlled or uncontrolled) in order to maximize collection probability and illustrated the benefits of fugacity modeling to assist in the determination of exploitable signatures for identification and their likely location, concentration and lifetime. This information can be graphically overlaid with the practical deployment scenario constraints and the available measurement instrumentation specifications and equipment operational requirements to present a visual illustration of where measurements are possible and where technology gaps exist that make determinations of good intelligence value less that optimal or unlikely. We also presented various techniques for estimating the size of the technology gaps which depend on the preferences of the end user community. This collection of the various assessment components provides a broad spectrum analysis method that leads to a rational and systematic method of technology assessment that should be of great value to both technology users and developers. 



\subsection{References}

Bennett DH, TE McKone, M Matthies, and WE Kastenberg. 1998. "General Formulation of Characteristic Travel Distance for Semivolatile Organic Chemicals in a Multimedia Environment," Environ. Sci. Technol., 32:4023-4030.

Beyer A and M Matthies. 2002. "ELPOS - Criteria for Persistence and Long-range Transport Potential of Pesticides and Industrial Chemicals," http://www.usf.uos.de/projects/elpos/

Beyer A, D Mackay, M Matthies, F Wania, and E Webster. 2000. "Assessing Long-Range Transport Potential of Persistent Organic Pollutants,” Environ. Sci. Technol., 34:699-703.

Bidleman, TF, Environ. Sci. Technol., 1988, 22, 361-367.

Carlson EC. 1996. "Don't Gamble with Physical Properties for Simulations," Chemical Engineering Progress, 35-45.

Egan JP. 1975. Signal Detection Theory and ROC Analysis, Academic Press, New York.

Fecht JB, RT Jaske, TV Lane, and JO Ludlow. 1955. “A PUREX Process One-Cycle Plant Study,” HW-39872, General Electric Hanford Company, Richland, Washington.

Glotfelty DE, JN Seiber, and LA Liljedahl. 1987. "Pesticides in Fog,” Nature, 325(12):602-605.

Hanley JA. 1989. "Receiver Operating Characteristic (ROC) Methodology: The State of the Art," Critical Reviews in Diagnostic Imaging, 29:307-335.

Hopkins HH, Jr. 1955. “Towards a Simplified PUREX Process,” HW-38267, General Electric Hanford Company, Richland, Washington.

Mackay, Donald, Eva Webster, Ian Cousins, Thomas Cahill, Karen Foster, and Todd Gouin. 2001. An Introduction to Multimedia Models - Final Report. Prepared as a background paper for OECD Workshop Ottawa, October 2001 by Canadian Environmental Modeling Centre. Report No 200102.

MacKay, Donald. 2001. Multimedia Environmental Models: The Fugacity Approach, Second Edition by Lewis Publishers, Inc., Boca Raton, FL, ISBN: 1566705428.

Probasco KM., JC Birnbaum and AD Maughan. 2002. Potential Signatures of Semi-volatile Compounds Associated with Nuclear Processing, PNNL-13922, Pacific Northwest National Laboratory, Richland, Washington.

Swets JA. 1988. "Measuring the Accuracy of Diagnostic Systems," Science, 240:1285-1293. 
Webster E, D Mackay and F Wania. 1998. "Evaluating Environmental Persistence," Environmental Toxicology and Chemistry, 17:2148-2158.

Webster E, J Hubbarde, D Mackay, L Swanston and A Hodge. 2003. "Development of Tools to Improve Exposure Estimation for Use in Ecological Risk Assessment: The TaPL3 Upgrade.” Report to Environment Canada. CEMC Report, Trent University, Peterborough, Ontario.

Webster E, J Hubbarde, D Mackay, L Swanston, and A Hodge. 2003. "Development of Tools to Improve Exposure Estimation for Use in Ecological Risk Assessment: The TaPL3 Upgrade," Report to Environment Canada. CEMC Report 2003xx, Trent University, Peterborough, Ontario.

Whelan G, JW Buck, DL Strenge, JG Droppo, Jr. and BL Hoopes. 1992. "Overview of Multimedia Environmental Pollutant Assessment System (MEPAS),” Hazardous Waste \& Hazardous Materials, 9(2):191-208. 
Appendix A

Basis for Selection of Table 3.1 Parameters 



\section{Appendix A}

\section{Basis for Selection of Table 3.1 Parameters}

(For reader convenience, Table 3.1 is duplicated at the end of this appendix.)

Key application requirements for chemical signature selection have been organized into two complementary categories (fate/transport and intelligence value) in an effort to delineate those signatures which are of value and which can be considered detectable in the given scenario. These signature requirements provide criteria that will allow technologists to consider measurement technologies for use on viable signature sets. Both categories hold a high priority; those signatures which fit into an acceptable range in both categories should be considered a viable signature. As an example, compounds that are direct and singular chemical progeny of an illicit process are poor signatures if their environmental lifetime is on the order of minutes.

Overly aggressive (demanding) specification of the signature requirements can have the detrimental effect of eliminating suitable measurement technology options and could impair the down selection of methods based on realistic trade-offs. See the discussion in the user weighted requirements section (Section 5) of this report.

It is important that end-user needs with respect to the potential signature compounds be included in the parameter selection. Information such as specific chemical compounds (or at least functional group) of interest as well as targeted media for detection (vapor, liquid, adsorbed on soil, etc.) are needed as input to allow for evaluations using the table. This information is necessary to make decisions on required performance of the systems under consideration.

\section{A.1 Fate and Transport}

These parameters for individual chemicals have major impact on the fate and transport behavior of chemicals in the environment and they also are important to understand for selecting suitable sensor technologies. These parameters have direct implications on where a chemical might be found, how long it is likely to survive in the environment after release, and how it might be best detected in the environment.

- Volatility/Diffusivity - This parameter indicates whether a chemical is most likely to be found in vapor phase or adsorbed to surfaces and materials in the region of release. It also indicates if a significant fraction of the chemical released is likely to be detectable in vapor phase. A chemical with a high vapor pressure is likely to be found in vapor phase and sensing that chemical should exploit its presence in the vapor. Conversely, chemicals with very low vapor pressures are less likely to be successfully detected using a vapor-phase measurement method. 
- Reactivity/Stability - This provides insights on how long a released chemical is likely to remain in its original chemical form. Chemicals with high reactivity are likely to undergo rapid chemical reactions in the environment after release and be converted to other molecular forms. This is common with chemicals that hydrolyze, or react, with water.

- Water Solubility - Allows an understanding of a chemical's probable tendencies to be affected by local water and possibly if it will be found in local run-off or surface water. Chemicals with high water solubility will readily dissolve if exposed to moisture and are likely to remain in solution for extended periods of time.

- Bio Metabolized/Breakdown Rate - Indicates if the chemical is highly susceptible to degradation by natural organisms in the environment. Chemicals that are readily digested by environmental organisms may not exhibit high environmental build-ups even if the chemical is released in an area over extended periods.

- Bio Stabilization/Uptake Rate - This indicates if a chemical is prone to accumulation in local biological systems (e.g., plants and vegetation, fish, insets, animals, workers, etc.). This knowledge could allow an optimized sampling scheme to increase probability of mission success.

- Organic Adsorption Tendency $\left(K_{o w}\right)-K_{o w}$ is essentially a quantitative thermodynamic measure of the hydrophilic/lipophilic balance of an organic compound (Sangster 1997). It is often used to estimate the distribution behavior between water and organic-based phases, such as tissue and soils/sediments.

\section{A.2 Intelligence Value}

These factors are of key importance for selecting sensing and measurement targets and for properly understanding the significance (or lack there-of) of any measurement findings. The factors will be of primary interest to analysts, mission planners, and staff establishing the requirements for measurement systems.

- Uniqueness of Primary Chemical - Detection of chemicals that are broadly used in industry provides very little exploitable information. These chemicals, because of their common use, may be found in the normal environment in significant levels. Further, detection of these chemicals in general manufacturing areas could arise from any number of facilities that have no value for answering the key question at hand. In contrast, if a chemical is detected that has no known (or at least very few) commercial uses beyond a weaponization process, the knowledge is much more definitive for understanding the situation. Sometimes a chemical's presence in the environment without certain common co-contaminants is also a key marker, since chemical, biological or nuclear processes may demand different process handling techniques that preclude certain contaminants.

- Uniqueness of Degradation Products - Detection of chemicals that are broadly used in industry provides very little exploitable information. These chemicals, because of their common use, may be 
found in the normal environment in significant levels. Further, detection of these chemicals in general manufacturing areas could arise from any number of facilities that have no value for answering the key question at hand. In contrast, if a chemical is detected that has no known (or at least very few) commercial uses beyond the development of weapons, the knowledge is much more definitive for understanding the situation.

- Storage Stability - The use of chemicals that require exceptional storage precautions, equipment, or facilities implies that the process supported by this chemical and the associated storage activities is serving a high-value function in the user's strategy.

- Safety/Transportation Constraints - The use of chemicals that require exceptional transportation precautions, equipment, or facilities implies that the process supported by this chemical and the associated transportation or on-site manufacturing activities is serving a high-value function in the user's strategy.

- Cost Including Waste Disposal (procurement of ingredients) - Detection of chemicals that have high procurement costs provides significant indications of potential use and importance to the end user. High-cost chemical ingredients that are claimed to be ingredients for a low-value commercial process would be an obvious warning indicator. High costs could be associated with unique chemicals that are very hard to manufacture or chemicals of exceptional purity that are not readily produced in the chemical industry for routine applications. Another potential cost indicator relates to the value of by-product. Detection of high-value chemical by-products of a process that are not being commercially exploited could indicate an illicit process operation. For example, if a high-value chemical by-product is being dumped rather than being processed for suitable commercial uses, it could indicate that the underlying driver for the operation is not creating commercial value (i.e., the normal commerce and financial motivation) and thus could indicate a threat scenario.

- Toxicity - The use of highly toxic chemicals that require exceptional worker safety precautions, equipment, or facilities implies that the process supported by this chemical and the associated safety activities is serving a high-value function in the user's strategy. When practical in normal commercial chemical industry, if less toxic material and process alternative exist for producing a product we can expect that industry will have adopted the more benign method. If the use of these toxic chemicals is unusual for routine commercial chemical industry applications, it could indicate a process that deviates from the normal commercial realm.

\section{A.3 Reference}

Sangster J. 1997. Octanol-Water Partition Coefficients: Fundamentals and Physical Chemistry, John Wiley \& Sons, Chichester. 
Table 3.1. Chemical Attributes vs. Evaluation Criteria

\begin{tabular}{|c|c|c|c|c|c|c|}
\hline & Attribute & \multicolumn{5}{|c|}{ Criteria } \\
\hline \multirow{6}{*}{ 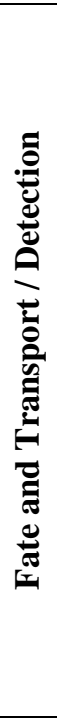 } & $\begin{array}{l}\text { Volatility / } \\
\text { Diffusion }\end{array}$ & $\begin{array}{l}\text { Very High } \\
\text { V.P. }>50 \text { torr }\end{array}$ & $\begin{array}{c}\text { High } \\
\text { V.P. }=1-50 \text { torr }\end{array}$ & $\begin{array}{c}\text { Moderate } \\
\text { V.P. }=0.05-1 \\
\text { torr }\end{array}$ & $\begin{array}{c}\text { Low } \\
\text { V.P. }=0.05 \text { to } \\
0.001 \text { torr }\end{array}$ & $\begin{array}{l}\text { Very Low } \\
\text { V.P. }<0.001 \\
\quad \text { torr } \\
\end{array}$ \\
\hline & $\begin{array}{l}\text { Reactivity / } \\
\text { Stability }\end{array}$ & $\begin{array}{l}\text { Very High } \\
t_{1 / 2}<1 \text { min }\end{array}$ & $\begin{aligned} & \text { High } \\
\mathrm{t}_{1 / 2}= & \text { min to hrs }\end{aligned}$ & $\begin{array}{c}\text { Moderate } \\
\mathrm{t}_{1 / 2}=\text { hrs to days }\end{array}$ & $\begin{array}{c}\text { Low } \\
\mathrm{t}_{1 / 2}=\text { days to } \\
\text { month }\end{array}$ & $\begin{array}{c}\text { Very Low } \\
t_{1 / 2}>\text { month }\end{array}$ \\
\hline & Water Solubility & $\begin{array}{l}\text { Very High } \\
100 \% \\
\text { miscible }\end{array}$ & $\begin{array}{c}\text { High } \\
10-100 \mathrm{~g} / 100 \mathrm{cc}\end{array}$ & $\begin{array}{c}\text { Moderate } \\
1-10 \mathrm{~g} / \\
100 \mathrm{cc}\end{array}$ & $\begin{array}{l}\text { Low } \\
0.001 \text { to } 1 \mathrm{~g} / \\
100 \mathrm{cc}\end{array}$ & $\begin{array}{l}\text { Very Low } \\
<0.001 \mathrm{~g} / \\
100 \mathrm{cc}\end{array}$ \\
\hline & $\begin{array}{l}\text { Bio Metabolized / } \\
\text { Breakdown Rate }\end{array}$ & $\begin{array}{c}\text { Very High } \\
\mathrm{t}_{1 / 2}<\mathrm{hr}\end{array}$ & $\begin{array}{c}\text { High } \\
\mathrm{t}_{1 / 2}=\mathrm{hr} \text { to day }\end{array}$ & $\begin{array}{c}\text { Moderate } \\
\mathrm{t}_{1 / 2}=\text { day to } \mathrm{wk}\end{array}$ & $\begin{array}{c}\text { Low } \\
\mathrm{t}_{1 / 2}=\text { wk to mo }\end{array}$ & $\begin{array}{l}\text { Very Low } \\
\mathrm{t}_{1 / 2}>\text { mo }\end{array}$ \\
\hline & $\begin{array}{l}\text { Bio Stabilization / } \\
\text { Uptake Rate }\end{array}$ & $\begin{array}{l}\text { Very High } \\
\mathrm{t}_{1 / 2}>\mathrm{mo}\end{array}$ & $\begin{array}{c}\text { High } \\
\mathrm{t}_{1 / 2}=\text { wk to mo }\end{array}$ & $\begin{array}{c}\text { Moderate } \\
\mathrm{t}_{1 / 2} \text { day to wk }\end{array}$ & $\begin{array}{c}\text { Low } \\
\mathrm{t}_{1 / 2}=\text { hr to day }\end{array}$ & $\begin{array}{c}\text { Very Low } \\
\mathrm{t}_{1 / 2}<\mathrm{hr}\end{array}$ \\
\hline & $\begin{array}{l}\text { Organic } \\
\text { Adsorption } \\
\text { Tendency (KOW) }\end{array}$ & $\begin{array}{l}\text { Very High } \\
>4\end{array}$ & $\begin{array}{l}\text { High } \\
2 \text { to } 4\end{array}$ & $\begin{array}{l}\text { Moderate } \\
0 \text { to } 2\end{array}$ & $\begin{array}{l}\text { Low } \\
-2 \text { to } 0\end{array}$ & $\begin{array}{l}\text { Very Low } \\
<-2\end{array}$ \\
\hline & $\begin{array}{l}\text { Uniqueness of } \\
\text { Primary Chemical }\end{array}$ & $\begin{array}{l}\text { Very Low } \\
\text { Common } \\
\text { commercial } \\
\text { uses }\end{array}$ & $\begin{array}{l}\text { Low } \\
\text { Some } \\
\text { commercial, } \\
\text { research }\end{array}$ & $\begin{array}{l}\text { Moderate } \\
\text { Little } \\
\text { commercial, } \\
\text { research use }\end{array}$ & $\begin{array}{c}\text { High } \\
\text { No comm., } \\
\text { specialty use }\end{array}$ & $\begin{array}{c}\text { Very High } \\
\text { Specialized } \\
\text { processes } \\
\text { only }\end{array}$ \\
\hline$\stackrel{\mathscr{E}}{=}$ & $\begin{array}{l}\text { Uniqueness of } \\
\text { Degradation } \\
\text { Products }\end{array}$ & $\begin{array}{c}\text { Very Low } \\
\text { Common } \\
\text { commercial } \\
\text { uses } \\
\end{array}$ & $\begin{array}{c}\text { Low } \\
\text { Some } \\
\text { commercial, } \\
\text { research }\end{array}$ & $\begin{array}{l}\text { Moderate } \\
\text { Little } \\
\text { commercial, } \\
\text { research }\end{array}$ & $\begin{array}{c}\text { High } \\
\text { No comm., } \\
\text { specialty use }\end{array}$ & $\begin{array}{c}\text { Very High } \\
\text { Specialized } \\
\text { processes } \\
\text { only }\end{array}$ \\
\hline ") & Storage Stability & $\begin{array}{c}\text { Very High } \\
\text { No special } \\
\text { handling } \\
\end{array}$ & $\begin{array}{c}\text { High } \\
\text { Some special } \\
\text { handing }\end{array}$ & $\begin{array}{c}\text { Moderate } \\
\text { Requires } \\
\text { special handling }\end{array}$ & $\begin{array}{c}\text { Low } \\
\text { Careful special } \\
\text { handling } \\
\end{array}$ & $\begin{array}{l}\text { Very Low } \\
\text { Prepared at } \\
\text { time of use }\end{array}$ \\
\hline 莺 & $\begin{array}{l}\text { Safety / } \\
\text { Transportation } \\
\text { Constraints }\end{array}$ & $\begin{array}{c}\text { Very Low } \\
\text { No special } \\
\text { handling }\end{array}$ & $\begin{array}{c}\text { Low } \\
\text { Some } \\
\text { precautions }\end{array}$ & $\begin{array}{l}\text { Moderate } \\
\text { Special } \\
\text { transport } \\
\text { conditions } \\
\end{array}$ & $\begin{array}{c}\text { High } \\
\text { Critical special } \\
\text { transport }\end{array}$ & $\begin{array}{c}\text { Very High } \\
\text { Not } \\
\text { transportable }\end{array}$ \\
\hline & $\begin{array}{l}\text { Cost Including } \\
\text { Waste Disposal }\end{array}$ & Very Low & Low & Moderate & High & Very High \\
\hline & Toxicity & $\begin{array}{l}\text { Very Low } \\
\text { PEL > \% }\end{array}$ & $\begin{array}{l}\text { Low } \\
\text { PEL high to } \\
\text { medium }\end{array}$ & $\begin{array}{l}\text { Moderate } \\
\text { PEL mid to } \\
\text { high }\end{array}$ & $\begin{array}{c}\text { High } \\
\text { PEL high }\end{array}$ & $\begin{array}{c}\text { Very High } \\
\text { No exposure } \\
\text { allowed }\end{array}$ \\
\hline
\end{tabular}




\section{Appendix B}

Basis for Selection of Parameters in Table 3.7 



\section{Appendix B}

\section{Basis for Selection of Parameters in Table 3.7}

(For reader convenience, Table 3.7 is duplicated at the end of this appendix.)

Key application requirements have been organized into four complementary categories in an effort to address complementary issues and to facilitate later comparison with the capabilities of individual measurement technologies. These application requirements provide criteria that will allow technologists to identify potentially viable measurement technologies for more detailed consideration.

Overly aggressive (demanding) specification of the application requirements can have the detrimental effect of eliminating suitable measurement technology options and could impair the down selection of methods based on realistic trade-offs. See the discussion in the User Weighted Requirements section (Section 5) of this report.

It is important that end-user needs with respect to the scenario be included in the parameter selection. Information such as chemical compounds (or at least functional group) of interest as well as targeted media for detection (vapor, liquid, adsorbed on soil, etc.) are needed as input to allow for evaluations using the table. This information is necessary to make decisions on required performance of the systems under consideration.

\section{B.1 Detection}

This category includes key issues associated with the analytical performance requirements for the application.

- Number of Analytes - The number of analytes that must be detected by a measurement system has major impact on the suitable technology options available. If the detection of a single analyte (i.e., a definitive smoking gun) can meet the application requirements, then a specialized measurement method tailored for the target analyte could be employed. However, if the measurement method must be able to measure multiple known analytes (or provide data on unanticipated chemicals), this will dramatically affect the selection of suitable method candidates.

- Detection Limits Required - The detection limit required for the application is critical information that must be considered for the measurement technology selection. It affects not only the detection method but also ancillary subsystems that might be required for sample collection, preconcentration, etc.

- Sampling Dynamic Range - It is important to understand the dynamic range requirements. For example, if it is sufficient to simply detect and report an analyte concentration above a threshold 
value, a high dynamic range for quantitative measurements my not be necessary. But quantification over a broad concentration range will reduce the number of viable measurement systems.

- Confidence/Uniqueness Requirements - This parameter represents issues associated with false positives and false negatives. This requirement will be affected by whether the application is seeking preliminary indicators of activities or seeking final, definitive confirmation or forensic information. It will also be affected by the role of the results in the overall assessment process (e.g., stand-alone data for decision making or data for consideration along with information from other sources).

\section{B.2 Timing}

This category covers timing issue requirements associated with deployment and operation of the equipment for the application.

- Sampling Time and Analysis Time - This indicates the field use time constraints for the application. For example, will the measurement system need to rapidly acquire and analyze samples (e.g., for use on a UAV flying through an effluent plume, etc.) or can the sample acquisition and analysis be performed over a longer time period.

- Time to Deployment - The measurement technologist must understand how quickly the solution is needed. A requirement for a very short time to deployment requires the use of currently available systems or with, at most, very modest adaptations. A less demanding requirement could allow the tailoring of a measurement system option to meet the specific application need.

- Mission Time Allowance - This describes the anticipated mission duration requirements. System requirements (and technology options) are very different for an application that anticipates the full mission will last less than a week versus an application that will include field deployment and operation over a period of months.

\section{B.3 Logistics}

This category presents key system requirements relating to logistic considerations.

- Power Availability - Viable measurement system candidates depend greatly on the probable access to power for the application scenario. For example, it is important to know if measurements can be made with access to the local grid power or if battery operation will be required.

- Portability Requirement - Obvious impact on measurement method options and system design. This would include the measurement system and any ancillary equipment or supplies that must be available for system use.

- Ruggedness/Transportability - Obvious impact on measurement method options and system design. 


\section{B.4 Training}

- Training Level Allowance - For the intended application, what is the upper level of operator skill/training that will be acceptable for the application? This can place major restrictions/ requirements on how integrated and automated a measurement system is, including sample acquisition, preparation (if any), sample analysis, and data reduction. For some applications, a highly trained specialist could be operating the system, while for other applications the operator may have very little training.

\section{B.5 Applicability Levels}

There are a number of applicability levels for end users to consider when developing the evaluation table for their specific application requirements. The following five levels can be considered:

1. An evaluation may state that the applicability indicates that it provides no value at all to the specific application. For example, if a signature compound release could not possibly provide a concentration greater than $10 \mathrm{ppm}$ due to limited inventory, a detector that can only detect percent levels of the chemical provides no value whatsoever.

2. An evaluation may show that a certain level of performance would just meet a minimum level of performance to be useful, such as operation of a detector for levels very near the detection limit of the device.

3. An evaluation may show that a specific level of performance in a criteria category meets the required level of performance for the application.

4. An evaluation may show that there is additional benefit to be gained by increasing the level of performance over the requirement (for example, additional analytes that provide useful information).

5. An evaluation may show that there is no benefit for performance over the requirement. For example, if the focused goal of an application is one signature compound, having a sensor that can measure other compounds provides capability that is not only of no use, but may be provided at a cost in performance. 
Table 3.7. Deployment Scenario Attributes vs. Evaluation Criteria

\begin{tabular}{|c|c|c|c|c|c|c|}
\hline & Attribute & \multicolumn{5}{|c|}{ Criteria } \\
\hline \multirow{4}{*}{ 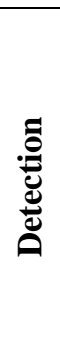 } & $\begin{array}{c}\text { Number of } \\
\text { analyte(s) }\end{array}$ & $\begin{array}{l}\text { Single } \\
\text { analyte }\end{array}$ & Single class & $\begin{array}{c}\text { Multiple } \\
\text { classes }\end{array}$ & $\begin{array}{c}\text { Broad } \\
\text { spectrum }\end{array}$ & Universal \\
\hline & $\begin{array}{c}\text { Detection limits } \\
\text { required }\end{array}$ & $>\%$ & $\begin{array}{c}\text { ppth } \\
10^{-3}\end{array}$ & $\begin{array}{c}\mathrm{ppm} \\
10^{-6}\end{array}$ & $\begin{array}{l}\mathrm{ppb} \\
10^{-9}\end{array}$ & $\begin{array}{l}<\mathrm{ppt} \\
10^{-12}\end{array}$ \\
\hline & $\begin{array}{c}\text { Sampling } \\
\text { dynamic range }\end{array}$ & $\begin{array}{c}\text { Very Low } \\
<10^{1}\end{array}$ & $\begin{array}{c}\text { Low } \\
10^{1} \text { to } 10^{2}\end{array}$ & $\begin{array}{l}\text { Moderate } \\
10^{2} \text { to } 10^{4}\end{array}$ & $\begin{array}{c}\text { High } \\
10^{4} \text { to } 10^{6}\end{array}$ & $\begin{array}{l}\text { Very High } \\
>10^{6}\end{array}$ \\
\hline & $\begin{array}{c}\text { Confidence } \\
\text { uniqueness reqs }\end{array}$ & $\begin{array}{c}\text { Very low } \\
10 \\
\end{array}$ & $\begin{array}{l}\text { Low } \\
10^{2} \\
\end{array}$ & $\begin{array}{c}\text { Moderate } \\
10^{3} \\
\end{array}$ & $\begin{array}{l}\text { High } \\
10^{4} \\
\end{array}$ & $\begin{array}{c}\text { Very high } \\
10^{5}\end{array}$ \\
\hline \multirow{4}{*}{ 覗 } & & & & & & \\
\hline & $\begin{array}{l}\text { Sampling time } \\
\text { analysis time }\end{array}$ & $>1$ day & $1 \mathrm{hr}$ to 1 day & $5 \mathrm{~min}$ to $1 \mathrm{hr}$ & 1 to $5 \mathrm{~min}$ & $<1 \mathrm{~min}$ \\
\hline & $\begin{array}{c}\text { Time to } \\
\text { deployment }\end{array}$ & $>1$ year & 6-12 months & $1-6$ months & 1-30 days & $<1$ day \\
\hline & $\begin{array}{c}\text { Mission time } \\
\text { allowance }\end{array}$ & $<1$ day & 1-30 days & $1-12$ months & $1-10$ years & $>10$ years \\
\hline & & & & & & \\
\hline \multirow{3}{*}{. } & $\begin{array}{c}\text { Power } \\
\text { requirement }\end{array}$ & $\begin{array}{c}\text { High volt } \\
\text { High current }\end{array}$ & $\begin{array}{c}\text { Standard Line } 1 \\
\text { generator }\end{array}$ & $\begin{array}{c}\text { Vehicle Lead / } \\
\text { acid }\end{array}$ & $\begin{array}{l}\text { Alkaline } \\
\text { NiCd, Li }\end{array}$ & $\begin{array}{l}\text { Passive/ } \\
\text { parasitic }\end{array}$ \\
\hline & $\begin{array}{l}\text { Portability } \\
\text { requirement }\end{array}$ & $\begin{array}{l}\text { Prepared } \\
\text { facility } \\
\text { required }\end{array}$ & $\begin{array}{l}\text { Laboratory } \\
\text { bench scale }\end{array}$ & $\begin{array}{c}\text { Vehicle } \\
\text { deployable }\end{array}$ & $\begin{array}{c}\text { Man } \\
\text { portable }\end{array}$ & Handheld \\
\hline & $\begin{array}{c}\text { Ruggedness / } \\
\text { transportability }\end{array}$ & $\begin{array}{c}\text { Very fragile, } \\
\text { controlled } \\
\text { transport }\end{array}$ & $\begin{array}{c}\text { Fragile, } \\
\text { transport } \\
\text { precautions req }\end{array}$ & $\begin{array}{c}\text { Moderate, } \\
\text { normal } \\
\text { precautions }\end{array}$ & $\begin{array}{l}\text { Minimal } \\
\text { Mil-spec } \\
\text { hardened }\end{array}$ & Bombproof \\
\hline . & $\begin{array}{c}\text { Training level } \\
\text { allowance }\end{array}$ & $\begin{array}{l}\text { Extensive } \\
\text { and } \\
\text { specialized }\end{array}$ & $\begin{array}{l}\text { High skill, } \\
\text { trained operator }\end{array}$ & $\begin{array}{c}\text { Well trained } \\
\text { operator }\end{array}$ & $\begin{array}{c}\text { Minimal } \\
\text { trained } \\
\text { operator }\end{array}$ & $\begin{array}{l}\text { Unskilled, } \\
\text { untrained }\end{array}$ \\
\hline
\end{tabular}




\section{Appendix C}

Basis for Selection of Parameters in Table 3.9 



\section{Appendix C}

\section{Basis for Selection of Parameters in Table 3.9}

(For reader convenience, Table 3.9 is duplicated at the end of this appendix.)

Key measurement system attributes are identified for consideration and the basis for their selection is delineated. It should be noted that this table cannot stand on its own; user input is needed to make the table useful. Information such as chemical compounds (or at least functional group) of interest as well as targeted media for detection (vapor, liquid, adsorbed on soil, etc.) are needed as input to allow for evaluations using the table.

\section{C.1 Detection}

This category directly describes the inherent properties of the detection system.

- Numbers of Analytes - Methods are usually defined as either "specific," meaning that they are useful for a single analyte, "selective," meaning that they are best used for the detection of a certain class of analytes, or "universal," meaning that they can be used on a very large spectrum of chemicals.

- Sensitivity/Minimum Detection Limit - Usually taken to mean the smallest amount of a chemical that a detection system will respond to. It can sometimes be difficult to make comparisons between techniques, as some detection systems are "mass selective," meaning that the systems respond proportionally to the absolute number of analyte molecules, or "concentration selective," meaning that the response is dependant on the distribution in a media. As an example, optical techniques are typically concentration selective, based on Beer's Law. The criteria levels are split here by 3 orders of magnitude, which increases the ease of delineation of detection system performance. It should be noted that detector additions such as preconcentration and enhanced extraction can greatly alter this value.

- Dynamic Range - This is the concentration range over which a detector system provides a useful response. For example, many detection systems "saturate" at high input concentrations. Saturation occurs when a system no longer provides an increasing response when additional analyte is added. Some systems may even provide a decreasing response under highly saturated conditions, which can be highly misleading. Dynamic range becomes a major issue when attempting to detect multiple analytes simultaneously at disparate concentrations. In this situation, when the lower concentration analyte is detectable, the higher concentration analyte may be saturated. The sample size can be adjusted to bring down the higher concentration analyte to below saturation; however, the lower concentration analyte may no longer be detectable. 
- Selectivity/Confidence - The ability to discern the response between different compounds or compound classes. This is often referred to as the resolution of the system and is often defined by the false alarm rate.

\section{C.2 Timing}

- Analysis Time per Sample - The amount of time needed to fully process a sample. This is a system term, and should include sampling, preconcentration, and data analysis time in addition to detector cycle time.

- Time to Deployment - The amount of time needed to properly configure the detection system for deployment into the defined scenario from an off-the-shelf state.

- System Life Expectancy - The length of time that a system can be reasonably expected to remain operational. This does not usually include simple replaceable items like batteries, although it may if the scenario demands it. For example, if a small covert sensor system will be dropped into an inaccessible area where it will not be retrieved, the system life will most likely be defined by the battery lifetime. However, in cases where there is periodic access to the detector system, the lifetime is usually not defined by consumable items such as batteries or filters. In this case, the integrity of system parts under ambient environmental conditions and items with known lifetime parameters (such as light sources) usually define the system operating life expectance.

\section{C.3 Logistics}

- Power Requirements - The energy needed to run a system. It is nearly always a key consideration in the field deployment of measurement systems. Each of the criteria levels covers a fairly wide range such that minor differences (such as the differences between AAA alkaline cells and D-sized cells) are not an issue.

- Size/Weight (Total System) - The physical bulk and deployed footprint of a system. It is also a key consideration in field deployment. It can be an issue in both transportation of a system to the measurement site and at the actual usage environment. This criterion can affect related items such as the need for covert deployment and vehicle logistics.

- Ruggedness/Transportability - How well the system holds up to the rigors of transportation and deployment into a non-laboratory environment. This mainly deals with vibration and impact resistance of the system.

- Environmental Operating Stability - The ability of the system to withstand various extremes in environmental operating conditions. This is mainly concerned with system stability with respect to changes in temperature, humidity, atmospheric pressure, etc. 
- Consumables/Support Requirements - The amount of extraneous equipment needed to support the operation of the system. This typically pertains to operational consumables such as filters, expendable sample holders, bottled instrument gases, solvents, etc. This is evaluated here, not on a cost basis, but on a logistical support basis.

- Waste Disposal Requirements - The quantity and logistics of system waste handling. The quantity of waste as well as the form (toxic, pungent odor, reactive, etc.) must be evaluated with respect to impact on the personnel and deployment situation. For example, specific waste forms might compromise mission security in some situations or be a hazard to mission personnel.

\section{C.4 Training}

- Collection/Sample Preparation Requirements - The level of effort and operator interaction required to properly collect and prepare a sample for introduction into the detection system.

- Calibration Requirements - The level of effort required to verify and maintain the instrument in an acceptable calibrated range such that it functions within its normal operating parameters. Out of calibration detection systems can provide misleading datasets.

- Training Requirements - The level of operator education and/or system training required to properly operate the system.

\section{C.5 Cost}

- Capital Cost of System - The price of the system. In some applications, such as a single unit deployment, this may not be important. However, if a large number of measurement systems are to be deployed, the capital cost of each unit may become critically important.

- Cost of Sample Analysis - This item excludes capital cost and expresses the "per sample" costs of running the system, which includes consumable, power, and maintenance costs. This item may be considered negligible for many applications, however; for some systems required to run numerous samples, the "per sample" totals may exceed the capital cost.

\section{C.6 Applicability Levels}

There are a number of applicability levels that can be applied to technologies when compared to required performance criteria. These evaluation levels can be defined as follows:

1. An evaluation may state that the technology can meet all the requirements with little or no adaptation.

2. An evaluation may show that the technology can meet all the requirements with modest adaptation. 
3. An evaluation may show that the technology can meet a significant portion of the requirements with moderate adaptation or development.

4. An evaluation may show that the technology can meet a significant portion of the requirements with significant adaptation or development.

5. An evaluation may show that the technology is unlikely to meet any useful portion of the requirements even with significant technical advances. 
Table 3.9. Measurement System Attributes vs. Evaluation Criteria

\begin{tabular}{|c|c|c|c|c|c|c|}
\hline & Attribute & \multicolumn{5}{|c|}{ Criteria } \\
\hline \multirow{4}{*}{ } & $\begin{array}{l}\text { Number of } \\
\text { analyte(s) }\end{array}$ & Single analyte & Single class & $\begin{array}{l}\text { Multiple } \\
\text { classes }\end{array}$ & $\begin{array}{c}\text { Broad } \\
\text { spectrum }\end{array}$ & Universal \\
\hline & $\begin{array}{c}\text { Sensitivity / min } \\
\text { detect }\end{array}$ & $>\%$ & $\begin{array}{l}\text { ppth } \\
10^{-3}\end{array}$ & $\begin{array}{l}\text { ppm } \\
10^{-6}\end{array}$ & $\begin{array}{l}\mathrm{ppb} \\
10^{-9}\end{array}$ & $\begin{array}{l}\mathrm{ppt} \\
10^{-12}\end{array}$ \\
\hline & Dynamic range & $\begin{array}{l}\text { Very Low } \\
<10^{1}\end{array}$ & $\begin{array}{c}\text { Low } \\
10^{1} \text { to } 10^{2}\end{array}$ & $\begin{array}{l}\text { Moderate } \\
10^{2} \text { to } 10^{4}\end{array}$ & $\begin{array}{c}\text { High } \\
10^{4} \text { to } 10^{6}\end{array}$ & $\begin{array}{l}\text { Very High } \\
>10^{6}\end{array}$ \\
\hline & $\begin{array}{l}\text { Selectivity / } \\
\text { confidence }\end{array}$ & $\begin{array}{c}\text { Very low } \\
10\end{array}$ & $\begin{array}{c}\text { Moderate low } \\
10^{2}\end{array}$ & $\begin{array}{c}\text { Moderate } \\
10^{3}\end{array}$ & $\begin{array}{l}\text { High } \\
10^{4}\end{array}$ & $\begin{array}{l}\text { Very high } \\
10^{5}\end{array}$ \\
\hline & $\begin{array}{l}\text { Analysis time } \\
\text { per sample }\end{array}$ & $>1$ day & $1 \mathrm{hr}$ to 1 day & $5 \mathrm{~min}$ to $1 \mathrm{hr}$ & 1 to $5 \mathrm{~min}$ & $<1 \mathrm{~min}$ \\
\hline 寻 & $\begin{array}{c}\text { Time to } \\
\text { deployment }\end{array}$ & $>1$ year & 6-12 months & $1-6$ months & $1-30$ days & $<1$ day \\
\hline & $\begin{array}{l}\text { System life } \\
\text { expectancy }\end{array}$ & $<1$ day & 1-30 days & 1-12 months & $1-10$ years & $>10$ years \\
\hline & $\begin{array}{c}\text { Power } \\
\text { requirements }\end{array}$ & $\begin{array}{l}\text { High volt High } \\
\text { current }\end{array}$ & $\begin{array}{l}\text { Standard Line / } \\
\text { generator }\end{array}$ & $\begin{array}{l}\text { Vehicle Lead } \\
\text { / acid }\end{array}$ & $\begin{array}{l}\text { Alkaline } \\
\text { NiCd, Li }\end{array}$ & $\begin{array}{l}\text { Passive/ } \\
\text { parasitic }\end{array}$ \\
\hline & $\begin{array}{l}\text { Size / weight } \\
\text { total system }\end{array}$ & $\begin{array}{c}\text { Prepared facility } \\
\text { required }\end{array}$ & $\begin{array}{l}\text { Laboratory } \\
\text { bench scale }\end{array}$ & $\begin{array}{c}\text { Vehicle } \\
\text { deployable }\end{array}$ & $\begin{array}{l}\text { Man } \\
\text { portable }\end{array}$ & Handheld \\
\hline & $\begin{array}{c}\text { Ruggedness / } \\
\text { transportability }\end{array}$ & $\begin{array}{c}\text { Very fragile, } \\
\text { controlled } \\
\text { transport }\end{array}$ & $\begin{array}{c}\text { Fragile, } \\
\text { transport } \\
\text { precautions }\end{array}$ & $\begin{array}{c}\text { Moderate, } \\
\text { normal } \\
\text { commercial }\end{array}$ & $\begin{array}{l}\text { Minimal } \\
\text { Mil-spec } \\
\text { hardened }\end{array}$ & Bombproof \\
\hline 吾 & $\begin{array}{l}\text { Environmental } \\
\text { op stability }\end{array}$ & $\begin{array}{l}\text { Poor, difficult } \\
\text { to operate with } \\
\text { any changes }\end{array}$ & $\begin{array}{l}\text { Low, affected } \\
\text { by minor } \\
\text { changes }\end{array}$ & $\begin{array}{l}\text { Moderate, } \\
\text { affected by } \\
\text { major change }\end{array}$ & $\begin{array}{l}\text { High, } \\
\text { affected by } \\
\text { extremes }\end{array}$ & $\begin{array}{l}\text { Very high, } \\
\text { works } \\
\text { always }\end{array}$ \\
\hline & $\begin{array}{l}\text { Consumables / } \\
\text { support } \\
\text { requirements }\end{array}$ & $\begin{array}{c}\text { Extensive multi- } \\
\text { component } \\
\text { logistics }\end{array}$ & $\begin{array}{c}\text { Substantial } \\
\text { supplies / } \\
\text { disposables } \\
\end{array}$ & $\begin{array}{c}\text { Moderate } \\
\text { supplies / } \\
\text { disposables } \\
\end{array}$ & $\begin{array}{c}\text { Minimal } \\
\text { supplies / } \\
\text { disposables } \\
\end{array}$ & $\begin{array}{c}\text { No ancillary } \\
\text { supplies, self } \\
\text { contained }\end{array}$ \\
\hline & $\begin{array}{l}\text { Waste disposal } \\
\text { requirements }\end{array}$ & $\begin{array}{c}\text { Extensive, } \\
\text { harmful, } \\
\text { special storage }\end{array}$ & $\begin{array}{l}\text { Substantial, } \\
\text { easy but } \\
\text { controlled }\end{array}$ & $\begin{array}{l}\text { Moderate } \\
\text { quantity and } \\
\text { risk } \\
\end{array}$ & $\begin{array}{l}\text { Minimal, } \\
\text { easily } \\
\text { managed }\end{array}$ & None \\
\hline & $\begin{array}{l}\text { Collection / } \\
\text { sample prep } \\
\text { requirements }\end{array}$ & $\begin{array}{l}\text { Extensive multi- } \\
\text { step, long time }\end{array}$ & $\begin{array}{c}\text { Substantial } \\
\text { operator } \\
\text { involvement }\end{array}$ & $\begin{array}{l}\text { Moderate } \\
\text { operator } \\
\text { interaction }\end{array}$ & $\begin{array}{c}\text { Minimal } \\
\text { operator } \\
\text { interaction } \\
\end{array}$ & $\begin{array}{l}\text { Automatic } \\
\text { operation }\end{array}$ \\
\hline 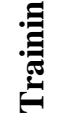 & $\begin{array}{l}\text { Calibration } \\
\text { requirements }\end{array}$ & $\begin{array}{l}\text { High, multi- } \\
\text { point, constant } \\
\text { attention }\end{array}$ & $\begin{array}{c}\text { Substantial, } \\
\text { multi-point, } \\
\text { frequent interval }\end{array}$ & $\begin{array}{c}\text { Moderate, } \\
\text { single point, } \\
\text { high frequency }\end{array}$ & $\begin{array}{l}\text { Low, single } \\
\text { point, low } \\
\text { frequency }\end{array}$ & $\begin{array}{l}\text { Very low, no } \\
\text { calibration or } \\
\text { self calib. }\end{array}$ \\
\hline & $\begin{array}{l}\text { Training level } \\
\text { allowance }\end{array}$ & $\begin{array}{c}\text { Extensive and } \\
\text { specialized }\end{array}$ & $\begin{array}{c}\text { High skill, } \\
\text { trained operator }\end{array}$ & $\begin{array}{c}\text { Well trained } \\
\text { operator }\end{array}$ & $\begin{array}{c}\text { Min. trained } \\
\text { operator }\end{array}$ & $\begin{array}{l}\text { Unskilled, } \\
\text { untrained }\end{array}$ \\
\hline$\vec{\omega}$ & $\begin{array}{l}\text { Capital cost of } \\
\text { system }\end{array}$ & $>\$ 250 \mathrm{~K}$ & $\$ 75 \mathrm{~K}-\$ 250 \mathrm{~K}$ & $\$ 15 \mathrm{~K}-\$ 75 \mathrm{~K}$ & $\$ 1 \mathrm{~K}-15 \mathrm{~K}$ & $<\$ 1 \mathrm{~K}$ \\
\hline u & $\begin{array}{c}\text { Cost of sample } \\
\text { analysis }\end{array}$ & $>\$ 25$ & $\$ 5-\$ 25$ & $\$ 1-\$ 5$ & $\$ 0.10-\$ 1$ & $<\$ 0.10$ \\
\hline
\end{tabular}




$$
\text { C. } 6
$$

